\title{
ESTUDO CEFALOMÉTRICO DAS ALTURAS FACIAIS ANTERIOR E POSTERIOR, EM JOVENS BRASILEIROS MELANODERMAS, COM “OCLUSÃO NORMAL"
}

Lívia Maria Andrade de Freitas Uchiyama

Dissertação apresentada à Faculdade de Odontologia de Bauru da Universidade de São Paulo, como parte dos requisitos para obtenção do Título de Mestre em Odontologia, área de Ortodontia.

(Edição Revisada)

\section{BAURU}

2005 


\section{ESTUDO CEFALOMÉTRICO DAS ALTURAS FACIAIS}

ANTERIOR E POSTERIOR, EM JOVENS BRASILEIROS

MELANODERMAS, COM “OCLUSÃO NORMAL"

\section{Lívia Maria Andrade de Freitas Uchiyama}

Dissertação apresentada à Faculdade de Odontologia de Bauru da Universidade de São Paulo, como parte dos requisitos para obtenção do Título de Mestre em Odontologia, área de Ortodontia.

(Edição Revisada)

Orientador: Prof. Dr. Arnaldo Pinzan

\section{BAURU}

2005 


\begin{tabular}{|c|}
\hline Uchiyama, Lívia Maria Andrade de Freitas \\
Uc4e $\quad$ Estudo cefalométrico das alturas faciais anterior e posterior, \\
em jovens brasileiros melanodermas, com "oclusão normal./ \\
Lívia Maria Andrade de Freitas Uchiyama.-- Bauru, 2005. \\
xxi 95 p.: il. ; $30 \mathrm{~cm}$. \\
Dissertação (Mestrado) -- Faculdade de \\
Odontologia de Bauru. Universidade de São Paulo. \\
Orientador: Prof. Dr. Arnaldo Pinzan
\end{tabular}

Autorizo, exclusivamente para fins acadêmicos e científicos, a reprodução total ou parcial desta dissertação/tese, por processos fotocopiadores e outros meios eletrônicos.

\section{Assinatura:}

Data:

Comitê de Ética da FOB: Projeto de pesquisa aprovado em 29 de setembro de 2004.

No do Protocolo: $124 / 2004$ 


\section{Dados Curriculares}

24 de agosto de $1975 \quad$ Nascimento - Salvador - BA

Filiação

Álvaro Marques de Freitas

Maria J osé Andrade de Freitas

1994-1998

Curso de Graduação em Odontologia Universidade do Sagrado Coração - Bauru$\mathrm{SP}$

2001-2004

Curso de Aperfeiçoamento em Ortodontia na ACOPEN - Bauru

2003-2005

Curso de Pós-graduação em Ortodontia, em nível de Mestrado, pela Faculdade de Odontologia de Bauru - Universidade de São Paulo

Associações Associação Paulista de Cirurgiões-Dentistas 


\section{Dedico este trabalho,}

"DEUS é o nosso organizador, o cérebro que tudo pensa e executa... .... Nós somos como um lápis com que DEUS escreve os textos que Ele quer ditos nos corações dos homens."

Irmã Dulce

A DEUS,

Pai de todos nós, que em sua infinita bondade, abençoou-me com mais uma oportunidade ímpar, a qual, por que Ele me ilumina, pude, com muito amor, abraçar.

Ainda que eu falasse a língua dos homens e dos anjos, se não tiver amor, serei como o bronze que soa ou como címbalo que retine, 
ainda que eu tenha o dom de profetizar

e conheça todos os mistérios e toda ciência,

ainda que eu tenha tamanha fé,

a ponto de transportar montanhas,

se não tiver amor, nada serei.

E ainda que eu distribua

todos os meus bens entre os pobres,

e ainda que eu entregue

o meu corpo para ser queimado,

se não tiver amor,

nada disso me aproveitará,

tudo passa, tudo,

só o amor jamais acaba.

Carta de São Paulo aos Coríntios (Co. 13:1-4) 
Ao meu querido pai,,

Álvaro,

meu exemplo, de retidão de caráter.

Dele sempre pude esperar

conselhos certos nas horas certas.

Conselhos sempre tão certeiros...

\section{Conselho \\ Flora Figueiredo}

Nunca chore um insucesso.

0 que pode parecer um abscesso,

também pode servir de recomeço,

Agarre o desaponto pelo avesso,

apare as pontas, corte o excesso.

Mude a covardia de endereço,

ponha a escavadeira em retrocesso

até que o mundo, esse réu confesso,

Ihe devolva seu mel e seu apreço.

Uma vez retomado esse processo,

devolva-me o sorriso que mereço. 
exemplo de força e coragem.

Fé na vida nunca Ihe faltou.

Esta poderia ser a descrição de uma mulher comum, mas nada comum para mim, pois descrevo assim a minha Mãe.

\section{Maria, Maria \\ Milton Nascimento e Fernando Brant}

Maria, Maria...

É um dom, uma certa magia, uma força que nos alerta, uma mulher que merece viver e amar como outra qualquer do planeta.

Maria, Maria...

É um som, é a cor, é o suor, é a dose mais forte e lenta de uma gente que ri quando deve chorar e não vive apenas agüenta.

Mas é preciso ter força,

É preciso ter gás,

É preciso ter gana sempre.

Quem traz no corpo essa marca

Maria, Maria...

Mistura a dor e alegria.

Mas é preciso ter manha, é preciso ter sonho, sempre.

Quem traz na pele essa marca, possui a estranha mania de ter fé na vida... 
"Passei toda a noite, sem saber dormir, vendo sem espaço a figura dela E vendo-a sempre de maneiras diferentes do que a encontro a ela. Faço pensamentos com a recordação do que ela é quando me fala, E em cada pensamento ela varia de acordo com a sua semelhança. Amar é pensar.

E eu quase que me esqueço de sentir só de pensar nela. Não sei bem o que quero, mesmo dela, e eu não penso senão nela. Tenho uma grande distração animada.

Quando desejo encontrá-la, Quase que prefiro não a encontrar,

Para não ter que a deixar depois.

E prefiro pensar dela, porque dela como é tenho qualquer medo. Não sei bem o que quero, nem quero saber o que quero.

Quero só pensar ela.

Não peço nada a ninguém, nem a ela, senão pensar.

\section{Fernando Pessoa}

Desculpe minha filha, pelos momentos de ausência. 


\section{À minha base, alicerce, "Familia":}

Minhas irmãs maravilhosas: Gigi, Noi, e minha grande e admirável incentivadora de profissão: Conça;

Meu irmão, minha paixão, Inho;

Meus sobrinhos(a): Quinho, Cacá, Tória, Cat, Dinda Clara, Alvinho, Bebê Conça;

Meus Cunhados(a): Marco, Nailton, Pimenta e Gabriela.

Amo vocês.

“Procuremos viver em união, em espírito de caridade, perdoando uns aos outros as nossas pequenas faltas e defeitos. É necessário saber desculpar para viver em paz e união."

Irmã Dulce 
Minha eterna família "Uchiyama",

Dr. I uji, Dona Izaura, Glauber, Glauce, Helder, Donizeti, Dandinha, Paula, Batian e Virgínia.

“Às vezes há uma dor invisível no coração.

Uma dor profunda, indescritível.

É a solidão, e a ela não podemos nos render.

DEUS criou gestos simples para curar essa dor..."

Irmã Dulce

Vocês sempre curaram minha dor, com muito carinho. Serei eternamente grata. 


\section{Meu Agradecimento Especial ao meu estimável "mentor", educador e orientador}

Ao Professor Doutor Arnaldo Pinzan e família

Quanto mais a gente ensina, mais aprende o que ensinou...

Quanto mais conhecimento, maior a humildade e maior sabedoria.

Um grande homem demonstra sua grandeza pelo modo como trata os pequenos (Carlyle)

Obrigado Mestre, pela sua profícua dedicação, apoio e orientação. se hoje sou um pouco melhor que ontem, reputo a ti a responsabilidade e a condição de meu Orientador. Que Deus, todo poderoso lhe abençoe pelo que fizeste por mim. Meu eterno agradecimento. 
Meu Agradecimento Especial com admiração e ternura

Ao Prof. Dr. Marcos Roberto de Freitas e familia

Um exemplo de dedicação à docência, que trabalhando sempre com entusiasmo e satisfação, procura ajudar a todos que o solicitam.

Ser-Ihe-ei eternamente grata por acreditar em mim e permitir que eu fizesse minhas escolhas galgando o caminho mais correto para conclusão deste curso de Mestrado. 


\section{Meu Agradecimento Especial}

Ao Prof. Dr. J osé Fernando Castanha Henriques, pela oportunidade concedida e pelos ensinamentos que contribuíram para minha formação ortodôntica.

Ao Prof. Dr. Guilherme dos Reis Pereira Janson, com a sua arte da sabedoria, pela oportunidade do conhecimento do mundo científico.

Ao Prof. Dr. Renato Rodrigues de Almeida, por honrar-me com seus ensinamentos, engrandecendo a Ortodontia e a minha formação profissional.

Ao Prof. Dr. Décio Rodrigues Martins e sua neta Maria Fernanda, pelos sábios ensinamentos transmitidos durante o curso. 


\section{Meu Agradecimento àqueles que serão inesquecíveis}

À tia Elaine, seu esposo, Paulinha, Renata, Pedro, Thomas, Rodrigo.

Minhas amigas que contribuíram neste trabalho e merecem minha eterna gratidão, Lenoca, Má, Ká e Lari.

Ao grande incentivador R.Henriques, importante na finalização desta grande conquista, que no momento de fraqueza, concedeu-me ânimo e coragem pela simples imensidão do seu ser.

Minhas amigas Letícia e Mariana e família, com muito amor, minha gratidão.

E aqueles que participaram da minha vida, de uma maneira extremamente intensa: Betinho, Ghisoca, Duda, Fábio, Jú e Erick, Júnior, Tati Matosinho, Dê Meira, Maria Clara, Lú Sgavioli, Gú Molina, Ziza, Maurício, Stelinha, Miloca, Olívia. 
Quando chega é paz... Presentes são palavras, gestos e sinais

Dizendo que é bem possível Continuar, continuar, continuar Sempre lutar 0 amigo de verdade Seca as lágrimas, todas as lágrimas É uma fusão de almas... A distância não existe, 0 difícil nunca é Pra correr e ver e ver E fazer você ainda rir E achar a vida linda como ela é 0 amigo de verdade não tem hora de partir Mas quando vai deixa a sensação De ainda estar ali É saudade, é saudade, é amigo de verdade... 


\section{Meu Agradecimento}

À Profa Dra Maria Fidela de Lima Navarro, Digníssima Diretora da Faculdade de Odontologia de Bauru, da Universidade de São Paulo.

Ao Prefeito do Campus Administrativo de Bauru-USP, Prof. Dr. J osé Fernando Castanha Henriques.

Ao Prof. Dr. José Carlos Pereira, Presidente da Comissão de PósGraduação da Faculdade de Odontologia de Bauru, da Universidade de São Paulo.

Ao Prof. Dr. José Roberto Lauris pela orientação, paciência e auxílio na realização dos testes estatísticos.

As Profas. Dras. Ana Claúdia Conti e Daniela Garib, pelos ensinamentos transmitidos e amizade.

Aos meus amigos do Curso de Mestrado, Alexandre, Darwin, Dri, Fer Ozzy,

Fer Pedrin, Kelinha, Paula, Marcos, Caco, Rafa, Rê, Sérgio pela amizade, pelos momentos vividos e por tudo que aprendemos e compartilhamos.

Aos meus amigos do Curso de Doutorado, Karina, Rejane, Celinha, Fernanda, Rodrigo, Leniana, Karina Lima, Analu, Fabrício, J osé Eduardo, Ricardo que sempre se dispuseram a me ajudar.

Aos funcionários da disciplina de Ortodontia, Vera(Verinha), Cristina(Cris), Neide(Neidinha), Sérgio, por toda a atenção e amizade durante todo 0 nosso convívio.

Obrigada, Verinha, pelos sábios ensinamentos de vida.

Aos funcionários da ACOPEN, Sônia, Luciana, César, Dani(Boné), Danilo, Walter e Wagner, por todo carinho, amizade e respeito com que sempre me trataram. 
Aos funcionários da Pós-Graduação pela atenção e simpatia.

Aos funcionários da Biblioteca, em especial Vera Bocato e Maristela, pelo carinho, amizade, ensinamentos, facilidades e atenção que sempre recebi.

Ao Fabrício, pela ajuda na finalização da parte gráfica deste estudo.

Aos pacientes, que contribuíram para o meu enriquecimento profissional, com carinho.

Ao CNPq pelo auxílio à minha pesquisa, por meio de concessão de bolsa de estudo.

Enfim, agradeço a todos aqueles que contribuíram, direta ou indiretamente, por proporcionar inúmeros momentos de felicidade e sonhos realizados. 


\section{SUMÁRIO}

LISTA DE FI GURAS ................................................................XVI I I

LISTA DE TABELAS ................................................................ XX

RESUMO ............................................................................... XXI I

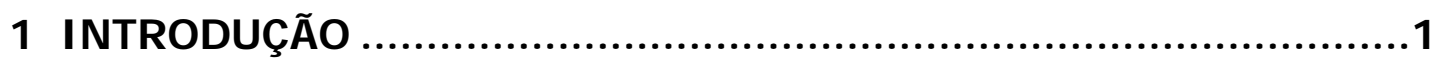

2 REVISÃO DA LITERATURA ...................................................

3 PROPOSI ÇÃO....................................................................... 30

4 MATERI AL E MÉTODOS ..................................................... 32

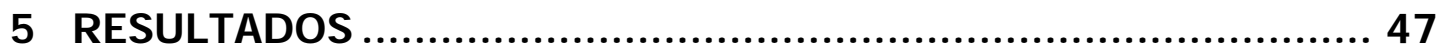

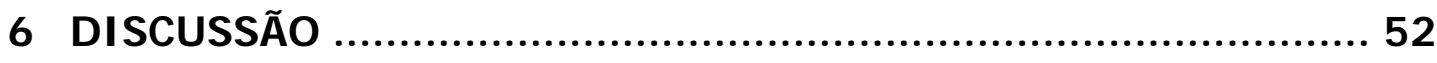

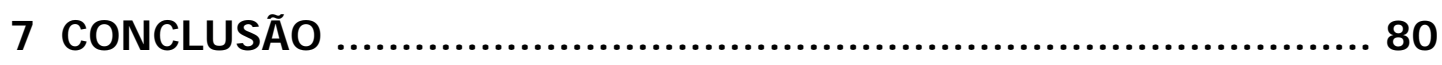

REFERÊNCI AS BI BLI OGRÁFI CAS............................................ 82

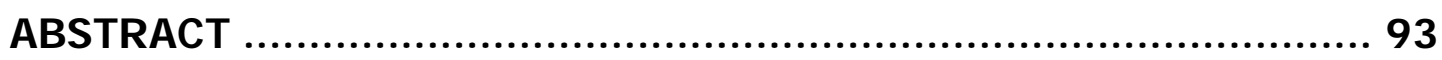

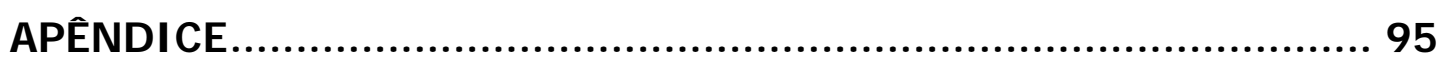




\section{LISTA DE FIGURAS}

FI GURA 4.1 - Desenho das estruturas anatômicas $\quad$ D......................... 36

FI GURA 4.2 - Demarcação dos pontos cefalométricos ...................... 38

FI GURA 4.3 - $\quad$ Representação das linhas e planos........................... 39

FIGURA 4.4 - Medidas empregadas de acordo com a Análise de WYLIE; JOHNSON ${ }^{114}$

FIGURA 4.5 - Medidas empregadas de acordo com a Análise de SIRIWAT; JARABAK ${ }^{100}$

FI GURA 4.6 - Medidas empregadas de acordo com a Análise de GEBECK; MERRIFIELD ${ }^{47}$ 45

FI GURA 6.1 - Valores de AFAT da amostra de melanodermas brasileiros $X$ melanodermas de distintas áreas geográficas 61

FIGURA 6.2 - Valores de AFAS da amostra de melanodermas brasileiros $\mathrm{X}$ melanodermas de distintas áreas geográficas 63

FIGURA 6.3 - Valores de AFAI da amostra de melanodermas brasileiros $X$ melanodermas de distintas áreas geográficas 65

FI GURA 6.4A - Valores de AFPT da amostra de melanodermas brasileiros $\mathrm{X}$ melanodermas de distintas áreas geográficas

FI GURA 6.4B - Valores de AFPS da amostra de melanodermas brasileiros $X$ melanodermas de distintas áreas geográficas

FIGURA 6.4C - Valores de AFPI da amostra de melanodermas brasileiros 68 
FIGURA 6.5A - Valores de AFAS/AFAT da amostra de melanodermas brasileiros $X$ melanodermas de distintas áreas geográficas ...................................................... 69

FIGURA 6.5B - Valores de AFAI/AFAT da amostra de melanodermas brasileiros $X$ melanodermas de distintas áreas geográficas .................................................... 70

FIGURA 6.5C - Valores de AFPS/AFPT da amostra de melanodermas brasileiros 70

FIGURA 6.5D - Valores de AFPI/AFPT da amostra de melanodermas brasileiros

FIGURA 6.6A - Valores de AFA da amostra de melanodermas brasileiros.

FIGURA 6.6B - Valores de AFP da amostra de melanodermas brasileiros

FIGURA 6.6C - Valores de IAF da amostra de melanodermas brasileiros $X$ melanodermas de distintas áreas geográficas 73 


\section{LISTA DE TABELAS}

TABELA 5.1 - Apresentação das médias e desvios-padrão, para os dois tempos realizados, do teste " $\mathrm{t}$ " de Student e do erro casual (DAHLBERG) ${ }^{35}$

TABELA 5.2 - Análise estatística das médias das idades em ambos os gêneros 50

TABELA 5.3 - Análise descritiva da amostra, com os valores das médias e desvios-padrão em jovens brasileiros melanodermas 50

TABELA 5.4 - Análise estatística do teste " $\mathrm{t}$ " independente para 0 dimorfismo entre gêneros, em jovens brasileiros melanodermas.... 51

TABELA 6.1 - Valores das médias dos melanodermas brasileiros desta pesquisa $X$ leucodermas brasileiros da amostra de TAKAHASHI ${ }^{103}$ 74

TABELA 6.2 - Valores das médias dos melanodermas brasileiros do gênero feminino desta pesquisa $X$ leucodermas brasileiros da

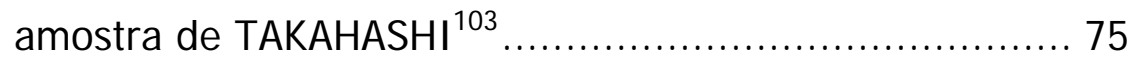

TABELA 6.3 - Valores das médias dos melanodermas brasileiros do gênero masculino desta pesquisa $X$ leucodermas brasileiros da amostra de TAKAHASHI ${ }^{103}$ 75 
RESUMO 


\section{RESUMO}

Com o propósito de apresentar um padrão cefalométrico específico para os jovens brasileiros melanodermas, este estudo objetivou obter os valores médios de normalidade para algumas das grandezas cefalométricas esqueléticas, no sentido vertical da face, (alturas faciais anterior e posterior) e verificar a presença de dimorfismo entre os gêneros. A amostra constituiu-se de 56 telerradiografias, em norma lateral, sendo 28 do gênero masculino, com idade média de 13,93 anos (idade mínima de 12,08 anos e máxima de 15,75 anos) e 28 do gênero feminino, com idade média de 13,79 anos (idade mínima de 12,58 anos e máxima de 15,67 anos), obtidas de amostras de jovens brasileiros, melanodermas, não submetidos a tratamento ortodôntico e que apresentavam "oclusão normal", pertencentes ao arquivo da Disciplina de Ortodontia da Faculdade de Odontologia de Bauru - Universidade de São Paulo. As medidas cefalométricas empregadas foram de acordo com as Análises de: WYLIE; JOHNSON ${ }^{114}$ (1952); SIRIWAT; JARABAK $^{100}$ (1985); GebeCK; MerRIFIELD ${ }^{47}, \operatorname{HoRN}^{51}(1989,1992)$. Os valores foram submetidos à análise estatística pelo teste " $\mathrm{t}$ " independente para comparar as variáveis entre os gêneros. Pôde-se observar a presença de dimorfismo, com os valores das grandezas AFAT, AFAS, AFPT, AFPS, além das proporções AFPS/AFPT e AFPI/AFPT significantemente alterados. 


\section{INTRODUÇÃO}




\section{I NTRODUÇÃO}

Destaca-se como fator primordial, a necessidade de um amplo conhecimento das características esqueléticas e dentárias, que ocorrem em indivíduos normais, não tratados ortodonticamente. Tal informação auxilia no planejamento do tratamento ortodôntico, proporcionando uma correlação entre as alterações normais do desenvolvimento e os objetivos almejados durante a terapêutica ${ }^{48,99}$. Os problemas ortodônticos são complexos por apresentarem variações no padrão dentoesquelético, nos sentidos vertical, horizontal e transversal e ainda possuírem alterações naturais decorrentes do crescimento e desenvolvimento craniofacia ${ }^{38}$.

A relação entre os elementos dentários e o complexo craniofacial uniu a ortodontia, a anatomia e a antropologia buscando os meios de diagnósticos mais eficazes. Em 1931, BROADBENT ${ }^{23}$ criou o cefalostato introduzindo a padronização da cefalometria radiográfica no diagnóstico ortodôntico. Vários estudos foram realizados com amostras diversas para avaliação do crescimento e desenvolvimento craniofacial que contribuíram para o aprimoramento da ortodontia como ciência ${ }^{23,26}$.

Contudo, o impacto do tratamento sobre a face, visando o "ideal cefalométrico" começou a ser questionado. A idade e a raça se tornaram fatores importantes ${ }^{49}$. As medidas obtidas dos estudos cefalométricos não se aplicavam a todos os indivíduos, devido as suas distintas características étnicas e de miscigenação. Surgiu assim a necessidade de obtenção de valores e análises específicas para os diferentes grupos étnicos ${ }^{4}$.

RICHARDSON $^{90}$, em 1980, questionou se realmente existiam diferenças étnicas nas características faciais. A dúvida seria quanto à sua magnitude. Estas diferenças estariam relacionadas com maior intensidade a fatores geográficos e ecológicos. 
Portanto, com a finalidade de propor um padrão cefalométrico específico para os jovens brasileiros melanodermas, este estudo objetivou obter os valores médios de normalidade para as grandezas cefalométricas esqueléticas, das alturas e proporções faciais e verificar a presença ou ausência de dimorfismo entre os gêneros. 


\section{REVISÃO DE LITERATURA}




\section{REVI SÃO DE LI TERATURA}

Almejando um melhor entendimento deste trabalho, a pesquisa literária, apresentada a seguir, incluiu os estudos pertinentes ao crescimento e desenvolvimento craniofacial, a análise vertical da face, a avaliação das grandezas cefalométricas em diferentes grupos étnicos e a avaliação das grandezas cefalométricas em indivíduos melanodermas.

\subsection{Crescimento e Desenvolvi mento Crani ofacial}

As inúmeras análises difundidas buscam definir a orientação do crescimento facial, a relação das bases apicais entre si e com a base do crânio e as posições dentárias ${ }^{28}$.

Em ortodontia, o conhecimento do crescimento craniofacial assume importância incomensurável no diagnóstico ortodôntico. Este complexo processo recebe a influência de diversos fatores, como os genéticos e os ambientais. Alguns mecanismos serão brevemente abordados pelo importante papel que representam no estudo das dimensões verticais como: a rotação mandibular, o mecanismo de compensação dentária e o papel desempenhado pelos tecidos moles e componentes funcionais ${ }^{18,41,108}$.

\subsubsection{Rotação mandibular}

Com o objetivo de identificar as áreas de aposição e reabsorção nos maxilares, examinando as variações individuais na direção e intensidade, BJ ÖRK ${ }^{18}$, em 1969, estudou o crescimento craniofacial. Neste estudo, dois tipos diferentes de crescimento rotacional condilar foram descritos: 0 crescimento anterior, que resulta no tipo facial com mordida profunda, e 0 posterior, que resulta no tipo facial com mordida aberta. Além disso, 
observou que os indivíduos portadores de mordida aberta apresentaram um aumento na altura facial posterior. O potencial de crescimento mandibular em comprimento localizou-se essencialmente nos côndilos, raramente ocorrendo na direção do ramo, sendo observado mais freqüentemente em uma direção suavemente anterior. Ao mesmo tempo, uma reabsorção na região inferior do ângulo goníaco e uma aposição maior na região inferior da sínfise puderam ser observados, contribuindo para o aumento na altura da mesma. Como conclusão desse estudo, listou sete características cefalométricas alteradas em pacientes com rotação anormal da mandíbula durante o crescimento, as quais influenciam decisivamente no padrão de erupção dentária, a saber: (1) inclinação do côndilo; (2) curvatura do canal mandibular; (3) forma da borda inferior da mandíbula; (4) inclinação da sínfise; (5) ângulo interincisivos; (6) ângulo inter pré-molar e intermolar e, (7) altura facial anterior inferior. De acordo com BJÖRK ${ }^{18}$, o somatório dessas características pode constituir ferramentas importantes na previsão de crescimento. A mandíbula cresce proporcionalmente para frente e para baixo, embora possa também seguir mais um vetor em detrimento do outro. Para que haja uma rotação mais para anterior da mandíbula, por exemplo, ocorre um abaixamento das fossas articulares e uma aposição óssea superiormente localizada na cabeça do côndilo. Com isto, a altura facial posterior passa a ser maior que a anterior, caracterizando uma tendência ao crescimento horizontal ${ }^{18}$.

A variação no crescimento está associada às diferenças na intensidade dos processos envolvidos ${ }^{108}$. Com a finalidade de investigar as relações entre os parâmetros verticais e a rotação mandibular, ISAACSON et al. ${ }^{55}$, em 1971, estudaram a variação extrema no crescimento facial vertical associando as relações esqueléticas e dentárias. Segundo os autores ${ }^{55}$, em um padrão facial normal, os incrementos de crescimento na região do côndilo deveriam ser iguais ao somatório dos incrementos verticais dos processos alveolares maxilar e mandibular, bem como das suturas faciais, do contrário, observar-se-ia uma rotação mandibular. 
A mandíbula cresce para cima e para trás e se desloca para frente e para baixo. Parte deste deslocamento é primário e parte é secundário. Então os três movimentos primordiais de crescimento da espécie humana são: deslizamento, deslocamento primário e deslocamento secundário $^{41,42}$.

\subsubsection{Mecanismo de compensação dentoalveolar}

O desenvolvimento dentário também desempenha um importante papel no crescimento facial. Dentro do enfoque das variações dos padrões faciais, BJ ÖRK; SKIELLER ${ }^{21}$ descreveram um mecanismo dentoalveolar de compensação às diversas inter-relações espaciais entre as bases apicais, incluindo-se as direções de rotação da mandíbula. Estas compensações foram definidas como um conjunto de alterações dentoalveolares no afã de manter relações interarcos normais, mesmo quando da presença de discrepâncias entre as bases apicais. Este mecanismo se utiliza da irrupção dentária para as compensações no sentido vertical e das inclinações dos incisivos e caninos para as compensações no sentido ântero-posterior. Como por exemplo, basta citar-se que, diante de uma maxila retroposta, os incisivos superiores sofrem vestibularização, diminuindo-se 0 ângulo interincisivos. No entanto, frente a enormes discrepâncias ântero-posteriores entre as bases apicais, o mecanismo de compensação dentoalveolar torna-se ineficiente.

Um outro exemplo de compensação dentoalveolar manifesta-se sob a forma de migração dentária ao longo do arco inferior, como resposta ao tipo de rotação mandibular presente.

A altura do processo alveolar costuma ser fortemente influenciada pelo grau de irrupção dentária, nível de rizogênese e grau de exposição da coroa na cavidade bucal. 
Logo, as alterações na posição e inclinação dentária, se relacionadas aos fatores esqueléticos, funcionais ou ambos, parecem resultar de um mecanismo de compensação. Este mecanismo serve para manter um equilíbrio entre as relações faciais, esqueléticas e dentárias. 0 desequilíbrio dessas estruturas pode causar uma má oclusão ${ }^{99}$.

\subsubsection{Papel dos tecidos moles}

Quando o assunto é crescimento, o esqueleto craniofacial assume um papel secundário em relação às estruturas de tecido mole nele inseridas, tais como os músculos faciais e mastigatórios, e em relação aos espaços funcionais, tal como o espaço aéreo superior ${ }^{42}$.

Partindo-se do princípio de que o crescimento do esqueleto craniofacial depende principalmente da demanda imposta pelos tecidos moles, pode-se afirmar facilmente que o equilíbrio ou o desequilíbrio entre as matrizes funcionais interna e externa determina os tipos de rotação mandibular e, portanto, o padrão facial dos indivíduos em crescimento ${ }^{69}$.

Sendo assim, ainda que estes mecanismos atuem sobre um padrão morfogeneticamente pré-determinado, uma série de adaptações morfológicas ocorrem sob o domínio da competição existente entre ambas as matrizes funcionais ${ }^{41,109}$.

LINDER-ARONSON; WOODSIDE ${ }^{69}$, em 2000, sustentaram a opinião de que muitas más oclusões podem ser parcialmente revertidas pela remoção do impacto neuromuscular. Um exemplo seria a alteração da respiração bucal crônica para a respiração nasal. A suposição destes estudos é de que grandes alterações nos padrões esqueléticos e dentários da má oclusão, anteriormente atribuídas à genética, possam ser obtidas quando a correção biológica acompanha a terapia ortodôntica nas más oclusões verticais. 
Resumidamente, a suspensão neuromuscular da mandíbula é um mecanismo altamente sensível que responde com postura mandibular alterada em alguns casos de obstrução nasofaríngea crônica. Quando esta alteração ocorre, distúrbios associados como aumento na altura facial inferior, retrognatismo mandibular, arcos estreitos e apinhamento dos incisivos inferiores acompanham a alteração primária em vários graus nos pacientes individualmente $^{112}$. 0 tratamento das más oclusões com excesso de altura facial é uma das áreas mais desafiadoras do tratamento ortodôntico. A grande variabilidade na resposta de um indivíduo aos estímulos ambientais adversos, dificulta a terapêutica ${ }^{69}$.

\subsection{ANÁLI SE VERTI CAL DA FACE}

A análise vertical da face, por meio das alturas faciais anterior e posterior, por suas proporções faciais e por seus índices faciais, permite um diagnóstico preciso das discrepâncias verticais, orientando o profissional na obtenção de uma face harmônica, com equilíbrio entre os terços faciais e buscando a estabilidade dos resultados ortodônticos conquistados ${ }^{103}$.

Para um melhor desenvolvimento literário a respeito das dimensões verticais, este estudo abordou os seguintes tópicos: alturas faciais anterior e posterior, as proporções faciais e o índice da altura facial de HORN $^{51}$.

\subsubsection{Alturas faciais anterior e posterior}

As alturas faciais anterior e posterior desempenham papéis fundamentais no equilíbrio e harmonia da face humana ${ }^{39,50,63,72}$. Essas dimensões foram investigadas em estudos transversais e longitudinais ${ }^{18,43,84,97}$. 
Muitos pesquisadores confirmaram o efeito intenso da altura anterior da face sobre o ângulo do plano mandibular e sobre a formação de diferentes padrões faciais. Indivíduos leucodermas com mordida aberta são caracterizados por uma maior altura anterior da face quando comparados a indivíduos com mordida profunda $43,84,93,97$. A altura posterior da face também influencia o ângulo do plano mandibular e a formação do padrão facial, mas em menor extensão. Isto pode explicar os estudos contraditórios de BJ ÖRK ${ }^{18}$, SASSOUNI; NANDA ${ }^{93}$, FIELDS et al. ${ }^{43}$, com relação à importância relativa da altura posterior da face em indivíduos com mordida aberta.

Pelos resultados sobre a relação entre os parâmetros individuais de crescimento, pode-se concluir que as diferenças entre as mordidas aberta e profunda são determinadas principalmente pela altura anterior da face e, em menor extensão, pela altura posterior da face ${ }^{43,84,93}$.

COBEN $^{31}$, em 1955, observou nos indivíduos do gênero masculino um maior aumento na altura facial, com o crescimento vertical da face maior na região anterior em relação à posterior. Para o estudo, utilizou uma amostra com oclusão normal de 47 indivíduos leucodermas, sendo 25 do gênero masculino e 22 feminino, entre 8 e 16 anos. Os indivíduos do gênero masculino apresentaram maiores alterações nas proporções faciais, tornando a face proporcionalmente maior do que a face feminina, que se comportou de maneira similar, tanto na região anterior quanto na posterior, bem como no crescimento em profundidade ${ }^{31}$.

SCHUDY ${ }^{98}$, em 1964, investigou a relação entre as alturas anterior e posterior da face. Enfatizou um aumento das alturas anterior facial inferior e total, naqueles indivíduos com mordida aberta esquelética.

SASSOUNI; NANDA ${ }^{93}$, em 1964, desenvolveram uma análise das proporções verticais dentofaciais, propondo uma classificação das más oclusões, associando-as ao tipo facial. Neste contexto, apontaram dois tipos faciais antagônicos, denominados de mordida aberta e profunda. Relataram que, na mordida aberta, o crescimento facial vertical anterior inferior (ENAMe) excede o crescimento vertical posterior (ENP-Go); o posicionamento 
condilar é mais superior gerando, conseqüentemente, uma maior distância ortogonal côndilo-molar e o comprimento do ramo é menor. Estas diferenças provavelmente estavam relacionadas ao aumento da inclinação dos planos oclusal e mandibular, da altura facial anterior inferior e da distância entre os molares e incisivos superiores ao plano palatino, bem como à redução da altura facial posterior inferior.

SUBTELNY; SAKUDA ${ }^{101}$, em 1964, compararam as características cefalométricas de 25 indivíduos portadores de mordida aberta anterior, com um grupo de 30 indivíduos portadores de oclusão normal, apresentando ambos os grupos idades acima de 12 anos. Observaram, nos indivíduos portadores de mordida aberta, uma altura facial anterior excessiva (restrita ao terço inferior da face). Todavia, não foi observada diferença estatisticamente significante na dimensão vertical posterior.

Objetivando avaliar a altura facial anterior, WEINBERG; KRONMAN ${ }^{111}$, em 1966, examinaram uma amostra de 30 indivíduos com oclusão normal, com idades entre 11 e 12,8 anos, e outra com o mesmo número de indivíduos, com má oclusão e idade inicial entre 8,4 e 13,9 anos e final entre 11 e 15,10 anos, nos períodos pré e pós-tratamento ortodôntico. Constataram que a média para a altura facial total anterior é de $108,7 \mathrm{~mm}$ e a porcentagem da altura facial inferior é de 54,86\% em relação a AFAT.

Com a finalidade de avaliar as alturas craniofaciais e as alterações em profundidade, CANNON $^{27}$, em 1970, estudou cefalometricamente 52 indivíduos, em quantidades iguais para ambos os gêneros, dos 3 aos 8 anos de idade, todos com oclusão normal e não tratados ortodonticamente. Durante este período, observou que o aumento da altura facial posterior é pequeno, enquanto que a altura facial anterior apresenta um aumento médio maior. O aumento na altura facial ântero-inferior mostrou-se maior do que na posterior.

DERMAUT; O'REILLY37, em 1978, estudaram cefalometricamente as alterações da altura facial anterior em 24 indivíduos leucodermas, do gênero feminino, radiografados dois ou três anos antes e depois da menarca. 
Todos apresentavam uma relação esquelética normal, tanto no sentido ântero-posterior quanto no vertical e não tinham sido tratados ortodonticamente. Verificaram que existe grande variação na quantidade e no período de crescimento para as variáveis medidas (altura facial total - NMe, altura facial superior - N-ENA, altura facial inferior - ENA-Me). A maior parte do crescimento vertical processou-se antes da menarca. 0 pico da velocidade de crescimento para a altura facial ântero-superior ocorreu mais freqüentemente entre 11 e 12 anos e entre 12 e 13 anos para as alturas faciais total e inferior.

WOODSIDE; LINDER-ARONSON ${ }^{112}$, em 1979, verificaram que a altura facial ântero-inferior variou duas a três vezes mais que a altura facial ântero-superior que se mostrou relacionada com o crescimento da base do crânio. A altura ântero-inferior teve uma tendência de não possuir relação com outras partes esqueléticas. A altura ântero-inferior mostrou possuir uma dependência da direção do crescimento mandibular e dos fatores neuromusculares que influenciam a postura da mandíbula, como a respiração bucal e a postura da cabeça.

FIELDS et al. ${ }^{43}$, em 1984, concluíram que a altura anterior da face era significativamente maior em crianças com face longa, comparada ao grupo de crianças normais com face equilibrada. A altura posterior da face pareceu não diferir significativamente entre estes grupos.

Em um estudo acerca dos padrões de crescimento vertical da face, NANDA $^{84}$, em 1988, observou que o padrão de crescimento vertical era estabelecido em uma idade precoce, mantendo-se característico daquele indivíduo. Os pacientes hipo e hiperdivergentes pareciam crescer diferentemente e essa aparente diferença residia nos segmentos anteriores da face. Concluiu que a altura facial posterior e a altura do ramo não diferiam significativamente entre os pacientes hipo e hiperdivergentes.

VAN DER BEEK et al. ${ }^{107}$, em 1991, investigaram, por meio de um estudo longitudinal dos 7 aos 14 anos de idade, o crescimento vertical da face. Para o estudo, foram utilizadas telerradiografias em norma lateral de 72 
indivíduos leucodermas. Os autores avaliaram as seguintes dimensões: S-Go, $\mathrm{N}-\mathrm{Gn}$ e, finalmente, o ângulo do plano mandibular, sendo que este último foi utilizado para dividir os grupos estudados em mordida aberta e profunda esquelética. As correlações encontradas no estudo ${ }^{107}$ indicaram que as alterações no ângulo do plano mandibular, na formação dos diferentes tipos faciais, estão mais relacionadas à altura facial anterior do que à altura facial posterior. Conseqüentemente, os indivíduos avaliados em estágios precoces apresentando altura facial anterior aumentada e plano mandibular excessivo, apresentaram uma probabilidade maior de desenvolver uma mordida aberta esquelética. Concluíram, ainda, que as diferenças entre os tipos faciais hipodivergentes e hiperdivergentes eram determinadas pela altura anterior da face e, em uma menor extensão, pela altura posterior da face, corroborando com literatura acerca do intenso efeito que a altura anterior da face exerce no ângulo do plano mandibular e na formação dos diferentes tipos faciais ${ }^{107}$.

Estes inúmeros estudos ${ }^{18,43,93,101,107,112}$ citados anteriormente, que descreveram as características esqueléticas e dentárias da mordida aberta anterior, assim como das discrepâncias esqueléticas verticais, geralmente incluíram apenas indivíduos leucodermas, em suas amostras.

Entretanto, BEANE et al. ${ }^{13}$, em 2003, relataram resultados de estudos onde a prevalência e a severidade da mordida aberta anterior foram associadas com a etnia. A mordida aberta foi definida por qualquer grau de sobremordida negativa (menos de $0 \mathrm{~mm}$ ). Significativamente, mais crianças melanodermas apresentavam mordidas abertas que crianças leucodermas (16,3\% comparadas a apenas $4 \%$ ), indicando que a população de melanodermas pode, às vezes, ter até quatro vezes mais mordida aberta que a leucoderma. Porém, são escassos os trabalhos na literatura ${ }^{92}$ que explicam os motivos desta maior incidência em indivíduos melanodermas ${ }^{13}$.

Este estudo realizado por BEANE et al. ${ }^{13}$ objetivou comparar indivíduos melanodermas com e sem mordida aberta, para identificar os fatores esqueléticos ou dentários que poderiam auxiliar a categorizar a 
mordida aberta nesta população. Seus resultados confirmaram estudos anteriores, que associaram a mordida aberta com uma maior altura inferior da face, maior ângulo do plano mandibular e maior ângulo goníaco. As diferenças médias na altura posterior da face e angulação do plano palatino não tiveram influência importante. Concluíram que indivíduos melanodermas portadores de mordida aberta diferem daqueles que não apresentam, quanto ao desenvolvimento vertical na região anterior da face e rotação mandibular; e uma inclinação dentoalveolar protrusiva como um componente significativo dessa má oclusão ${ }^{13}$.

Portanto, cabe ressaltar que a avaliação da variação craniofacial na dimensão vertical deve ter um papel importante na abordagem do ortodontista quanto ao diagnóstico e tratamento da má oclusão ${ }^{69}$.

\subsubsection{As proporções faciais}

Os estudos de BRODIE $24-26$ realizados nos anos 40 e que se tornaram clássicos, introduziram a visão de que o crescimento facial ocorre de uma forma uniforme ${ }^{26}$. Os maxilares crescem anteriormente, a mandíbula mais que a maxila e que a altura facial aumenta, expressando o equilíbrio das proporções das estruturas faciais entre si. Nesta mesma década, vários autores $^{26,106}$, em seus estudos relataram que a altura facial ântero-superior (AFAS), medidas do ponto Násio à Espinha Nasal Anterior, representa cerca de $43 \%$ da altura facial anterior total (AFAT). Da distância do Násio ao Mento subtraindo-se a AFAT, resulta na altura facial ântero-inferior (AFAl) que representa 57\% desta proporção, independentemente da idade.

Após toda esta década, de estudos observou-se na literatura pertinente, trabalhos valiosos no afã de compreender as alterações do complexo processo que ocorre para o estabelecimento do padrão de crescimento e a estabilidade das proporções faciais, desde o nascimento até a fase adulta. 
BJ ÖRK ${ }^{19}$ relacionou 0 aumento do prognatismo devido à alteração da relação entre a base craniana e o comprimento das bases apicais.

WYLIE ${ }^{114}$, em 1952, descreveu que em faces equilibradas há uma menor medida do ângulo goníaco, um maior comprimento do corpo da mandíbula, uma maior altura do ramo mandibular e equilíbrio na proporção entre as alturas faciais superior e inferior. Realizou um estudo cefalométrico avaliando as proporções faciais de 171 indivíduos, sendo 97 do gênero masculino e 74 feminino, com idades entre 11 e 13 anos. Nas faces equilibradas obtiveram os seguintes resultados:

- A altura facial superior (AFS), distância medida do Násio à Espinha Nasal Anterior (ENA), correspondia a $45 \%$ da altura facial total (AFT). A distância do Násio ao Mento e a altura facial inferior (AFI) correspondia a $55 \%$ da AFT.

DOWNS $^{38}$, em 1956, utilizou uma amostra composta por indivíduos aos 3 anos, 9 anos e 6 meses e 12 anos e 8 meses, com oclusão normal, e observou um crescimento vertical maior na região do ramo do que na região anterior o que ocasionaria a redução do ângulo do plano mandibular.

Em um estudo sobre o crescimento, RICKETTS ${ }^{91}$, em 1957, relatou que as estruturas dentárias são responsáveis por aproximadamente $60 \%$ do aumento da altura facial total.

MEREDITH; KNOTT; HIXON ${ }^{75}$, em 1958, utilizaram o índice AFAS, AFAl, em uma amostra composta por 55 indivíduos dos 4 aos 12 anos de idade, em um estudo longitudinal. Determinaram que:

- AFAS aumenta gradativamente em relação a AFAl de acordo com a idade. Aos 4 anos, a proporção da AFAS em relação a AFAl é de $71,7 \%$ e aos 12 anos, 79,2\%, sem dimorfismo entre os gêneros.

As dimensões verticais e suas proporções identificam mais apropriadamente os tipos faciais, do que as dimensões ântero-posteriores ${ }^{98}$.

As proporções estudadas por SCHUDY ${ }^{98}$, em 1964, variaram de acordo com o padrão de crescimento. A AFAS (N-ENA) não apresentou 
diferenças estatisticamente significantes entre os tipos faciais, o que permitiu concluir que a diferença localiza-se na AFAl, que em média corresponde a $56 \%$ da AFAT, nos retrognatas, $59,5 \%$ e nos prognatas, $54,4 \%$.

Segundo SCHUDY ${ }^{96}$, em 1968, o crescimento vertical da maxila, através do contato oclusal, juntamente com o crescimento alveolar posterior da maxila denota relação direta com as proporções faciais e com o aumento da altura facial anterior.

JONES; MEREDITH ${ }^{66}$, em 1966, concluíram que a AFAS e AFAT são maiores nos meninos do que nas meninas, sendo que o gênero masculino, aos 5 anos, a AFAS representa 44\% da AFAT e aos 15 anos, 46\%. No gênero feminino, varia de $44,5 \%$ para $46,5 \%$. Ressaltaram que a AFAS permanece praticamente constante entre os 11 e 15 anos de idade, numa amostra de oclusão normal composta por 20 meninos e 20 meninas estudada entre os 5 e 15 anos de idade.

A análise cefalométrica de JARABAK ${ }^{3,65}$ prediz a direção de crescimento mandibular utilizando um polígono facial que inclui o ângulo sela (N.S.Ar), ângulo articular (S.Ar.Go) e ângulo goníaco (Ar.Go.Me). Além disso, a proporção da altura facial posterior (S-Go) em relação à anterior ( $\mathrm{N}-\mathrm{Me})$, de $56 \%$ a $62 \%$ indica um padrão de crescimento posterior, enquanto que uma proporção de $65 \%$ a $80 \%$ indica uma tendência de crescimento em direção anterior ${ }^{3}$.

JANSON et al. ${ }^{62}$, em 1998, estudaram a maturação dentária em jovens com tipos faciais extremos, tendo utilizado a proporção entre a altura facial ântero-inferior (ENA- Me) e a altura facial anterior total (N-Me) para definir estes tipos faciais. Consideraram como indicativo de um padrão horizontal extremo quando o valor médio da proporção entre estas alturas faciais era igual ou inferior a 52,85\% e com sobremordida igual ou superior a $4,8 \mathrm{~mm}$. Para um padrão vertical extremo de crescimento os valores foram $59,4 \%$, ou acima e de $-1 \mathrm{~mm}$ ou abaixo, respectivamente. 
A relação entre a rotação dos maxilares e a alteração nas proporções faciais foi investigada por ISAACSON et al. ${ }^{55-58}$, assim como $\mathrm{SCHUDY}^{95,97,98}$. Estes autores sugeriram que deve existir harmonia na quantidade, direção de crescimento e grau de rotação entre a maxila e mandíbula, se proporções faciais constantes forem mantidas.

\subsection{3 Í ndice da altura facial de HORN ${ }^{51}$}

O Índice da altura facial de HORN ${ }^{51}$, proposto em 1992, pode ser definido como sendo a proporção entre a medida PFH (distância em milímetros do ponto articular ao plano mandibular), e AFH (distância em milímetros do ponto mentoniano ao plano palatino).

$\mathrm{HORN}=\mathrm{PFH} / \mathrm{AFH} \times 100$

Índice da Altura Facial [IAF $=(A F P / A F A) \times 100]$ - razão entre as medidas Altura Facial Posterior (AFP) e Altura Facial Anterior (AFA), multiplicado por 100.

Este índice indica o sentido da rotação mandibular durante 0 tratamento ortodôntico. Segundo o autor, é particularmente útil no tratamento da Classe II divisão 1, pois se a altura facial posterior aumentar mais rapidamente que a altura facial anterior, o índice irá aumentar, colaborando para a obtenção de um perfil facial mais harmonioso, além de auxiliar na correção ântero-posterior da má oclusão, uma vez que a mandíbula estaria sofrendo rotação no sentido anti-horário, como nos casos de oclusão normal.

LOCKS $^{70}$, em 1996, estudou as alturas faciais anterior e posterior, em uma amostra composta por 79 indivíduos, leucodermas, brasileiros com idade entre 8 e 11 anos, com má oclusão de Classe I não tratados. Verificou que 0 crescimento das dimensões faciais anterior e posterior mantiveram-se constantes. Além disso, o Índice da altura facial de HORN ${ }^{51}$ foi de $66 \%$ com tendência a aumentar com a idade. As proporções faciais anteriores 
apresentaram-se praticamente constantes, com 42\% para a atura facial ântero-superior e 58\% para a inferior, sendo que esta última teve maior participação no aumento da altura facial anterior total. Não houve dimorfismo entre os gêneros, nem em relação às proporções faciais anteriores, nem ao Índice da altura facial de HORN ${ }^{51}$.

\subsection{Avaliação das Grandezas Cefalométricas em Diferentes Grupos ÉtNI cos}

Atualmente, as áreas metropolitanas do mundo têm uma população muito mais diversa, trazendo a necessidade de reconhecer que um único padrão de estética facial, pode não ser apropriado para as decisões de diagnóstico e plano de tratamento para indivíduos de vários passados étnicos, que migraram para distintas regiões geográficas ${ }^{77}$.

A importância em estudar os componentes verticais da face e relacioná-los com as características normais e individuais em diversos grupos étnicos, com diferentes influências culturais e sociais, está fundamentada no questionamento das limitações do tratamento ortodôntico e suas implicações clínicas, utilizando mecânicas que comprometam a estética facial e as metas terapêuticas. Os valores normativos das grandezas cefalométricas, que são específicas para diferentes grupos étnicos, devem ser interpretados para complementarem o diagnóstico e plano de tratamento, de acordo com as necessidades e expectativas individuais do paciente ${ }^{4}$. A literatura ressalta a carência de estudos cefalométricos, referente às diferenças e comparações da morfologia facial entre esses indivíduos de diferentes grupos ${ }^{4,9,32,33,53,60,77}$. A aplicabilidade dessas medidas deve ser considerada em diferentes situações.

Realizando uma breve retrospectiva das análises cefalométricas mais difundidas, observa-se que as mesmas foram desenvolvidas a partir de amostras de indivíduos norte-americanos, de origem essencialmente anglo- 
saxônica. Por este motivo, pesquisas foram realizadas com 0 propósito fundamental de verificar dentre as referidas análises, quais as que poderiam ser aplicadas em amostras de distintos grupos étnicos ${ }^{71,104}$.

A primeira tentativa de aplicar a análise cefalométrica a grupos étnicos além daqueles de etnia européia foi publicada em 1951 por COTTON, TAKANO, WONG ${ }^{34}$ que aplicaram a análise de DOWNS ${ }^{38}$ a afro-americanos, nipo-americanos, e sino-americanos. A partir de então vários pesquisadores analisaram afro-americanos, africanos, chineses, índios e outros grupos étnicos.

No intuito de abordar os estudos $8,14,46,50,63,71,72,79,80,85,86,88,89,103$ realizados em indivíduos brasileiros, estes serão brevemente citados pela importância que representam na literatura, pela grande diversidade geográfica, variação de raças e miscigenação ente elas. Sendo assim, surge a necessidade de reconhecer que um único padrão de estética facial pode não ser apropriado para as decisões de diagnóstico e plano de tratamento para pacientes de vários passados étnicos.

OLIVEIRA $^{86}$, em 1977, determinou as medidas cefalométricas 1-NB e P-NB em indivíduos brasileiros, leucodermas, dos 12 aos 18 anos e comparou os valores encontrados na pesquisa, com os de Holdaway. Concluiu que dos 12 aos 18 anos a variação dos incisivos foi estatisticamente insignificante, ao contrário dos valores de P-NB que indicaram um aumento significante, havendo crescimento do mento com predominância no gênero masculino. Do ponto de vista prático, considera-se que a relação de 1-NB com P-NB diminui com a idade às custas do crescimento do mento, sendo este, por sua vez, quantificado em $0,5 \mathrm{~mm}$ no gênero feminino e $1 \mathrm{~mm}$ no gênero masculino dos 12 aos 18 anos.

MARTINS ${ }^{71}$, em 1979, ao comparar certas análises cefalométricas aplicadas às medidas de jovens brasileiros, leucodermas, dos gêneros masculino e feminino, comprovou que da análise de ALABAMA ${ }^{105}$ preconizada por TAYLOR; HITCHCOCK ${ }^{105}$, somente poderiam ou podem ser considerados os valores pertencentes ao padrão dentário. 
JANSON; MARTINS ${ }^{63}$, em 1992, realizaram um estudo longitudinal em indivíduos leucodermas, com oclusão normal, não tratados ortodonticamente, na faixa etária dos 13 aos 18 anos. Compararam as medidas cefalométricas de indivíduos brasileiros com as da amostra do padrão Bolton e do "Centro de Pesquisas Ortodônticas" de Burlington e concluíram que o padrão esquelético dos brasileiros não apresentou diferença significante em relação a norte-americana. No entanto, o padrão dentário se mostrou ligeiramente mais protruído para os brasileiros.

ARIZA DIAS; PINZAN; HENRIQUES ${ }^{8}$, em 1993, verificaram se os valores das medidas Co-A, Co-Gn, AFAl e Dif. Mand./Max. propostos pela análise de MCNAMARA JR. ${ }^{74}$ poderiam ser utilizados em crianças leucodermas brasileiras durante a fase da dentadura mista, bem como avaliar as características do crescimento facial em ambos os gêneros. Avaliaram as telerradiografias de 15 jovens do gênero masculino e 13 do feminino com idade inicial de 5 anos até aos 12 anos. Os resultados obtidos apontaram que entre as amostras brasileira e de Bolton não houve diferenças significantes, mas quando as amostras de Burlington e a brasileira foram comparadas, algumas distinções foram encontradas, no entanto, não impossibilitando a aplicação da análise de MCNAMARA JR. ${ }^{74}$ para as crianças brasileiras. Apenas deve ser utilizada com considerações para o gênero masculino, que apresentou valores maiores para Co-A e Co-Gn.

Neste mesmo ano, PINZAN et al. ${ }^{88}$ realizaram um estudo correlacionando os valores obtidos no trabalho de ARIZA DIAS ${ }^{8}$ e na amostra de JANSON ${ }^{61}$ com os resultados obtidos na amostra de Bolton da análise de MCNAMARA JR. ${ }^{74}$, utilizando as medidas Co-A, Co-Gn, Diferença mand./max. e AFAl. Com a junção dos dados das duas amostras de brasileiros, a idade dos jovens variou dos 5 aos 18 anos. Concluíram que os valores de Co-A para os brasileiros se mostraram semelhantes ao dos americanos, exibindo valores menores para o gênero feminino em todas as fases estudadas. A medida Co-Gn também se revelou menor em todas as fases para o gênero feminino, o que demonstrou ser uma semelhança com os valores dos jovens 
americanos. Estes resultados evidenciam que o crescimento no gênero feminino ocorre antes do masculino, cessando seu pico de crescimento por volta dos 13 anos. Contudo, o estudo limitou-se a idade 17 anos e 10 meses para o gênero masculino, mas percebe-se pelos gráficos que os valores são ascendentes, denotando continuidade de crescimento. A diferença mand./max. mostrou valores maiores para amostra brasileira em relação à amostra de Bolton em ambos os gêneros. A AFAl apresentou-se diminuída para o gênero feminino, com valores similares ao da amostra de Bolton; e os brasileiros do gênero masculino apresentaram valores maiores comparados a esta amostra.

Baseados em estudos longitudinais, MARTINS et al. ${ }^{72}$, em 1998, apresentaram o resultado de uma pesquisa que resultou no Atlas de crescimento e desenvolvimento craniofacial. Utilizaram uma amostra composta por indivíduos brasileiros leucodermas, descendentes de mediterrâneos, não submetidos ao tratamento ortodôntico e que foram acompanhados dos 6 aos 18 anos de idade. Obtiveram os dados relacionados a diversas medidas de diferentes análises cefalométricas, no sentido vertical e ântero-posterior, representando um trabalho valioso para a execução do diagnóstico e plano de tratamento, em pacientes da mesma origem pesquisada ${ }^{72}$.

Com os resultados das pesquisas literárias que denotam a necessidade de utilizar um padrão cefalométrico específico para os diferentes grupos étnicos, vários estudos descreveram as principais características faciais e os valores médios de normalidade para as grandezas cefalométricas esqueléticas, dentárias e tegumentares nos diferentes grupos $73,33,34,40,72$. Variações fundamentais existem nas estruturas craniofaciais em diferentes raças que indicam a necessidade da avaliação da morfologia facial individual.

0 resultado da pesquisa realizada por TAKAHASHI ${ }^{104}$, em 1998, determinou os valores médios de normalidade para as grandezas cefalométricas esqueléticas, dentárias e tegumentares utilizando um padrão cefalométrico específico para os brasileiros, descendentes de xantodermas 
japoneses. Este mesmo autor ${ }^{103}$, em 2002, verificou a necessidade de se utilizar um padrão cefalométrico específico, no sentido vertical da face, para os brasileiros, descendentes de xantodermas e leucodermas. Encontrou dimorfismo entre gêneros e diferenças estatísticas entre os diferentes grupos, utilizando as medidas: AFAT; AFAS; AFAl; AFAS/AFAT; AFAI/AFAT; AFPT; AFPS; AFPI; AFPS/AFPT; AFPI/AFPT; AFA; AFP; IAF ${ }^{103}$.

Em 2002, ISHII; DEGUCHI; HUNT ${ }^{59}$ avaliaram e compararam as características craniofaciais de xantodermas japoneses e leucodermas britânicos, com idades entre 11 e 12 anos, que apresentavam má oclusão de Classe II, Divisão 1, com trespasse horizontal acentuado e não submetidos ao tratamento ortodôntico. A amostra de leucodermas foi constituída com as mesmas características da amostra de xantodermas. Verificaram os seguintes resultados: aumento significante da altura facial anterior superior (N-ENA) e da altura facial anterior total ( $\mathrm{N}-\mathrm{Me}$ ) na amostra de xantodermas, com um maior desenvolvimento vertical. A medida do comprimento do ramo mandibular ( $\mathrm{Ar}-\mathrm{Go}$ ) não apresentou diferenças entre os grupos ${ }^{59}$.

HWANG et al. ${ }^{53}$, em 2002, compararam os perfis de tecido mole de indivíduos coreanos e europeu-americanos com oclusão normal e faces equilibradas. Uma menor inclinação do ângulo nasal inferior e um maior grau da protrusão dos lábios foram relatados na amostra de indivíduos coreanos. A protrusão do mento dos coreanos foi menos proeminente que aquela dos europeu-americanos. Essas diferenças devem ser consideradas no diagnóstico e plano de tratamento para os indivíduos com esta variabilidade de grupos étnicos distintos ${ }^{53}$.

\subsection{AVAliação das grandezas cefalométricas em indivíduos MELANODERMAS}

RICHARDSON $^{90}$, em 1980, definiu que raça é, na melhor das hipóteses, difícil de definir, e as referências aos grupos étnicos são feitas 
com mais precisão com base naqueles unidos por alguma ligação em comum. Tal dificuldade pode ser evidenciada na literatura quando a etnia em questão aborda os indivíduos melanodermas.

Para um melhor entendimento das relações esqueléticas, dentárias e tegumentares peculiares dos indivíduos melanodermas, de diversos grupos geográficos, abordou-se os seguintes aspectos: as relações entre as bases apicais, as posições dentárias, o tecido mole e as dimensões verticais.

\subsubsection{Relação entre as bases apicais}

ALTEMUS $^{6}$, em 1968, ao estudar 6 grupos étnicos diferentes (caucasianos, negros, chineses, japoneses, indianos e australianos) relatou que as bases ósseas dos melanodermas são as mais protrusivas e 0 comprimento mandibular efetivo foi maior que nos caucasianos.

JACOBSON $^{60}$, em 1978, descreveu que os indivíduos melanodermas possuem geralmente um menor comprimento anterior da base do crânio (SN), um plano mandibular mais inclinado e um maior ângulo ANB.

No mesmo ano, FONSECA; KLEIN ${ }^{45}$, estudaram uma amostra de 40 indivíduos melanodermas de 20 a 30 anos, com oclusão dentária de Classe I de Angle. Em comparação a uma amostra controle de 20 indivíduos leucodermas, encontraram que a maxila e a mandíbula tiveram maior prognatismo esquelético.

CONNOR; MOSHIRI ${ }^{32}$, em 1985, compararam uma amostra de 50 indivíduos melanodermas com uma amostra de 50 indivíduos leucodermas, ambos com má oclusão de Classe I de Angle. Encontraram maior prognatismo esquelético maxilar do que mandibular.

MORAES; FREITAS; HENRIQUES ${ }^{80}$, em 1988, verificaram em indivíduos melanodermas que a maxila e a mandíbula estavam mais 
protruídas em relação à base do crânio e o padrão do esqueleto cefálico mostrou-se semelhante aos leucodermas.

FLYNN et al. ${ }^{44}$, em 1989, concluíram que em indivíduos melanodermas houve maior prognatismo esquelético maxilar, maior comprimento da base craniana posterior, maior comprimento do corpo mandibular e maior convexidade facial esquelética, comparado aos indivíduos leucodermas.

Alguns autores relataram que não ocorreu diferença significante, no valor da medida SNB, em indivíduos leucodermas e melanodermas. Porém, um aumento significante no valor da medida ANB foi justificado pela protrusão maxilar. As medidas foram próximas para os diversos grupos estudados: melanodermas americanos; africanos "Sotho-Tswana"; leucodermas ${ }^{5,7,30}$.

Em 2003, DANDAJENA; NANDA ${ }^{36}$, relataram um aumento significante no ângulo SNB em melanodermas africanos da amostra "Zimbabwean", comparados aos indivíduos melanodermas americanos e leucodermas.

Portanto, torna-se fundamental uma observação analítica das informações nos diferentes grupos étnicos sob vários aspectos. 


\subsubsection{Relação entre as posições dentárias}

A principal diferença no padrão esquelético craniofacial entre melanodermas sul-africanos e melanodermas americanos é representada por uma inclinação vestibular dos incisivos superiores, maior nos melanodermas americanos. Entretanto, para as medidas SNA, SNB, ANB, inclinação axial dos incisivos inferiores e ângulo do plano mandibular há mínima diferença entre os grupos. Possivelmente, o que difere se atribui ao fato de que os negros americanos são principalmente uma mistura de negros africanos, caucasianos do oeste da Europa e Mongolóides (índios americanos) ${ }^{40,60}$.

Em 1974, KOWALSKI et al. ${ }^{67}$ encontraram na medida 1-NB, a mais discrepante entre os indivíduos melanodermas e leucodermas, dentre as medidas da análise de Steiner. Sendo que, a protrusão do incisivo inferior com relação à linha NB foi muito maior em melanodermas, assim como o grau de protrusão maxilar medido pelo ângulo SNA. A inclinação do plano oclusal com relação à base do crânio foi também um pouco maior e 0 ângulo interincisivos foi consideravelmente maior na amostra de leucodermas.

JACOBSON $^{60}$, em 1978, apresentou um diagrama traçado sobre cada telerradiografia lateral para visualizar a inclinação axial dos incisivos e para expor a quantidade de espaço ocupado. Através desses diagramas, relatou que em comparação com os caucasianos, os incisivos superiores nos indivíduos melanodermas são um pouco mais inclinados para vestibular, já os incisivos inferiores são consideravelmente mais vestibularizados.

FONSECA; KLEIN ${ }^{45}$, em 1978, relataram uma maior vestibularização dos incisivos superiores e inferiores em melanodermas.

BERTOZ; MARTINS ${ }^{15}$, em 1981, evidenciaram um posicionamento mais anterior dos incisivos inferiores, quando comparados com leucodermas. Salientaram que a aparente inclinação vestibular e excessiva protrusão dos incisivos inferiores nos indivíduos melanodermas, não implica em discrepância cefalométrica, uma vez que esta característica é inerente à etnia. 
CONNOR; MOSHIRI ${ }^{32}$, em 1985, descreveram uma maior altura dentária anterior, uma maior vestibularização dos incisivos inferiores, em indivíduos melanodermas comparado a indivíduos leucodermas. Corroborando com os resultados de FLYNN et al. ${ }^{44}$, em 1989.

As principais diferenças faciais entre indivíduos leucodermas e melanodermas parecem residir na protrusão dentária bimaxilar. Para estes, a posição do mento se estabelece mais retrusiva, com uma maior tendência de crescimento no sentido vertical e maior inclinação e protrusão dos incisivos. o prognatismo atribuído aos indivíduos melanodermas é eminentemente dentário. A inclinação do plano mandibular seria o responsável pela retroposição. O aumento no tamanho da língua e lábios hipertônicos permitem que os dentes se mantenham em equilíbrio e harmonia em uma posição protruída ${ }^{7,9,11,22,32,34,40,82}$.

\subsubsection{Relação do tecido mole}

DRUMMOND ${ }^{40}$, em 1968, fez um estudo comparativo entre jovens melanodermas e leucodermas americanos, no qual afirmou que a posição protruída dos dentes e a espessura dos lábios fazem com que o terço inferior da face aparente ser mais volumoso. Pelo fato do plano mandibular ter uma inclinação excessiva, o pogônio aparece pouco no contexto facial.

Interessado em propor medidas cefalométricas para indivíduos melanodermas e compará-las com as padronizadas para leucodermas, SUSHNER ${ }^{102}$, em 1977, estudou 100 fotografias de perfil de americanos melanodermas divididos igualmente entre gêneros, selecionados por ortodontistas, como tendo os perfis mais agradáveis entre 1000 fotos. Verificou que os melanodermas apresentam um perfil tegumentar mais protrusivo que os leucodermas, e quanto ao dimorfismo, essa protrusão é maior nos homens que nas mulheres. Assim, o autor concluiu que a 
avaliação de perfis em melanodermas deve ser feita sem a imposição dos padrões para leucodermas.

FONSECA; KLEIN ${ }^{45}$, em 1978, relataram uma maior protrusão dos lábios, entretanto a espessura labial absoluta não foi significativamente maior em indivíduos melanodermas do gênero feminino comparado aos indivíduos leucodermas do mesmo gênero.

CONNOR; MOSHIRI ${ }^{32}$, em 1985, descreveram um maior comprimento do lábio superior em indivíduos melanodermas comparado aos indivíduos leucodermas.

Os comprimentos labiais superiores e inferiores, e espessura de tecido mole dos lábios e mento são maiores em indivíduos melanodermas que em leucodermas. Porém, há menor profundidade e projeção nasal, menor profundidade do mento ósseo, e menor ângulo nasolabial em indivíduos melanodermas ${ }^{44}$.

Visando estabelecer a preferência estética de ortodontistas, artistas plásticos e leigos quanto ao contorno do perfil facial mole, OKUYAMA; MARTINS ${ }^{85}$, em 1997, selecionaram 180 fotografias pertencentes a 60 jovens de diferentes etnias. A pesquisadora fez as medições de tecido mole dos 21 perfis classificados como bom, para cada grupo, e constatou que os avaliadores dos indivíduos melanodermas selecionaram os perfis destes, que mais se aproximaram dos perfis dos leucodermas. Além disso, verificou que os perfis preferidos pelos 27 avaliadores apresentaram uma suave convexidade facial para todas as etnias e maior convexidade e maior protrusão labial para os brasileiros melanodermas.

NAIDOO; MILES ${ }^{83}$, em 1997, concluíram que os valores médios cefalométricos para as medidas de tecido mole de indivíduos sul-africanos se diferem dos indivíduos caucasianos norte-americanos e os afro-americanos. 


\subsubsection{Relação das dimensões verticais}

FONSECA; KLEIN ${ }^{45}$, em 1978, relataram para os melanodermas uma altura mais curta do terço médio da face, e altura facial inferior mais longa.

Em indivíduos melanodermas, há maior altura facial anterior inferior esquelética, maior altura facial posterior superior, que em leucodermas. Além disso, suas alturas dentárias anteriores superiores e inferiores, são maiores ${ }^{44}$.

JACOBSON $^{60}$, em 1978, relatou que a altura dentária posterior média dos leucodermas é significativamente maior do que a dos melanodermas ${ }^{60}$.

Esses achados corroboram com o estudo clássico de BJÖRK ${ }^{19}$, 1950 que foi realizado com uma amostra comparando indivíduos suecos e bantos. Ressaltou 0 aumento no prognatismo alveolar relacionado aos incisivos mais protruídos e o mento retroposicionado, em indivíduos melanodermas. Seus resultados revelam a altura facial ântero-inferior maior que a altura facial ântero-superior comparado aos da amostra de leucodermas americanos ${ }^{19}$.

BACON; GIRARDIN; TURLOT ${ }^{9}$, em 1983, compararam indivíduos melanodermas "Bantu-africanos" e indivíduos leucodermas. Concluíram um aumento significante da altura facial ântero-inferior nos melanodermas, em contraste com um desenvolvimento menor no terço médio da face nestes indivíduos. BRIEDENHANN; ROOS ${ }^{22}$, em 1988, realizaram um estudo com indivíduos melanodermas "Herero-speaking", onde as proporções encontradas foram de $41 \%$ (AFAS); $59 \%$ (AFAI).

BARTER et al. ${ }^{11}$, em 1995, descreveram seu grupo de indivíduos melanodermas "Sotho-Tswana", caracterizando-os por uma base do crânio diminuída e conseqüentemente uma redução da altura facial anterior.

LINDER-ARONSON; WOODSIDE ${ }^{69}$, em 2000, apresentaram uma comparação entre as informações do Centro de Crescimento de Burlington, 
amostra do King's College, amostra do Centro de Crescimento de Ann Arbor, e estudos de populações asiáticas e afro-americanas. Todas estas informações foram corrigidas para os diferentes graus de ampliação radiográfica utilizados em cada centro. Compararam os valores de quatro medidas para a dimensão facial vertical e tamanho das vias aéreas. As medidas da altura facial total foram bastante semelhantes entre caucasianos (amostras de Burlington e King's College) e japoneses. Por exemplo, o grupo de Burlington é apenas 2,0 a 3,0mm menor que as amostras do King's College, Ann Arbor e japonesa. Os afro-americanos foram um grupo distintamente separado, com uma altura facial total aproximadamente 15,0mm maior que os outros grupos. Também houve uma diferença de apenas $1-2 \mathrm{~mm}$ entre as medidas das alturas superior e inferior da face para todos os grupos, com exceção dos afro-americanos. Estes apresentaram uma altura superior da face $3 \mathrm{~mm}$ maior, em média e uma altura inferior da face $12 \mathrm{~mm}$ maior. A proporção das alturas superior e inferior da face foi semelhante para caucasianos norte-americanos, caucasianos europeus e japoneses. A proporção de afro-americanos indicou uma altura inferior da face mais longa neste grupo racial.

Corroborando com os resultados de ROSA; ARVYSTAS ${ }^{92}$, em 1978, BEANE et al. ${ }^{13}$, em 2003, concluíram que indivíduos melanodermas portadores de mordida aberta diferem daqueles que não a apresentam, quanto ao desenvolvimento vertical da região anterior da face.

Portanto, tendo em vista essas ponderações, considerou-se importante realizar esta pesquisa para determinar os valores médios de normalidade para algumas das grandezas cefalométricas esqueléticas de jovens brasileiros melanodermas, no sentido vertical da face. 
Proposição 


\section{PROPOSI ÇÃO}

Com o propósito de apresentar um padrão cefalométrico específico das alturas faciais anterior e posterior, para os jovens brasileiros melanodermas, utilizando medidas no sentido vertical da face, este estudo objetivou:

- Obter os valores médios de normalidade para as grandezas cefalométricas esqueléticas de jovens brasileiros melanodermas, e

- Identificar a presença ou ausência de dimorfismo entre os gêneros. 
MATERIAL E MÉTOdos 


\section{MATERI AL E MÉTODOS}

\subsection{MATERI AL}

0 material utilizado constituiu-se de 56 telerradiografias cefalométricas, em norma lateral, referentes a uma amostra de brasileiros melanodermas com oclusão normal, pertencentes ao arquivo da Disciplina de Ortodontia - Faculdade de Odontologia de Bauru da Universidade de São Paulo, e gentilmente cedidas para esta pesquisa.

Os critérios utilizados para a seleção da amostra, foram a presença dos dentes permanentes em oclusão, exceto os terceiros molares, as relações normais de molares, pequeno ou nenhum grau de apinhamento, ausência de mordida cruzada, trespasses vertical e horizontal normais, um perfil agradável e nunca submetidos a tratamento ortodôntico.

A amostra de oclusão normal de brasileiros melanodermas foi composta por 56 jovens, sendo 28 do gênero masculino e 28 do gênero feminino, com idade média de 13,86 anos (idade mínima de 12,08 anos e máxima de 15,75 anos).

\subsection{MÉtodos}

\subsubsection{Radiografias cefalométricas}

As telerradiografias foram obtidas e reveladas de acordo com as normas preconizadas pela Disciplina de Radiologia da mesma instituição.

O fator de magnificação da imagem radiográfica do aparelho utilizado foi calculado e posteriormente efetuou-se a correção deste fator para que, durante a comparação entre as amostras, se obtivesse maior precisão. 0 aparelho apresentou o fator de magnificação de $6 \%{ }^{103}$. 


\subsubsection{Elaboração do Cefalograma}

Para a obtenção dos cefalogramas, foi utilizado um negatoscópio, folhas de acetato transparente "ultraphan" para traçado cefalométrico, de $0,07 \mathrm{~mm}$ de espessura recortado em $17,5 \times 17,5 \mathrm{~cm}$; lapiseira 0,3 mm; fita adesiva (Scotch - 3M) e uma moldura preta de polipropileno, semi-rígida, com recorte central de $47 \times 19 \mathrm{~cm}$ e outra de $17,5 \times 18,5 \mathrm{~cm}$ adaptadas ao negatoscópio no intuito de concentrar a luz para promover melhor visualização das áreas anatômicas de interesse na telerradiografia.

O desenho do traçado anatômico, a localização e a demarcação dos pontos cefalométricos de todos os traçados foram realizados em uma sala escura, onde a luz do negatoscópio foi a única fonte de iluminação.

Após a execução do desenho anatômico, os pontos foram identificados e, posteriormente, digitalizados por intermédio de uma mesa digitalizadora Numonics A-30TL. $F^{1}$, conectado a um microcomputador com processador AMD K-6 II $500 \mathrm{MHz}$, para obtenção das grandezas cefalométricas. Os traçados e a digitalização dos pontos foram realizados pelo examinador, utilizando-se o padrão Ortho Lateral do programa Dentofacial Planner $7.02^{2}$ para a realização das medições. Foi efetuada a correção do fator de magnificação $(6 \%)$, realizada pelo próprio programa.

\footnotetext{
${ }^{1}$ Numonics Corporation, Montgomeryville, PA, EUA.

${ }^{2}$ Dentofacial Planner Software Inc., Toronto, Ontário, Canadá.
} 


\subsubsection{Delimitação das estruturas anatômicas}

O desenho anatômico está de acordo com o preconizado por KROGMAN; SASSOUNI ${ }^{68}$, INTERLANDI ${ }^{54}$ e VION $^{110}$ (Figura 4.1, p.36), com as seguintes estruturas anatômicas:

1 - Sela Túrcica;

2 - Clívus;

3 - Cortical externa do osso frontal e ossos nasais;

4 - Média da fissura pterigomaxilar;

5 - Média das bordas inferiores das órbitas;

6 - Média dos meatos acústicos externos;

7 - Maxila;

8 - Mandíbula;

9 - Dentes;

10 - Perfil tegumentar. 


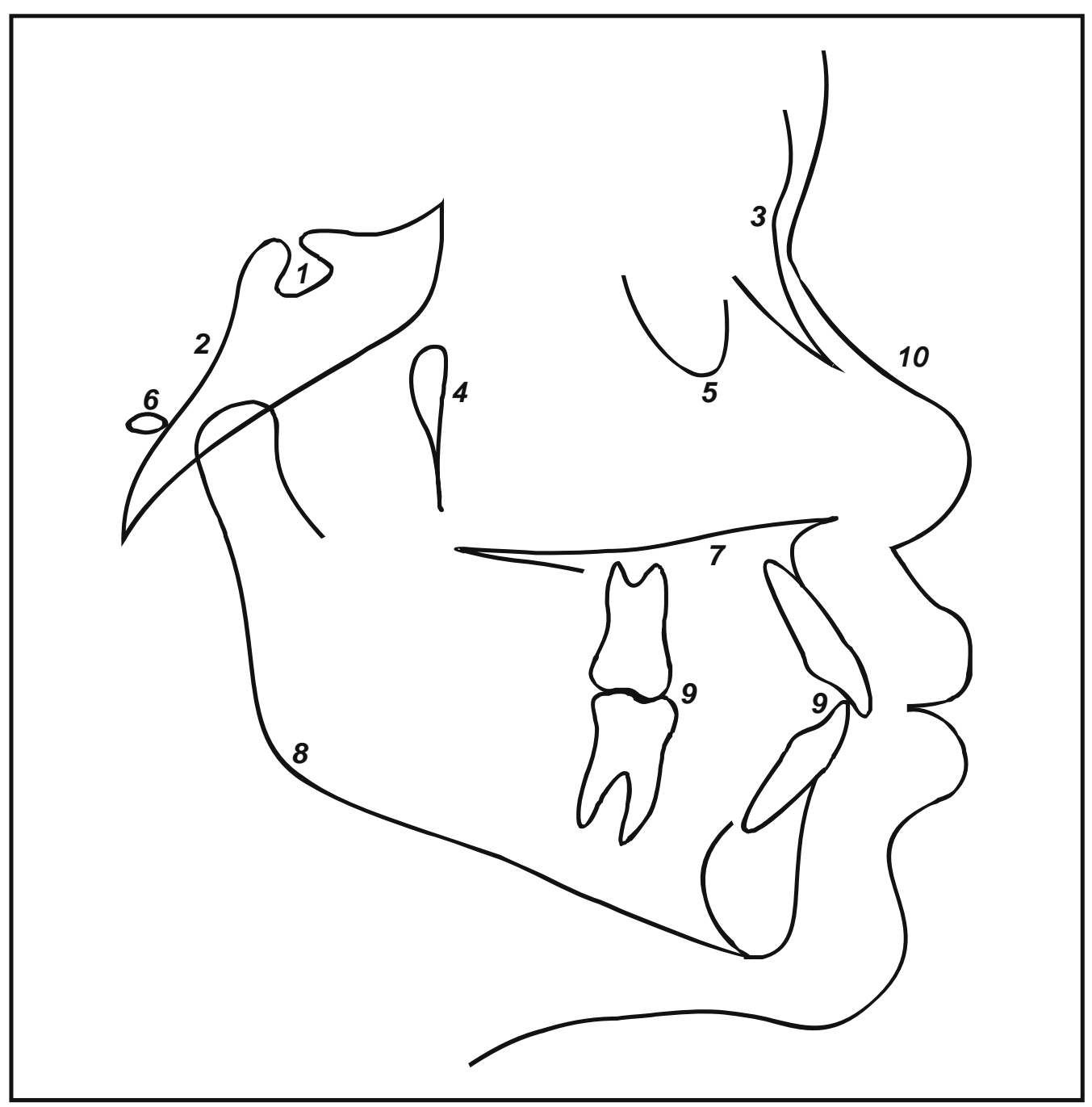

FI GURA 4.1 - Desenho das estruturas anatômicas 


\subsubsection{Demarcação dos pontos e traçado de orientação: linhas e planos}

Após a confecção do desenho anatômico, localizou-se os pontos cefalométricos, de acordo com KROGMAN; SASSOUNI ${ }^{68}$ e MIYASHITA ${ }^{78}$ : $\boldsymbol{S}$ (Sela); N (Násio); ENA (Espinha nasal anterior); ENP (Espinha nasal posterior); Me (Mentoniano); Go (Gônio); Ar (Articular) (Figura 4.2, p.38).

Localizados os pontos cefalométricos traçaram-se os planos, as linhas e demarcados os pontos construídos, $\operatorname{Ar}^{\prime}$ e ENA', de acordo com WYLIE; JOHNSON ${ }^{114}$, SIRIWAT; JARABAK ${ }^{100}$ e HORN $^{51}$. (Figura 4.3, p.39).

1 - Linha $\mathbf{N}$ - Me (linha $\mathbf{N}$ - Me): linha formada pela união dos pontos Násio (N) e Mentoniano (Me);

2 - Linha ENA perp.: linha formada pela projeção do ponto Espinha nasal anterior (ENA) e perpendicular à linha N - Me;

3 - Plano Palatino (PP): linha que une as Espinhas nasais anterior (ENA) e posterior (ENP);

4 - Linha PP - Me (PP - Me): linha perpendicular ao Plano Palatino (PP) que une este plano ao ponto Mentoniano (Me);

5 - Plano Mandibular (PM): representado pela linha que passa pelo ponto Mentoniano (Me) e tangente ao bordo posterior da base da mandíbula;

6 - Linha Ar - PM (Ar - PM): linha que une o ponto Articular (Ar) ao Plano Mandibular (PM), tangenciando 0 bordo posterior do ramo da mandíbula;

7 - Linha $\mathbf{S}$ - Go (S - Go): linha formada pela união dos pontos Sela (S) e Gônio (Go);

8 - Linha Ar perp.: linha formada pela projeção do ponto Articular (Ar) e perpendicular à linha S - Go; 
9 - Ponto ENA' (projeção do ponto ENA): ponto formado pela intersecção da linha ENA perp. com a linha N-Me;

10 -Ponto Ar' (projeção do ponto Ar): ponto formado pela intersecção da linha Ar perp. com a linha S-Go.

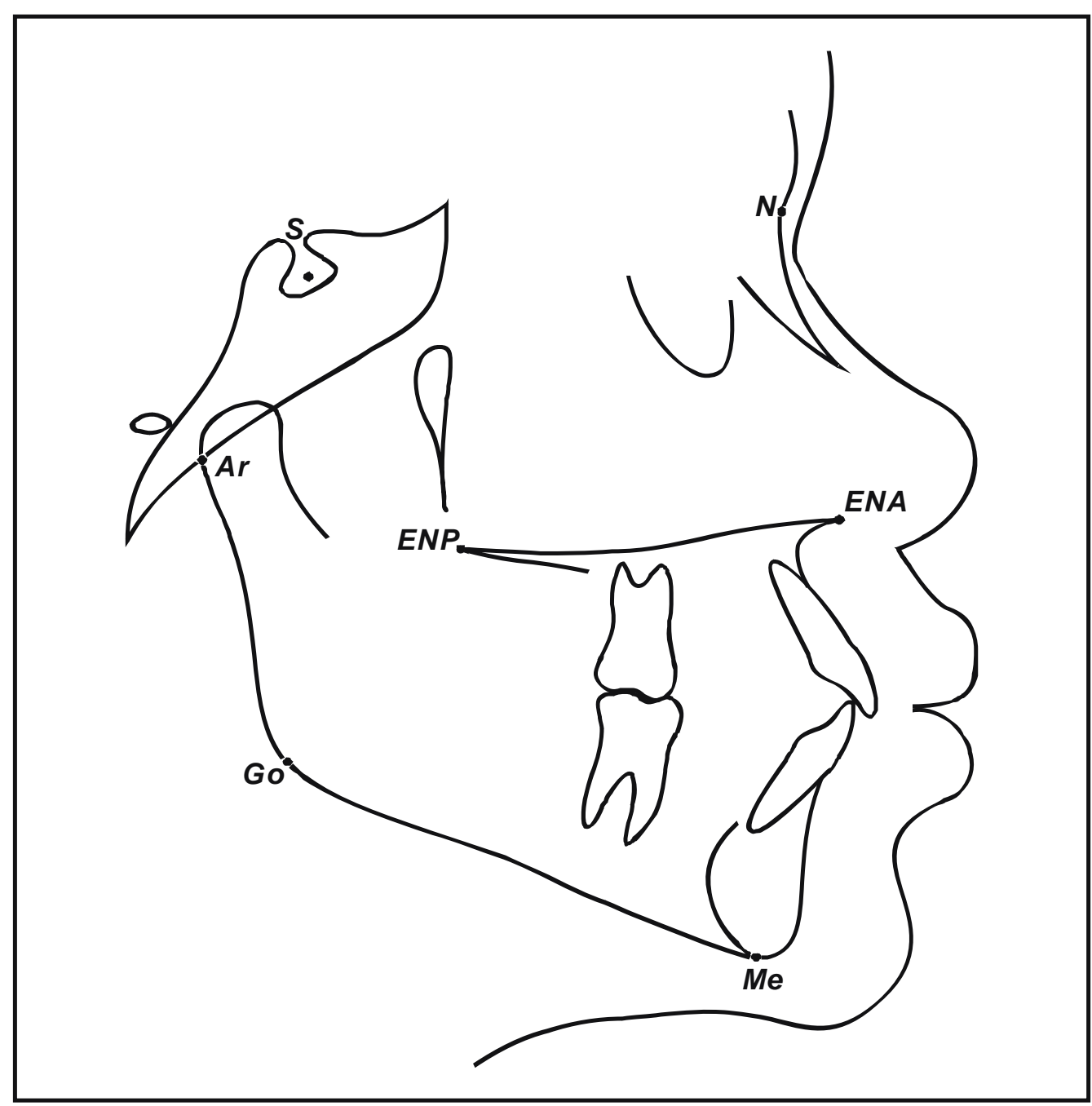

FI GURA 4.2 - Demarcação dos pontos cefalométricos 


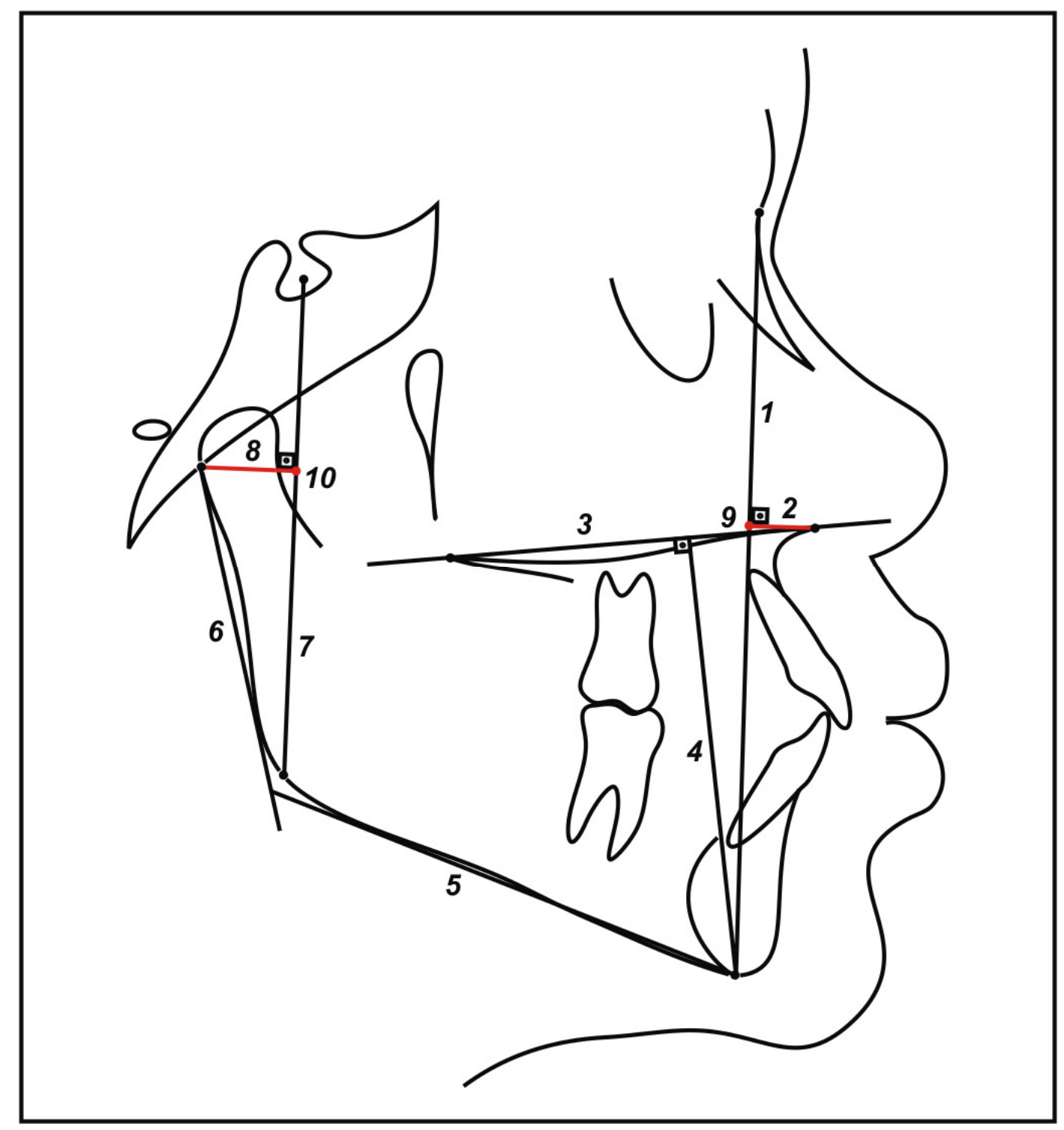

FIGURA 4.3 - Representação das linhas e planos 


\subsubsection{Medidas Cefalométricas no sentido vertical da face}

\subsubsection{Medidas empregadas de acordo com a Análise de WYLIE; JOHNSON $^{114}$. (Figura 4.4, p.41).}

- Altura Facial Anterior Total (AFAT) - distância linear do ponto Násio (N) ao ponto Mentoniano (Me);

- Altura Facial Anterior Superior (AFAS) - distância linear, mensurada sobre a linha $\mathrm{N}-\mathrm{Me}$, do ponto Násio (N) ao ponto ENA';

- Altura Facial Anterior Inferior (AFAl) - distância linear, mensurada sobre a linha $\mathrm{N}$ - Me, do ponto ENA' ao ponto Mentoniano (Me);

- Proporção entre a Altura Facial Anterior Superior e a Altura Facial Anterior Total (AFAS/ AFAT) - razão entre as medidas Altura Facial Anterior Superior (AFAS) e a Altura Facial Anterior Total (AFAT);

- Proporção entre a Altura Facial Anterior Inferior e a Altura Facial Anterior Total (AFAl/ AFAT) - razão entre as medidas Altura Facial Anterior Inferior (AFAI) e a Altura Facial Anterior Total (AFAT). 


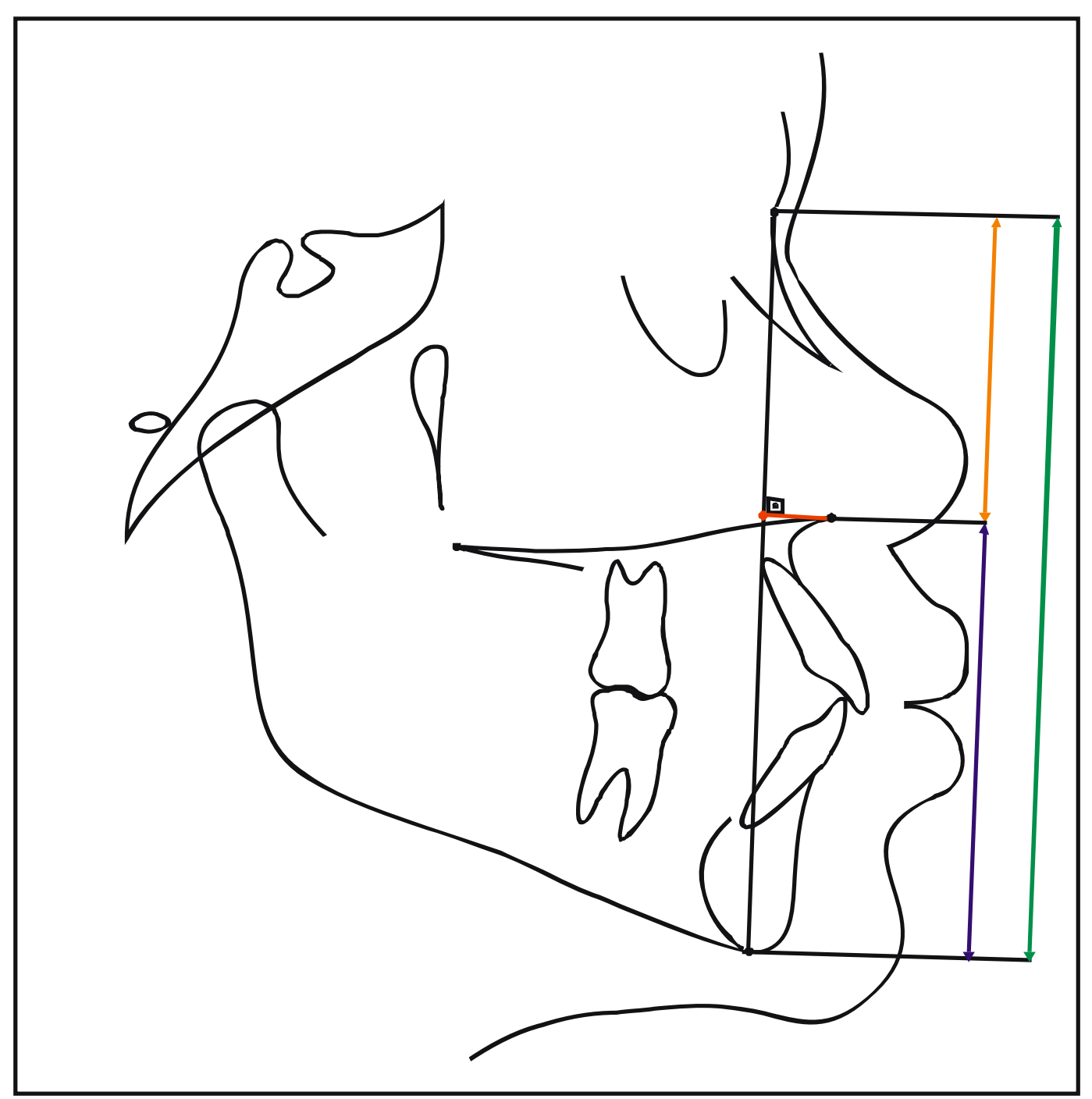

FIGURA 4.4 - Medidas empregadas de acordo com a Análise de WYLIE; JOHNSON ${ }^{114}$

Legenda das referentes medidas diferenciada por cores:
- Altura Facial Anterior Total (AFAT)
- Altura Facial Anterior Superior (AFAS)
- Altura Facial Anterior Inferior (AFAl) 


\subsubsection{Medidas empregadas de acordo com a Análise de SI RI WAT; JARABAK $^{100}$. (Figura 4.5, p.43)}

a Altura Facial Posterior Total (AFPT) - distância linear do ponto Sela (S) ao ponto Gônio (Go);

- Altura Facial Posterior Superior (AFPS) - distância linear, mensurada sobre a linha S - Go, do ponto Sela (S) ao ponto Ar';

- Altura Facial Posterior Inferior (AFPI) - distância linear, mensurada sobre a linha S - Go, do ponto Ar' ao ponto Gônio (Go);

- Proporção entre a Altura Facial Posterior Superior e a Altura Facial Posterior Total (AFPS/ AFPT) - razão entre as medidas Altura Facial Posterior Superior (AFPS) e a Altura Facial Posterior Total (AFPT);

- Proporção entre a Altura Facial Posterior Inferior e a Altura Facial Posterior Total (AFPI/ AFPT) - razão entre as medidas Altura Facial Posterior Inferior (AFPI) e a Altura Facial Posterior Total (AFPT). 


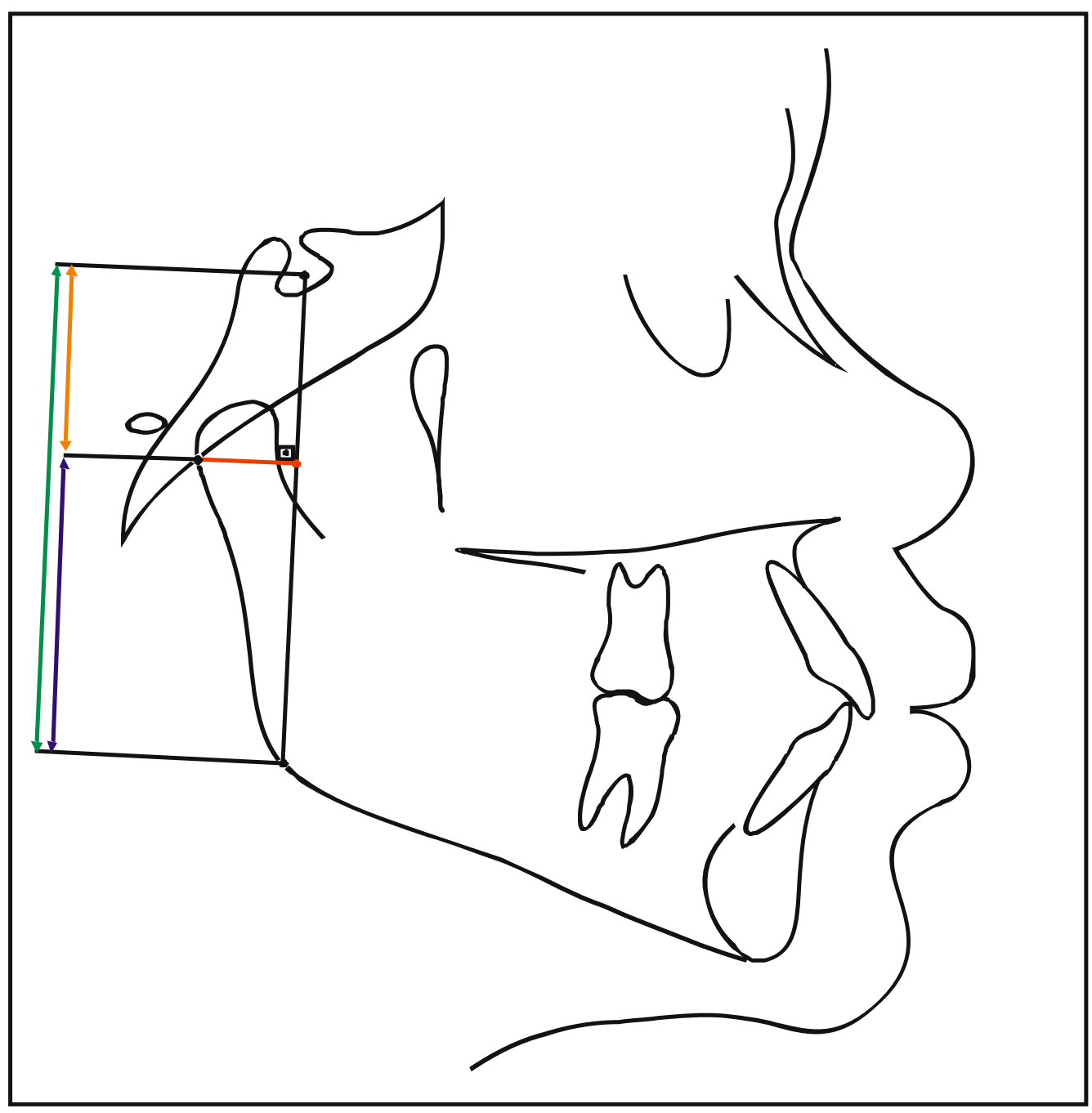

FIGURA 4.5 - Medidas empregadas de acordo com a Análise de SIRIWAT; JARABAK 100

Legenda das referentes medidas diferenciada por cores:

- Altura Facial Posterior Total (AFPT)

- Altura Facial Posterior Superior (AFPS)

- Altura Facial Posterior Inferior (AFPI) 


\subsubsection{Medidas empregadas de acordo com a Análise de GEBECK;} MERRI FI ELD ${ }^{47,76}$ (Figura 4.6, p.45)

口 Altura Facial Anterior (AFA) - distância linear do Plano Palatino (PP) perpendicular ao ponto Mentoniano (Me);

- Altura Facial Posterior (AFP) - distância linear do ponto Articular (Ar) ao Plano Mandibular (PM);

\subsubsection{4 Í ndice da Altura Facial de acordo com HORN ${ }^{51}$}

Índice da Altura Facial [IAF = (AFP/ AFA) x 100] - razão entre as medidas Altura Facial Posterior (AFP) e Altura Facial Anterior (AFA), multiplicado por 100. 


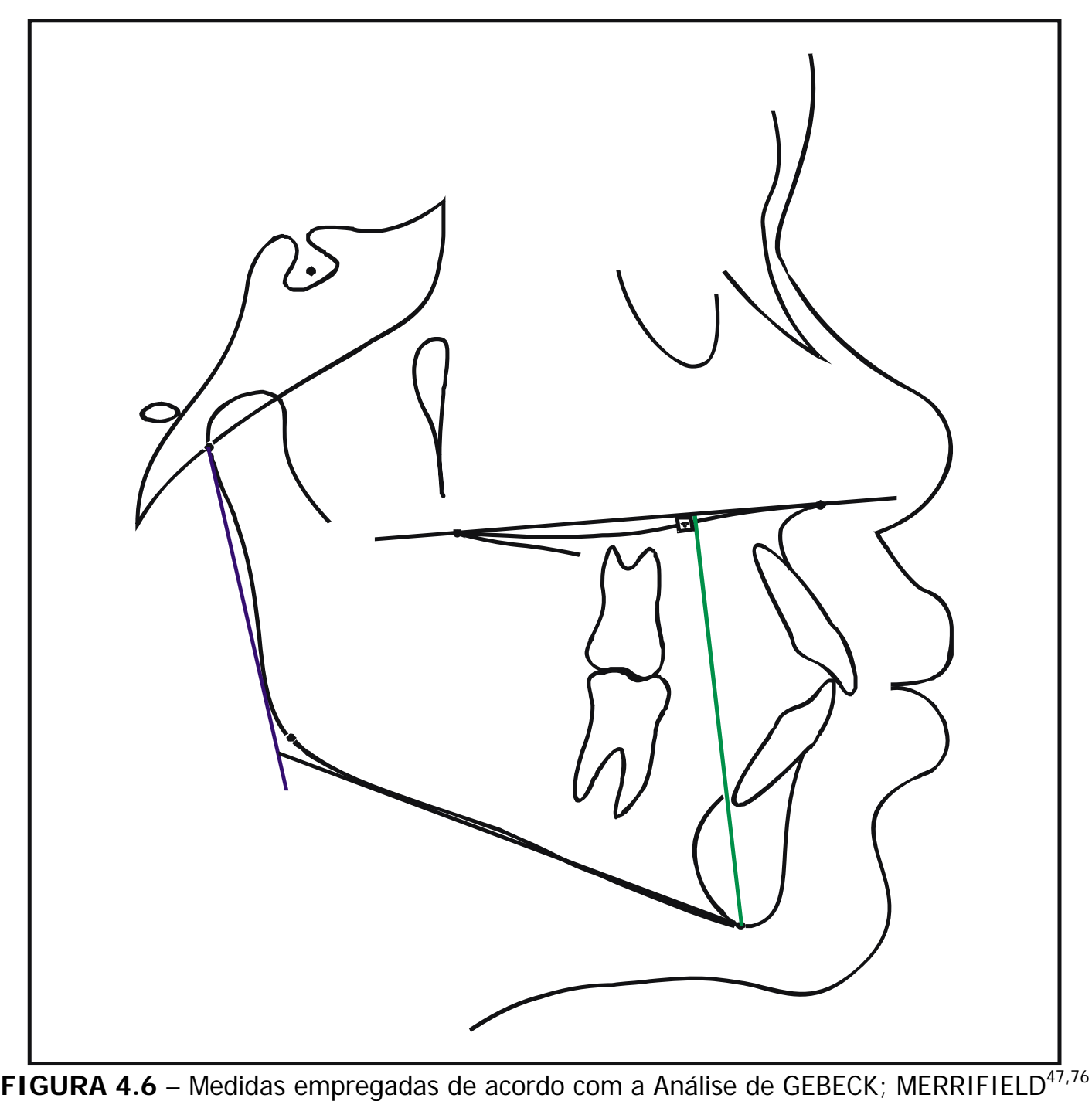

Legenda das referentes medidas diferenciada por cores:

- Altura Facial Anterior (AFA)

- Altura Facial Posterior (AFP) 


\subsubsection{Análise Estatística}

\subsubsection{Erro do método}

Os traçados e as mensurações das grandezas cefalométricas foram refeitos pelo mesmo examinador, após a obtenção dos cefalogramas iniciais. Para a determinação da confiabilidade dos resultados, vinte radiografias selecionadas ao acaso foram traçadas e digitalizadas, pelo mesmo pesquisador, com um intervalo de 10 dias.

Para cada uma das grandezas cefalométricas estudadas, foram avaliados os erros sistemáticos e casuais, independentemente. 0 erro sistemático foi calculado pelo teste " $\mathrm{t}$ " pareado, conforme preconizado por HOUSTON $^{52}$. A aplicação da fórmula proposta por DAHLBERG ${ }^{35}\left(\mathrm{Se}^{2}=\right.$ somatória $\left.d^{2} / 2 n\right)$ possibilitou estimar a resultante dos erros casuais. Consideram-se significantes os erros acima de 1 milímetro para as medidas lineares e 1,5 grau para as angulares ${ }^{35}$.

\subsubsection{Análise descritiva e comparativa}

Para a análise estatística dos dados utilizou-se o teste " $\mathrm{t}$ " independente, para comparação dos valores das grandezas cefalométricas. Estes testes foram realizados no programa de computador Statistica for Windows $5.0^{3}$. Os resultados foram considerados estatisticamente significantes com valor de $p<0,05$.

\footnotetext{
${ }^{3}$ STATISTICA for Windows. StatSoft, Inc. (1995). Tulsa, OK, EUA.
} 
RESULTADOS 


\section{RESULTADOS}

Os resultados estão apresentados sob a forma de tabelas. As tabelas exibem as médias, os desvios-padrão e a significância estatística dos resultados observados. Os valores individuais, referentes a todas as grandezas cefalométricas utilizadas, apresentam-se nas tabelas do apêndice. $\mathrm{Na}$ tabela 5.1 estão dispostos os valores dos erros casuais ${ }^{35}$ e sistemáticos ${ }^{52}$, da avaliação intra-examinador. A Tabela 5.2 representa a compatibilidade da idade entre os gêneros e apresenta os valores das médias e desvios-padrão da medida SN.GoGn. A análise descritiva da amostra, com os valores das médias e desvios-padrão no sentido vertical da face, em jovens brasileiros melanodermas está disposta na Tabela 5.3. E a análise estatística do teste " $\mathrm{t}$ " independente para o dimorfismo entre os gêneros na Tabela 5.4. A apresentação dos resultados na forma de gráficos no capítulo da Discussão tem por finalidade, facilitar a interpretação. 
TABELA 5.1- Apresentação das médias e desvios-padrão, para os dois tempos realizados, do teste " $\mathrm{t}$ " de Student e do erro casual (Dahlberg) ${ }^{35}$

\begin{tabular}{|c|c|c|c|c|c|c|c|}
\hline \multirow{3}{*}{ Variáveis } & & & & & \multirow[t]{2}{*}{ Dahlberg } & \multirow[t]{2}{*}{$\begin{array}{c}\text { Teste } \\
\text { "t" }\end{array}$} & \\
\hline & \multicolumn{2}{|c|}{ Tempo1 } & \multicolumn{2}{|c|}{ Tempo2 } & & & \\
\hline & $X$ & D.P & $X$ & D.P & $E$ & $p$ & \\
\hline AFAT(N-Me) & 109,15 & 5,45 & 109,26 & 5,61 & 1,154 & 0,761 & n.s. \\
\hline AFAS(N-ENA') & 45,71 & 3,03 & 46,23 & 2,90 & 1,002 & 0,105 & n.s. \\
\hline AFAI(ENA'-Me) & 62,90 & 4,40 & 63,03 & 4,33 & 0,531 & 0,453 & n.s. \\
\hline AFASIAFAT & 42,06 & 2,16 & 42,33 & 2,08 & 0,526 & 0,106 & n.s. \\
\hline AFAI/AFAT & 57,85 & 2,21 & 57,67 & 2,08 & 0,578 & 0,324 & n.s. \\
\hline AFPT(S-Go) & 69,09 & 4,36 & 69,11 & 4,04 & 0,669 & 0,927 & n.s. \\
\hline AFPS(S-Ar') & 28,38 & 2,48 & 28,78 & 2,75 & 0,988 & 0,214 & n.s. \\
\hline AFPI(Ar'-Go) & 40,85 & 3,12 & 40,33 & 2,88 & 1,124 & 0,152 & n.s. \\
\hline AFPSIAFPT & 41,02 & 2,56 & 41,63 & 2,82 & 1,363 & 0,162 & n.s. \\
\hline AFPI/AFPT & 59,02 & 2,57 & 58,37 & 2,82 & 1,365 & 0,132 & n.s. \\
\hline AFA(Me-PP) & 62,32 & 4,21 & 62,33 & 4,04 & 0,397 & 0,969 & n.s. \\
\hline AFP(Ar-PM) & 45,07 & 3,47 & 44,44 & 3,63 & 1,208 & 0,102 & n.s. \\
\hline IAF(AFP/AFA) & 72,41 & 5,54 & 71,38 & 5,70 & 1,304 & 0,141 & n.s. \\
\hline
\end{tabular}

* Significante para $p<0,05$. 
TABELA 5.2 - Análise estatística das médias e desvios-padrão das idades e de SN.GoGn em ambos os gêneros

\begin{tabular}{|c|c|c|c|c|c|c|c|c|}
\hline & \multicolumn{3}{|c|}{ Total $(\mathrm{N}=56)$} & \multicolumn{2}{|c|}{ Feminino $(\mathrm{N}=28)$} & \multicolumn{2}{|c|}{ Masculino( $\mathbf{N}=\mathbf{2 8})$} & \multirow[b]{2}{*}{$p$} \\
\hline & $x$ & D.P & $x$ & D.P & $x$ & D.P & $\mathrm{t}$ & \\
\hline Idade & 13,86 & 0,91 & 13,79 & 0,78 & 13,93 & 1,04 & $-0,585$ & 0,560 \\
\hline Idade mínima & 12,08 & & 12,58 & & 12,08 & & & \\
\hline Idade máxima & 15,75 & & 15,67 & & 15,75 & & & \\
\hline SN.GoGn & & & $28,44^{\circ}$ & $2,93^{\circ}$ & $29,12^{\circ}$ & $2,72^{\circ}$ & 0,896 & 0,374 \\
\hline
\end{tabular}

*Significante para $p<0,05$.

TABELA 5.3 - Análise descritiva da amostra, com os valores das médias e desvios-padrão em jovens brasileiros melanodermas

\begin{tabular}{|c|c|c|c|}
\hline Variáveis & \multicolumn{1}{|c|}{$\mathbf{X}$} & $\mathbf{D . P}$ & $\mathbf{N}$ \\
\hline AFAT(N-Me) & 110,15 & 5,33 & 56 \\
\hline AFAS(N-ENA') & 46,97 & 2,32 & 56 \\
\hline AFAI(ENA'-Me) & 63,18 & 4,16 & 56 \\
\hline AFAS/AFAT & 42,66 & 1,69 & 56 \\
\hline AFAI/AFAT & 57,33 & 1,69 & 56 \\
\hline AFPT(S-Go) & 70,10 & 4,94 & 56 \\
\hline AFPS(S-Ar') & 29,53 & 2,91 & 56 \\
\hline AFPI(Ar'-Go) & 40,57 & 3,93 & 56 \\
\hline AFPS/AFPT & 42,15 & 3,37 & 56 \\
\hline AFPI/AFPT & 57,84 & 3,37 & 56 \\
\hline AFA(Me-PP) & 62,32 & 3,89 & 56 \\
\hline AFP(Ar-PM) & 44,72 & 4,25 & 56 \\
\hline IAF(AFP/AFA) & 71,89 & 6,81 & 56 \\
\hline
\end{tabular}


TABELA 5.4- Análise estatística do teste " $\mathrm{t}$ " independente para o dimorfismo entre os gêneros, em jovens brasileiros melanodermas

\begin{tabular}{|c|c|c|c|c|c|}
\hline \multirow[t]{2}{*}{ Variáveis } & \multicolumn{2}{|c|}{ Feminino } & \multicolumn{2}{|c|}{ Masculino } & \multirow[b]{2}{*}{$\mathbf{p}$} \\
\hline & Média & D.P. & Média & D.P. & \\
\hline AFAT(N-Me) & 108,73 & 3,67 & 111,57 & 6,35 & $0,045^{\star}$ \\
\hline AFAS(N-ENA') & 46,10 & 1,79 & 47,84 & 2,49 & $0,003^{*}$ \\
\hline AFAI(ENA'-Me) & 62,63 & 3,17 & 63,73 & 4,96 & 0,328 \\
\hline AFASIAFAT & 42,41 & 1,53 & 42,92 & 1,82 & 0,262 \\
\hline AFAI/AFAT & 57,58 & 1,53 & 57,07 & 1,82 & 0,262 \\
\hline AFPT(S-Go) & 68,55 & 3,43 & 71,66 & 5,74 & $0,016^{*}$ \\
\hline AFPS(S-Ar') & 28,16 & 2,16 & 30,90 & 2,95 & $0,000^{*}$ \\
\hline AFPI(Ar'-Go) & 40,39 & 3,41 & 40,75 & 4,45 & 0,732 \\
\hline AFPSIAFPT & 41,13 & 3,19 & 43,17 & 3,28 & $0,021^{*}$ \\
\hline AFPI/AFPT & 58,86 & 3,19 & 56,82 & 3,28 & $0,021^{*}$ \\
\hline AFA(Me-PP) & 61,84 & 2,81 & 62,81 & 4,75 & 0,356 \\
\hline AFP(Ar-PM) & 44,32 & 3,59 & 45,12 & 4,85 & 0,490 \\
\hline IAF(AFP/AFA) & 71,80 & 6,51 & 71,98 & 7,21 & 0,922 \\
\hline
\end{tabular}

*Significante para $p<0,05$. 
Discussão 


\section{DI SCUSSÃO}

No intuito de abordar as dificuldades desta pesquisa e favorecer a interpretação dos resultados, serão discutidas as características da amostra, as considerações da metodologia, a discussão dos resultados e finalmente algumas considerações clínicas.

\subsection{Caracterí Sti Cas da AMOSTRA}

Para a obtenção da amostra foram selecionados, de ambos os gêneros, um grupo de indivíduos melanodermas apresentando uma faixa etária entre 12 e 15 anos, com a idade média de 13,86 anos. Devido aos processos de crescimento e desenvolvimento facial, pode ser esperado que os modelos cefalométricos para crianças sejam diferentes daqueles de adultos. Desta forma, os estudos cefalométricos cujas amostras incluíram predominante ou exclusivamente crianças melanodermas ${ }^{6,7}$, se diferenciam em seus valores daqueles realizados com a amostra composta por adultos jovens.

Deve-se considerar problemas metodológicos, como tamanho da amostra, existente em alguns relatos de modelos cefalométricos em indivíduos melanodermas. 0 estudo de COTTON et al. ${ }^{34}$, foi baseado em apenas 20 indivíduos. ALTEMUS ${ }^{6,7}$ selecionou 80 indivíduos, de um grupo de 3289, com as melhores relações oclusais. KOWALSKI et al. ${ }^{67}$, por outro lado, estudou uma amostra considerável de 244 indivíduos. 0 presente estudo utilizou uma amostra de 56 jovens brasileiros melanodermas, 28 do gênero masculino, com idade média de 13,93 (mínima de 12,08 e máxima de 15,75) e 28 do gênero feminino, com idade média de 13,79 (mínima de 12,58 e máxima de 15,67). 
Foi requisito da presente pesquisa, uma oclusão dentária com relações normais de molares, sem a presença de mordida profunda, mordida aberta, rotações ou apinhamentos dentários significativos. Foi necessária a presença de todos os dentes permanentes e em oclusão, exceto os terceiros molares.

Os critérios pelos quais os indivíduos para estudos foram selecionados variavam entre os relatos disponíveis. A maior parte dos estudos utilizados aceitou modelos para oclusão, tais como Classe I de Angle, enquanto outros não67. Alguns estudos realizaram a seleção de acordo com 0 alinhamento ideal e presença de todos os dentes permanentes ${ }^{6,7}$ enquanto outros exigiram apenas Classe I de Angle e não especificaram se a mordida aberta, mordida profunda, ou outras condições anormais foram excluídas ${ }^{32,45}$. Entretanto, a maior parte dos relatos excluiu indivíduos que sofreram trauma facial ou foram submetidos a cirurgia facial ou tratamento ortodôntico.

A amostra desta pesquisa consistiu de indivíduos melanodermas com características faciais agradáveis, dentro de um conceito inevitavelmente subjetivo. Por este motivo foi obtido o valor da medida SN.GoGn, para o conhecimento do padrão de crescimento facial e as características morfológicas da presente amostra. Os valores individuais desta medida seguem em anexo nos apêndices 5 e 6 .

Outro aspecto importante é a origem dos melanodermas brasileiros, que na discussão dos resultados serão comparados aos inúmeros estudos realizados em indivíduos melanodermas de diversas origens geográficas $^{9,10,13,32,44,69,92}$.

No Brasil, muito particularmente devido à experiência colonial lusitana, não houve segregação de grupos. A miscigenação entre 0 colonizador português, o indígena e o negro resultou na formação, desde os primeiros tempos da história, em uma população diversificada, sendo o produto de cruzamento de branco-negro, branco-índio, negro-índio parcela ponderável da população brasileira ${ }^{1}$. Cada um dos três grupos básicos (índio, branco e negro) está longe de representar uma etnia pura. Torna-se 
importante estudar as características da população brasileira, analisando os aspectos somáticos respectivos.

Em particular o negro, introduzido como escravo, também é morfologicamente heterogêneo. Pela sua procedência geográfica, pode-se fazer uma idéia da filiação racial dos representantes importados do grupo negróide. Nas regiões da costa e contracosta da África predominam os povos bantos, selecionados para esta pesquisa, formados pela mistura de nigricianos e de paleonegróides, com sua divisão em ocidentais, orientais e meridionais, exibindo cada qual maior ou menor influência ${ }^{1}$.

Tendo em vista o índice cefálico e a estatura, pode-se distinguir as seguintes etnias, no grupo negróide:

1. A nigriciana, com grande percentagem de indivíduos altos e dolicocéfalos; concentrando-se no Sudão e na Guiné;

2. A paleonegróide, com alta percentagem de indivíduos baixos e mesocéfalos, e concentração na região de florestas do Congo, Senegal, de Angola.

3. A nilótica, com indivíduos muito altos e dolicocéfalos, com dispersão nas regiões do Alto Nilo e dos grandes lagos;

4. A coisan (Khoisan) com alta percentagem de indivíduos baixos, mesocéfalos; está dispersa no Sul da África, bem como em regiões da floresta e do deserto.

Portanto, satisfazendo os critérios citados, convém mencionar a necessidade da interpretação minuciosa dos resultados quanto à miscigenação e as áreas geográficas distintas entre os grupos comparados, de outros estudos na literatura.

\subsection{Consi derações da Metodologia}

Muitos estudos que compararam modelos estatísticos em melanodermas e leucodermas utilizaram os valores médios para indivíduos 
leucodermas desenvolvidos por pesquisadores diferentes, que podem ter-se utilizado definições de pontos de reparo e técnicas de medidas diferentes. Desta forma, os dois conjuntos de resultados podem não ser diretamente comparáveis.

BAUMRIND; FRANTZ ${ }^{12}$ avaliaram que 0 erro médio de identificação de pontos de reparo pode ser de 0,37 a $3,75 \mathrm{~mm}$, dependendo do ponto de reparo em particular, ${ }^{\mathbf{2 1}}$ e que o erro pode ser de 0,43 a $0,86 \mathrm{~mm}$ e de $0,62^{\circ}$ a $3,54^{\circ}$ para as medidas lineares e angulares, respectivamente, dependendo da medida.

Outro aspecto importante é o fator de magnificação. Neste estudo, efetuou-se a correção deste fator calculado no valor de $6 \%$. Diversos estudos não especificaram a realização da correção do fator de magnificação $2,9,11,22,44,82,92$. Dificultando-se assim uma comparação entre as amostras e os valores obtidos, já que a diferença é significativa entre os valores que não foram devidamente corrigidos.

Para um melhor esclarecimento, o fator de magnificação corresponde à porcentagem de ampliação da imagem radiográfica em relação ao tamanho real das estruturas do complexo craniofacial. Para seu cálculo, é preciso primeiramente medir a distância de uma oliva metálica a outra (A). Em seguida, mantendo-se a mesma medida $A$ entre as olivas, obtém-se uma radiografia PA (póstero-anterior) na qual apareça a imagem radiográfica apenas das olivas metálicas (B). Assim, o fator de magnificação $(X)$ é obtido por meio da seguinte fórmula matemática:

$X=B-A / A \times 100$

Em que:

$X=$ Fator de magnificação

$A=$ Distância de uma oliva metálica a outra

$\mathrm{B}=$ Distância de uma oliva metálica a outra na imagem radiográfica 


\subsection{Discussão dos Resultados}

A harmonia do complexo craniofacial nos sentidos horizontal, transversal e vertical é responsável por despertar o senso individual de beleza e admiração da face humana.

A dimensão vertical destaca-se como um dos fatores que diferencia as más oclusões com um relacionamento dentário idêntico ${ }^{87}$ sendo, portanto, decisivo na escolha da abordagem terapêutica a ser utilizada. Considerando que o tratamento ortodôntico influencia as características faciais, é de fundamental importância que se discuta e leve em consideração os interesses do paciente quanto ao resultado estético final esperado.

A face do indivíduo melanoderma que se apresenta inicialmente com características próprias e peculiares é escassamente explorada pela literatura, principalmente com relação às dimensões esqueléticas verticais, estimulando propostas de padrões cefalométricos específicos para seu estudo a fim de auxiliar no diagnóstico, no plano de tratamento e na avaliação dos resultados do tratamento ortodôntico.

Para um melhor desenvolvimento na interpretação dos resultados, apresentamos em cada tópico um gráfico comparativo com os valores médios das medidas estudadas pelos respectivos autores.

\subsubsection{Comparação das dimensões verticais em indivíduos melanodermas de diferentes regiões geográficas.}

\subsubsection{AFAT (Figura 6.1, p.61)}

A altura facial anterior total possui crescimento na infância, na adolescência e na fase adulta. 0 aumento vertical da face foi verificado até a quarta década de vida, entretanto, com o decorrer do tempo, ocorre uma tendência à diminuição ${ }^{103}$. 
Na presente pesquisa, os valores de AFAT encontrados para os melanodermas brasileiros com média de idade 13,8 anos apresentaram diferença estatística significante, para o dimorfismo entre os gêneros e maior desenvolvimento vertical da face anterior para o gênero masculino (Gráfico 6.1, p.61). Essa diferença entre os gêneros corrobora os relatos da literatura, com BARTER ${ }^{11}$, em 1995, FLYNN ${ }^{44}$, em 1989, LINDER-ARONSON; WOODSIDE ${ }^{69}$, em 2000, NAIDOO; MILES ${ }^{82}$, em 1997, ÁGUILA; ÁGUILA², em 1993, uma vez que a altura facial anterior dos indivíduos do gênero masculino é maior que a do feminino ${ }^{81}$, independentemente da idade.

Os afro-americanos avaliados em estudos comparativos apresentaram AFAT com valores amplamente distintos, sendo excessivamente maiores quando comparados aos valores da amostra de melanodermas brasileiros ${ }^{13,44,69,92}$.

Os valores aumentados para a AFAT encontrados por alguns autores $^{9,13,44,82,92}$, estudando melanodermas adultos, devem ser atribuídos em parte, às idades médias das amostras que diferem da idade média da presente amostra $(13,8 a)$ na qual os indivíduos, principalmente do gênero masculino, não expressaram ainda a plenitude de crescimento facial.

Os dados de LINDER-ARONSON; WOODSIDE ${ }^{69}$, em 2000 demonstram essa diferença na AFAT, com o passar da idade, já que os valores encontrados nos indivíduos do gênero masculinos aos 16 anos foram $5,5 \mathrm{~mm}$ maior do que os valores encontrados aos 14 anos, considerando ainda que a AFAT possui crescimento também na fase adulta. Além disso, alguns autores $2,9,11,22,44,82,92$ não citam se foram realizados ajustes para as diferenças na magnificação (na presente pesquisa, foi corrigido um aumento de $6 \%$ correspondente a magnificação).

ROSA; ARVYSTAS ${ }^{92}$, em 1978 encontraram altos valores para AFAT avaliando amostra de melanodermas norte-americanos da mesma região geográfica com idade média de 17 anos 7 meses.

Os valores para AFAT encontrados por FLYNN ${ }^{44}$, em 1989 para uma amostra de melanodermas adultos americanos com idade média de 
25,8 anos foram superiores aos resultados de NAIDOO; MILES ${ }^{83}$, em 1997 para adultos melanodermas sul-africanos da região de Western Cape, sul da África, com idade média de 24,8 anos para o gênero masculino e 23,4 anos para o gênero feminino.

Valores similares aos de NAIDOO; MILES ${ }^{83}$, em 1997 foram encontrados por BARTER et al. ${ }^{11}$, em 1995 no seu estudo com melanodermas de Botswana, pertencentes ao grupo Sotho-Tswana, com idade variando entre 11 e 16 anos.

0 único relato da literatura com valores de AFAT inferiores à presente pesquisa foi apresentado por BRIEDENHANN; ROOS ${ }^{22}$, em $1988 \mathrm{em}$ seu estudo com indivíduos melanodermas africanos com idioma "herero" e idade média de 14,6 anos.

Os valores de ÁGUILA; ÁGUILA², em 1993, LINDER-ARONSON; WOODSIDE ${ }^{69}$, em 2000 para uma faixa etária idêntica, de 12 anos também apresentaram diferenças, sendo os maiores valores encontrados para os afro-americanos ${ }^{69}$, os quais não indicaram dimorfismo entre os gêneros, e valores menores apresentados pela amostra de melanodermas cubanos ${ }^{2}$,com diferença significante entre os gêneros.

Essa notória variação entre os resultados dos autores supracitados para os melanodermas americanos de diferentes regiões geográficas é reflexo da miscigenação com caucasianos e índios americanos (Mongolóides) ${ }^{40}$.

Comparando-se os resultados dos estudos para melanodermas americanos e sul-africanos, constatou-se a significância nas diferenças cefalométricas entre esses dois grupos ${ }^{22}$.

A diferença entre os resultados do mesmo grupo étnico de diferentes regiões foi descrita por RICHARDSON ${ }^{90}$, em 1980. A autora observou que há diferenças médias nas características quantificáveis da face de alguns grupos étnicos.

RICHARDSON $^{90}$ afirmou ser surpreendente a semelhança no ângulo facial médio entre os diferentes grupos étnicos na mesma região 
geográfica. Questionou a existência de diversos grupos étnicos separados por fronteiras culturais climáticas e geográficas que causaram alterações sutis na morfologia facial. Concluiu assim, que a dificuldade em se definir raça tem como conseqüência a necessidade de acrescentar uma ligação comum aos grupos étnicos como leucodermas suecos, americanos, e outros, para que a referência a esses grupos seja feita com mais precisão. Afirmou ainda que as diferenças quantificáveis na região craniofacial somática dos grupos étnicos que persistem por várias gerações em áreas geográficas iguais ou semelhantes, são pequenas.

Segundo RICHARDSON ${ }^{90}$, os autores que especificaram diferenças morfológicas extremas nos vários grupos étnicos poderiam possivelmente ter obtido amostras de um segmento em um extremo da escala do perfil do grupo, ao invés de obter uma amostra que poderia ser considerada a média do grupo. As diferenças também poderiam representar a comparação de dois ou mais grupos de diferentes regiões geográficas, onde as diferenças são principalmente relacionadas a fatores geográficos e não a fatores étnicos.

Dentre a variação por distribuição geográfica de melanodermas nos EUA, outros problemas podem ser identificados na comparação de estudos cefalométricos de melanodermas americanos tais como o tipo de análise utilizada, idade da amostra, tamanho da amostra, critérios de seleção, métodos estatísticos, definições de normalidade clínica e definições da designação negra ${ }^{44}$. 


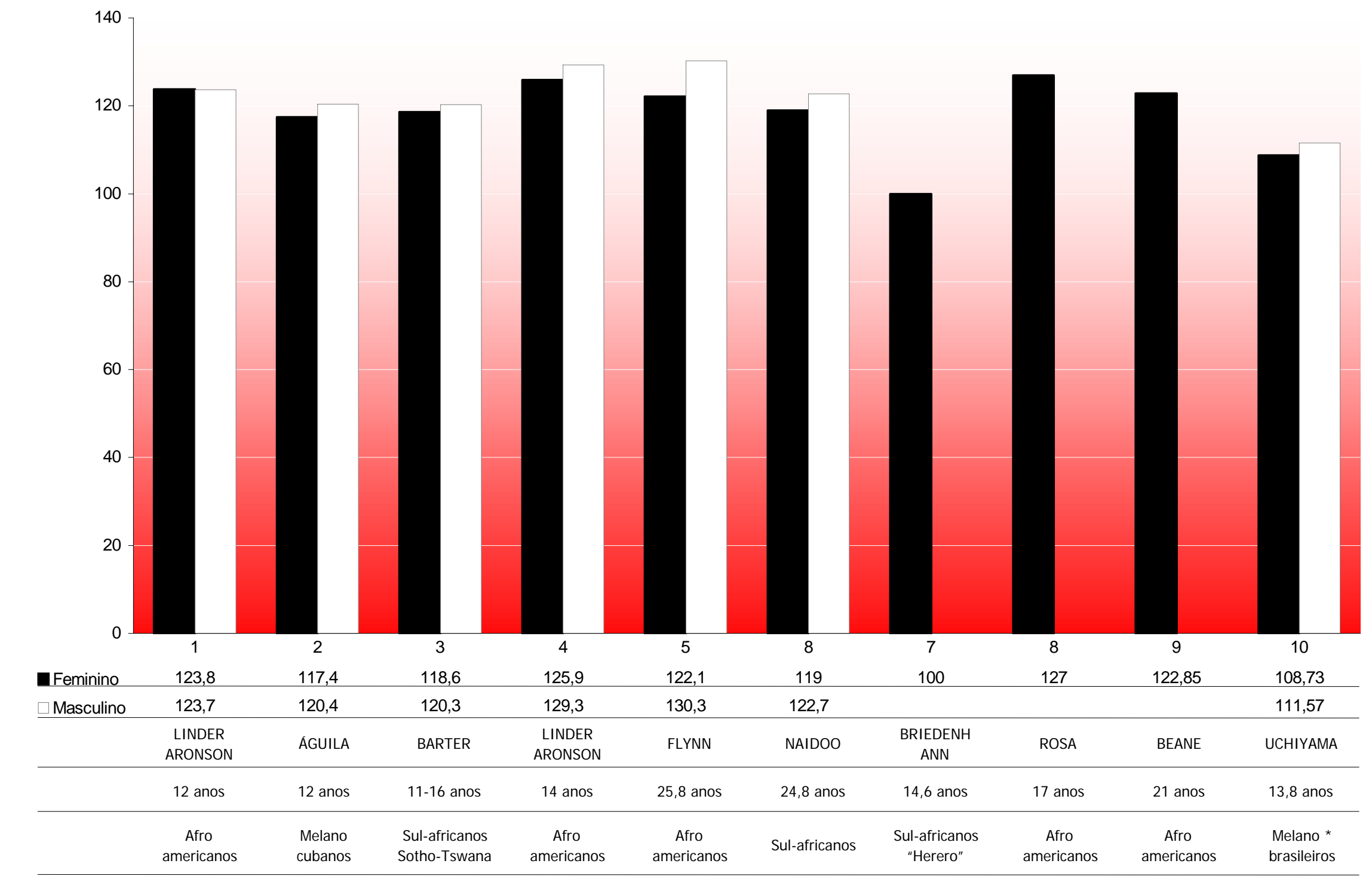

*Dimorfismo entre gêneros 


\subsubsection{AFAS (Figura 6.2, p.63)}

BISHARA $^{16,17}$ observou, em faces normais, maior desenvolvimento da AFAS em jovens de ambos os gêneros, com idades de 4,5 a 10 anos, e menor crescimento em jovens entre 15 e 25,5 anos; LINDER-ARONSON; WOODSIDE ${ }^{69}$ verificaram que a AFAS em faces equilibradas teve maior crescimento que a AFAI dos 7 aos 11 anos.

Os valores da AFAS da presente pesquisa indicaram dimorfismo entre os gêneros, com maior valor para o gênero masculino. Esta diferença existente está de acordo com os resultados encontrados por LINDERARONSON; WOODSIDE ${ }^{69}, 2000$, FLYNN $^{44}, 1989$, NAIDOO; MILES ${ }^{82}, 1997$, ÁGUILA; ÁGUILA 1993 e BAILEY; TAYLOR ${ }^{10}, 1998$, e é contrária aos relatos de BARTER ${ }^{11}$, em 1995.

O grupo africano de idioma "herero"22 apresentou o menor valor para AFAS, seguido, em ordem crescente, pela amostra melanoderma brasileira, cujos valores foram inferiores aos valores dos bantus africanos, afro-americanos de outros estudos ${ }^{10,13,44,69,92}$, melanodermas cubanos ${ }^{2}$, sulafricanos ${ }^{82}$ e pertencentes ao grupo Sotho-tswana ${ }^{11}$. 


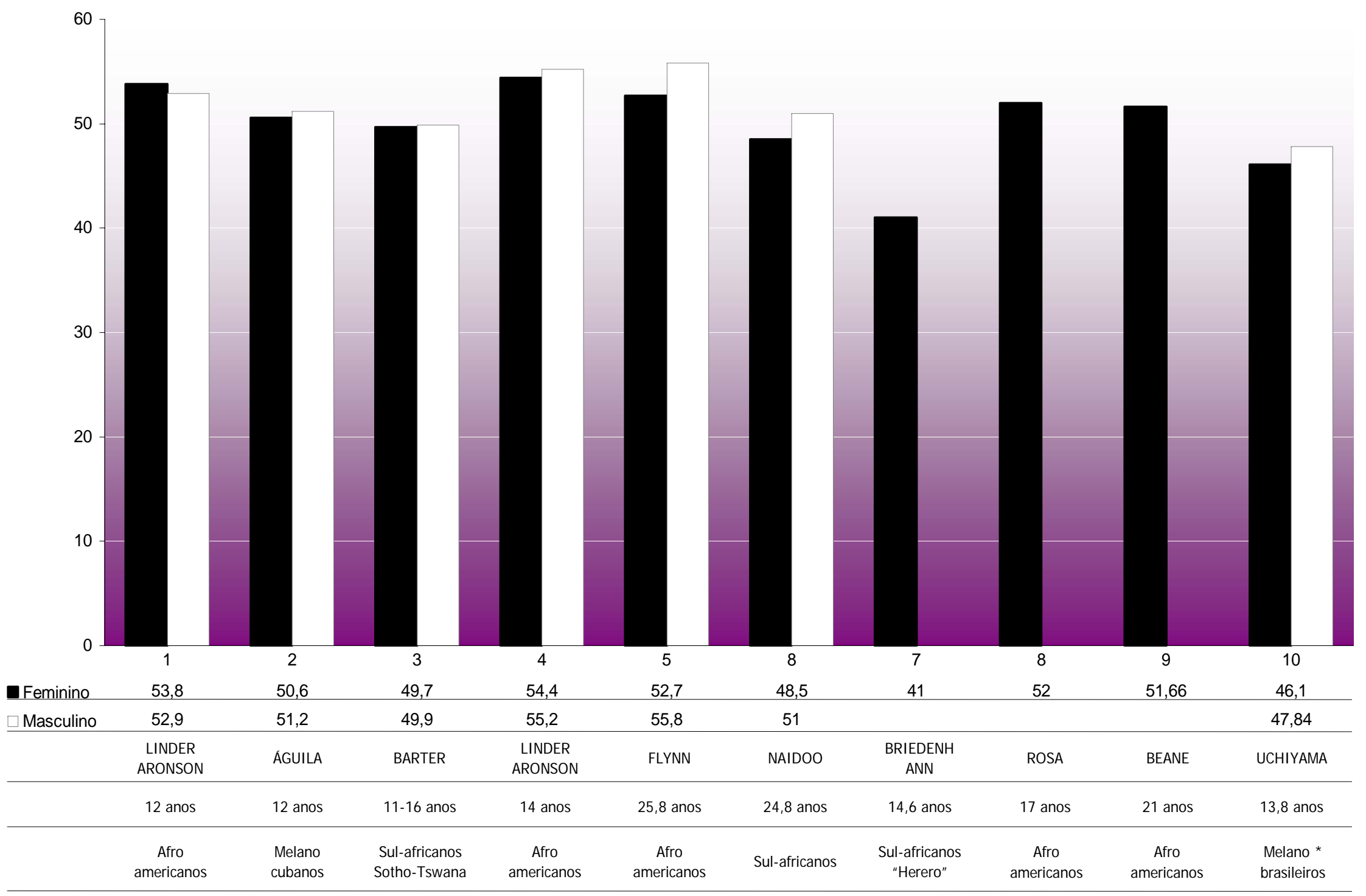

*Dimorfismo entre gêneros 


\subsubsection{AFAl (Figura 6.3, p.65)}

A literatura é unânime em ressaltar maior contribuição da AFAI em relação a AFAS na altura facial total de indivíduos melanodermas de diferentes regiões geográficas ${ }^{2,9,11,13,22,44,69,82,92}$.

É também importante considerar a influência das variações ambientais na AFAl e sua relação com a obstrução nasal apresentando-se aumentado em indivíduos com deficiência respiratória ${ }^{112}$. Os resultados encontrados neste trabalho para os valores de AFAl não indicaram dimorfismo entre os gêneros, confirmando os resultados de NAIDOO; MILES $^{82}, 1997$ e BARTER ${ }^{11}, 1995$ divergindo, entretanto, com LINDERARONSON; WOODSIDE ${ }^{69}, 2000$, FLYNN $^{44}, 1989$ e ÁGUILA; ÁGUILA², 1993, que encontraram dimorfismo entre gêneros.

Os valores de AFAl apresentados pelos indivíduos melanodermas brasileiros foram significativamente menores quando comparados aos afroamericanos estudados por BEANE et al. ${ }^{13}, 2003$, LINDER-ARONSON; WOODSIDE ${ }^{112}, 2000$ e FLYNN ${ }^{44}, 1989$ aos africanos ${ }^{11,82}$ e aos bantus africanos ${ }^{9}$. Os valores encontrados por ÁGUILA; ÁGUILA², em 1993 para melanodermas cubanos foram os que mais se aproximaram dos valores da presente pesquisa, os quais foram superiores ao valor apresentado por BRIEDENHANN; ROOS ${ }^{22}$, 1988. Já os resultados de BACON ${ }^{9}$, em 1983, para os bantus africanos foram os maiores, para esta grandeza. Estas diferenças devem estar relacionadas à diversidade das faixas etárias das amostras, como também ao grupo étnico e sua origem. As características raciais necessitam uma notória significância quanto à morfologia individual destas amostras, quando selecionadas. Diferencia-se o valor da medida entre indivíduos braquifacial, mesofacial e dólicofacial. 
FI GURA 6.3 - Valores de AFAl da amostra de melanodermas brasileiros X melanodermas de distintas áreas geográficas

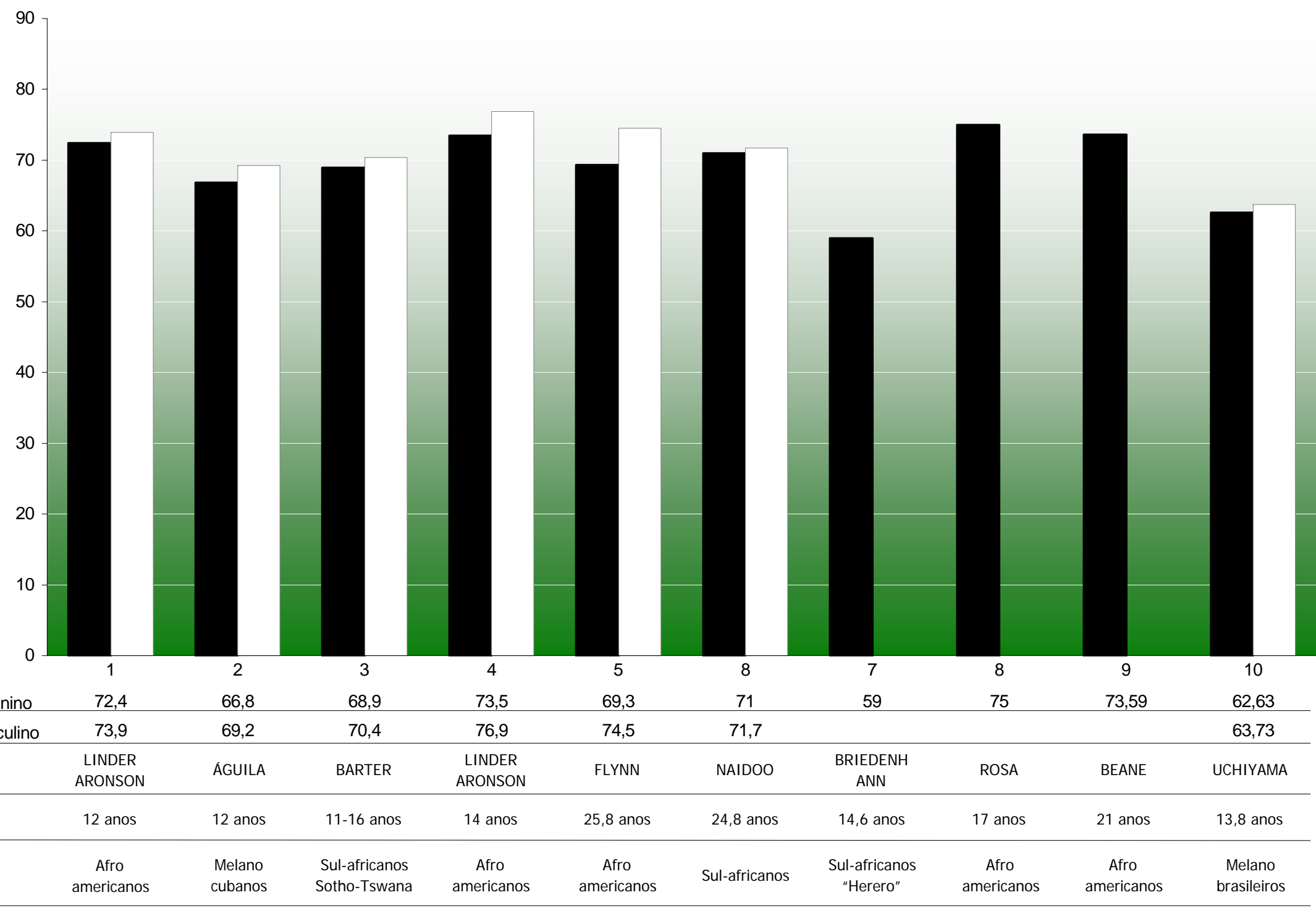




\subsubsection{AFPT (AFPS E AFPI ) (Figuras 6.4A;B;C, p.67/68)}

A AFPT dos indivíduos melanodermas brasileiros, assim como a AFPS apresentaram dimorfismo entre os gêneros e maior desenvolvimento vertical da face posterior para o masculino, confirmando os achados de ÁGUILA; ÁGUILA², 1993, que encontraram maior crescimento da dimensão vertical posterior e anterior da face no gênero masculino, tornando-se proporcionalmente maior que as faces femininas.

Estudos sobre o crescimento vertical da face com oclusão normal afirmam que a altura facial posterior desenvolve-se mais que a anterior 0 que não foi observado no presente trabalho, que apresentou valores da AFAT amplamente superiores ao da AFPT. Isto pode ser explicado pelas diferenças nos padrões de crescimento das amostras e principalmente pela idade. Inicialmente, ocorre maior desenvolvimento da altura facial anterior em jovens de ambos os gêneros, descrito na literatura por BISHARA ${ }^{16,17}$.

BEANE et al. ${ }^{13}, 2003$, ao estudar dois grupos de melanodermas com e sem mordida aberta anterior concluiu que a AFP é fortemente correlacionada à idade do paciente e após a compatibilidade das idades, a diferença entre os grupos não foi significante.

Os resultados da AFPT de BEANE et al. ${ }^{13}, 2003$, ÁGUILA; ÁGUILA², 1993, ROSA ${ }^{92}, 1978$ e da AFPS de FLYNN ${ }^{44}$, 1989, e NAIDOO; MILES ${ }^{82}, 1997$, foram também superiores aos valores encontrados para 0 grupo melanodermas brasileiros. Deve-se salientar, porém que pontos de referências diferentes foram utilizados por $\mathrm{FLYNN}^{44}$, 1989, e NAIDOO; MILES ${ }^{82}$, 1997 para determinar a AFPS.

A AFPI do grupo estudado não apresentou diferença estatística significante, indicando ausência de dimorfismo entre os gêneros. NAIDOO; MILES ${ }^{83}, 1997$, encontraram uma altura do ramo (Ar-Go) menor no grupo sul-africano, especialmente do gênero masculino corroborando os resultados de BARTER ${ }^{11}, 1995$. 
FI GURA 6.4A - Valores de AFPT da amostra de melanodermas brasileiros X melanodermas de distintas áreas geográficas

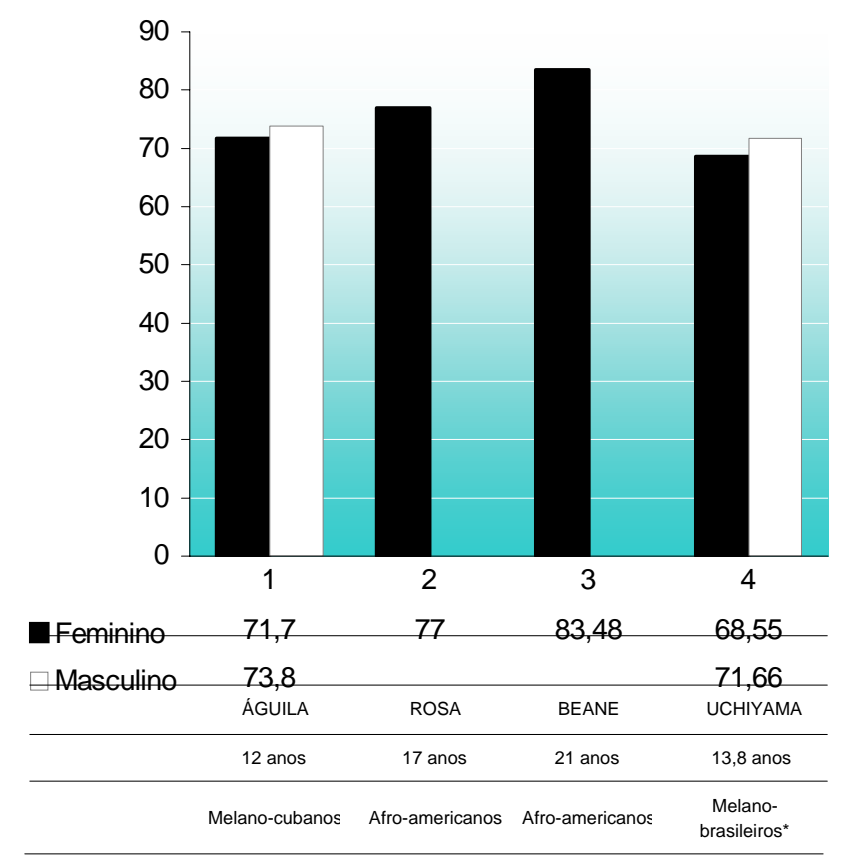

*Dimorfismo entre gêneros

FIGURA 6.4B - Valores de AFPS da amostra de melanodermas brasileiros $X$ melanodermas de distintas áreas geográficas

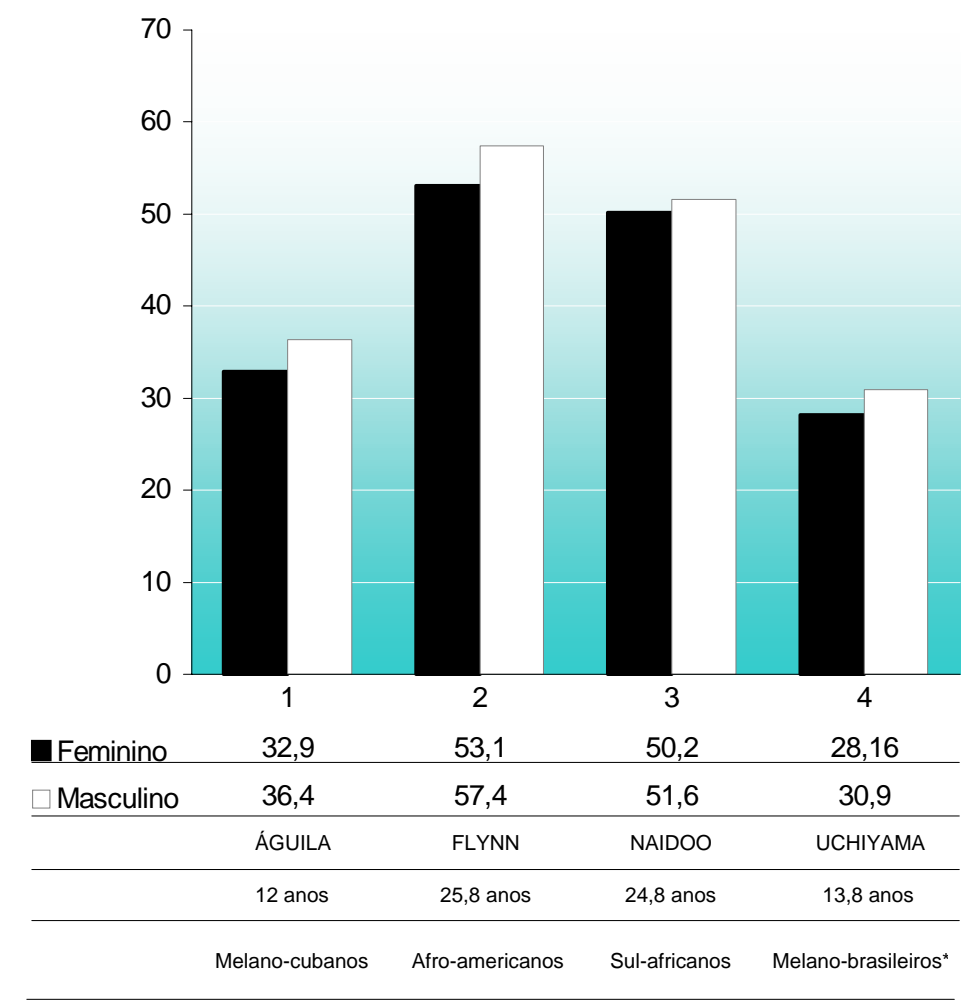

*Dimorfismo entre gêneros 
FI GURA 6.4C - Valores de AFPI da amostra de melanodermas brasileiros

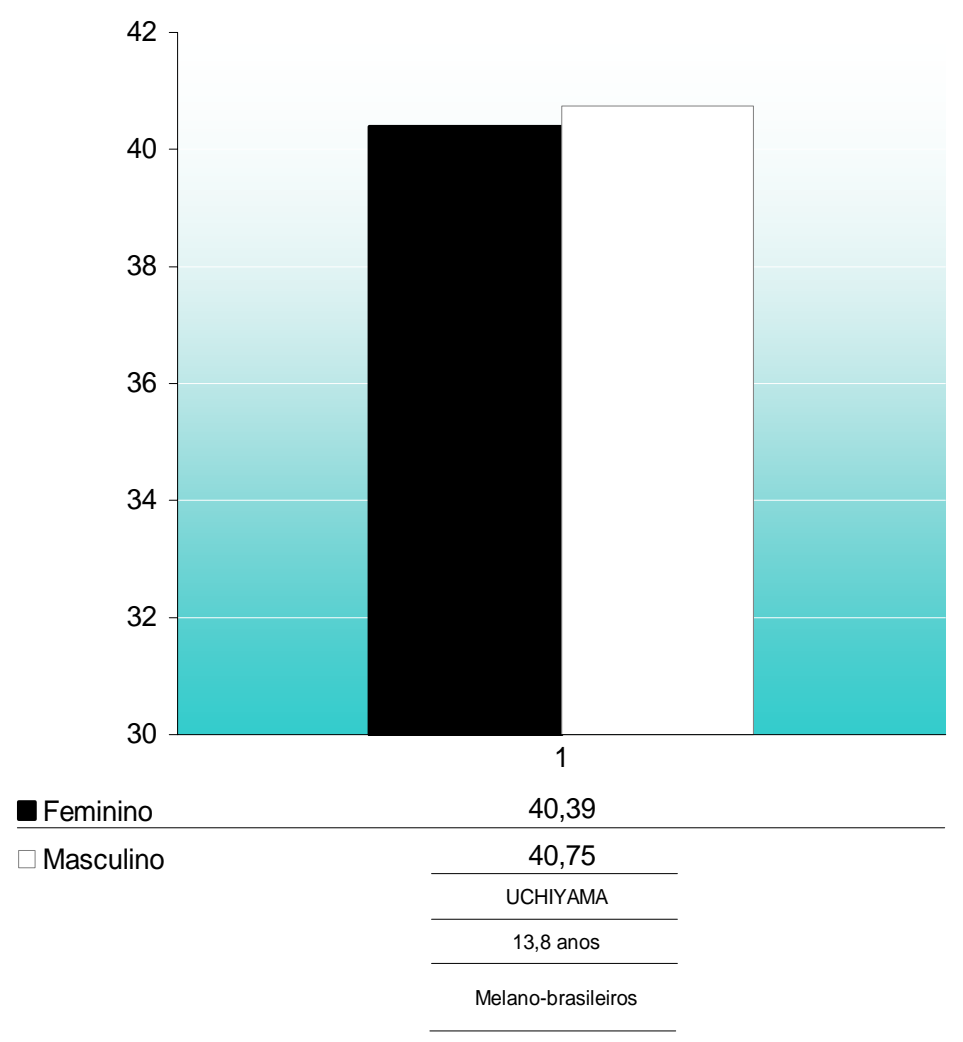

\subsubsection{Proporções entre as alturas faciais (AFAS/ AFAT, AFAI / AFAT; AFPS/ AFPT; AFPI / AFPT) (Figuras 6.5A;B;C;D, p.69-71)}

Tão importante quanto observar as alterações ocorridas nas grandezas cefalométricas, é considerar as proporções existentes entre as várias dimensões da face.

A proporção entre a AFAS e AFAT mostrou ser constante nas diferentes etnias, não apresentando dimorfismo entre os gêneros ${ }^{114}$. A ausência de dimorfismo foi também observada na presente amostra para esta grandeza, assim como para a proporção AFAl/AFAT. Foram encontrados maiores valores para a AFAl em relação a AFAS em toda a literatura para melanodermas, assim como na amostra do presente trabalho, os valores mais significativos entre estas duas grandezas foram alcançados por 
AFAI/AFAT, confirmando os resultados de NAIDOO; MILES ${ }^{82}$, 1997; BARTER $^{11}$, 1995 e BRIEDENHANN; ROOS ${ }^{22}$, 1988, os quais se aproximaram significativamente dos resultados para as referidas proporções anteriores na amostra de melanodermas brasileiros.

Os valores encontrados pelo presente estudo para AFPS/AFPT assim como para AFPI/AFPT apresentaram dimorfismo entre os gêneros, divergindo dos relatos de BISHARA ${ }^{16,17}$. Uma maior proporção AFPS/AFPT foi encontrada para o gênero masculino e o gênero feminino apresentou valor superior de AFPI. A AFPI/AFPT apresentou maiores valores que a proporção AFPS/AFPT.

FIGURA 6.5A - Valores de AFAS/AFAT da amostra de melanodermas brasileiros $X$ melanodermas de distintas áreas geográficas

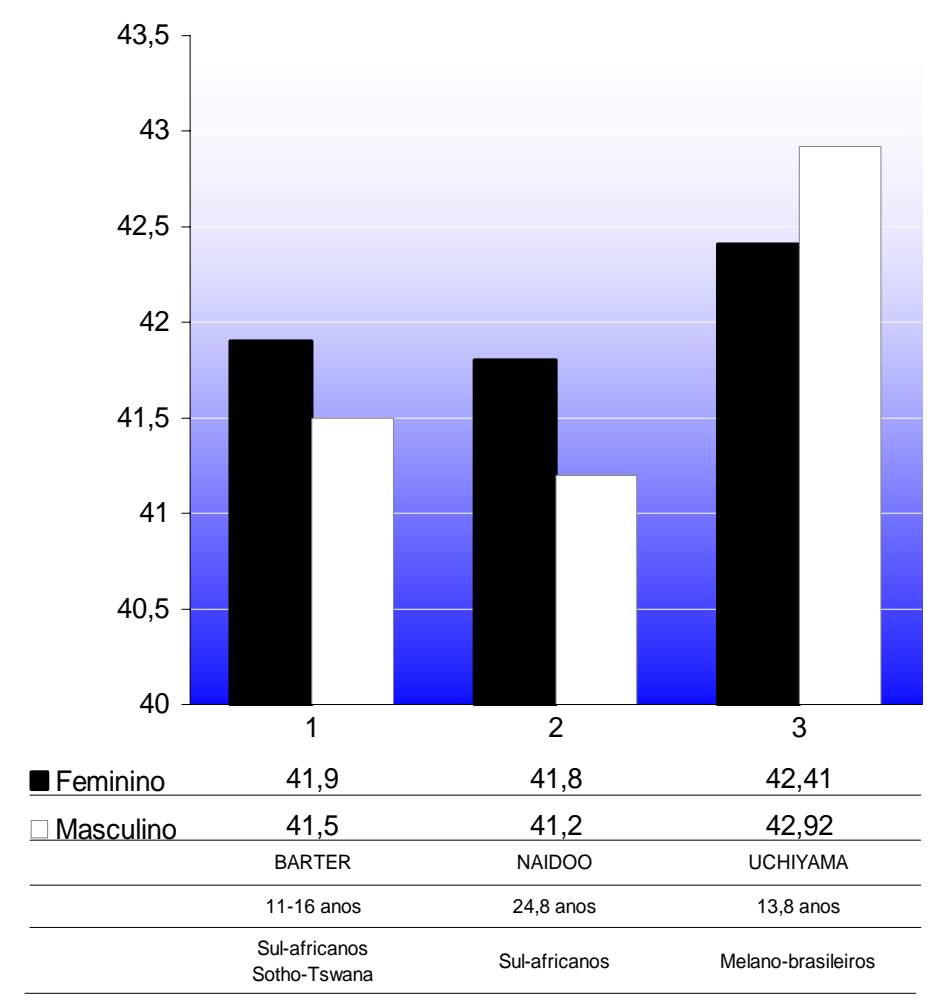


FIGURA 6.5B - Valores de AFAI/AFAT da amostra de melanodermas brasileiros $X$ melanodermas de distintas áreas geográficas

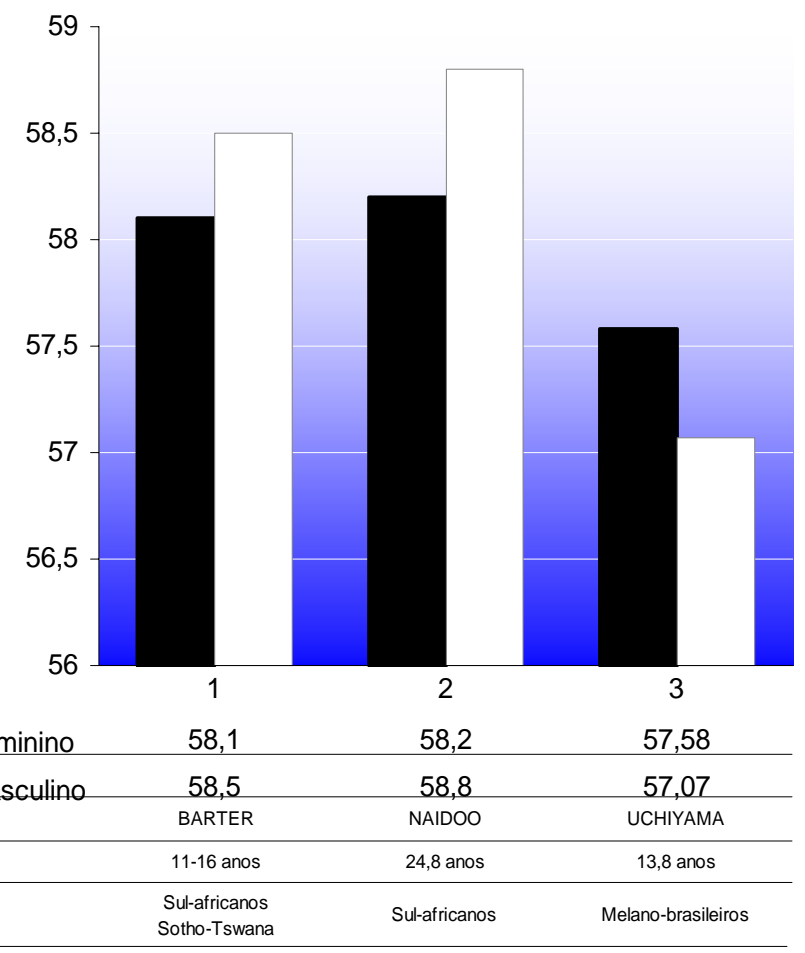

FI GURA 6.5C - Valores de AFPS/AFPT da amostra de melanodermas brasileiros

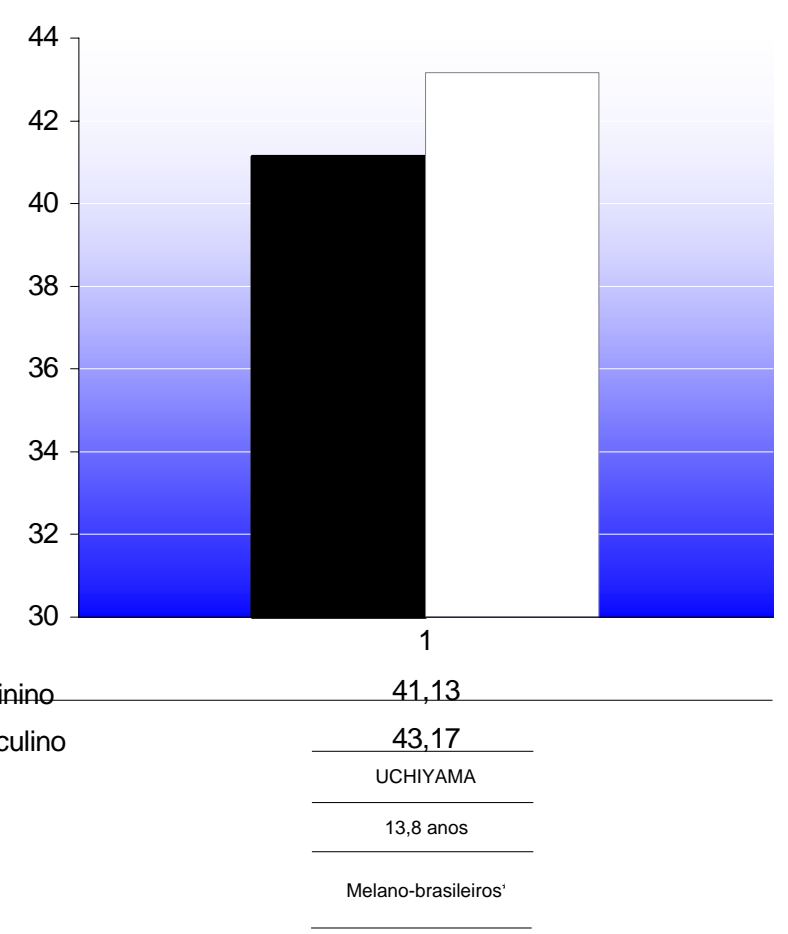

*Dimorfismo entre gêneros 
FI GURA 6.5D - Valores de AFPI/AFPT da amostra de melanodermas brasileiros

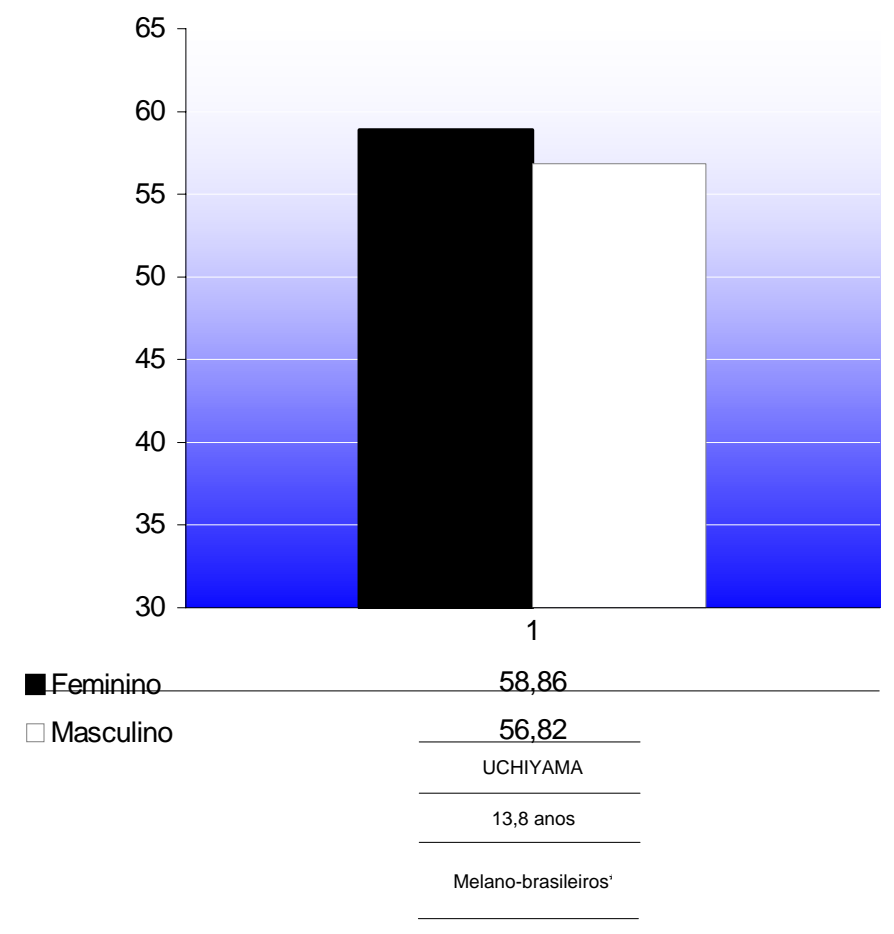

*Dimorfismo entre gêneros

\subsubsection{IAF (Figuras 6.6A;B;C, p.72/ 73)}

0 índice da altura facial descrito por HORN ${ }^{51}, 1992$ é definido pela proporção entre a altura facial posterior (AFP) e a altura facial anterior (AFA). Este índice indica o sentido da rotação mandibular durante o tratamento ortodôntico e permite o conhecimento da relação dinâmica entre AFA e AFP com o objetivo de maior controle sobre a altura facial anterior e melhora da altura facial posterior. Esse controle é ainda mais importante no que se refere aos indivíduos melanodermas, devido aos significantes valores de AFAI apresentados na literatura $2,9,11,13,22,44,69,82,92$.

No grupo de melanodermas brasileiros, os valores encontrados não apresentaram diferença estatística significante, indicando ausência de dimorfismo entre os gêneros. 0 valor médio da presente amostra foi superior ao valor apresentado de BRIEDENHANN; ROOS ${ }^{22}, 1988$, para os sul-africanos de idioma "herero". 
FI GURA 6.6A - Valores de AFA da amostra de melanodermas brasileiros

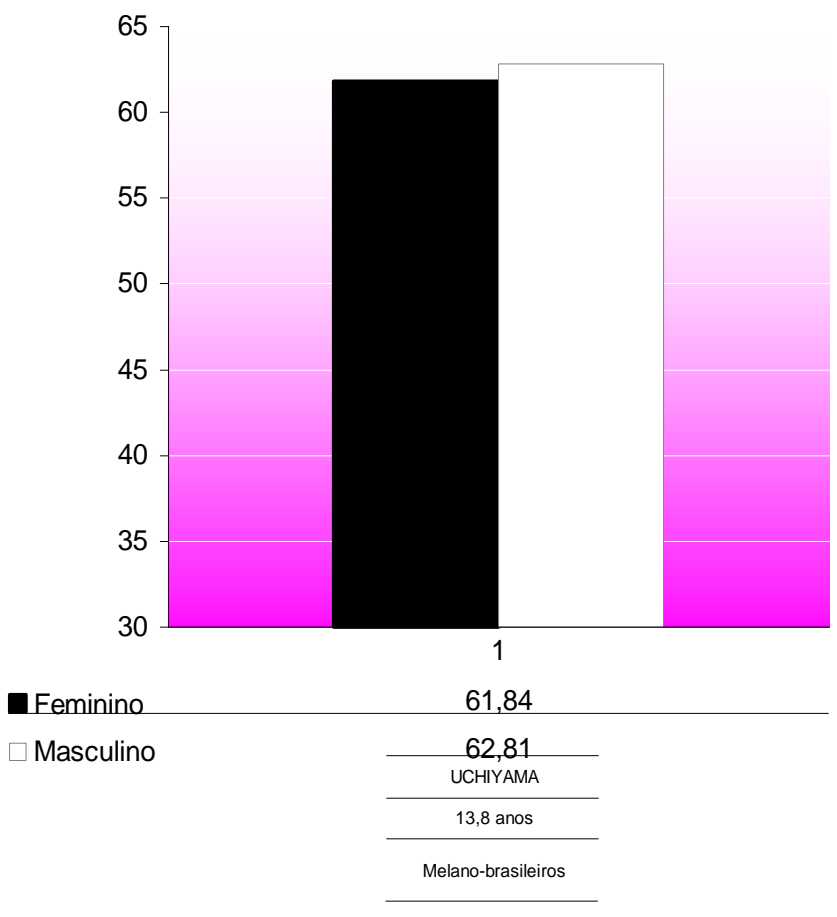

FI GURA 6.6B - Valores de AFP da amostra de melanodermas brasileiros

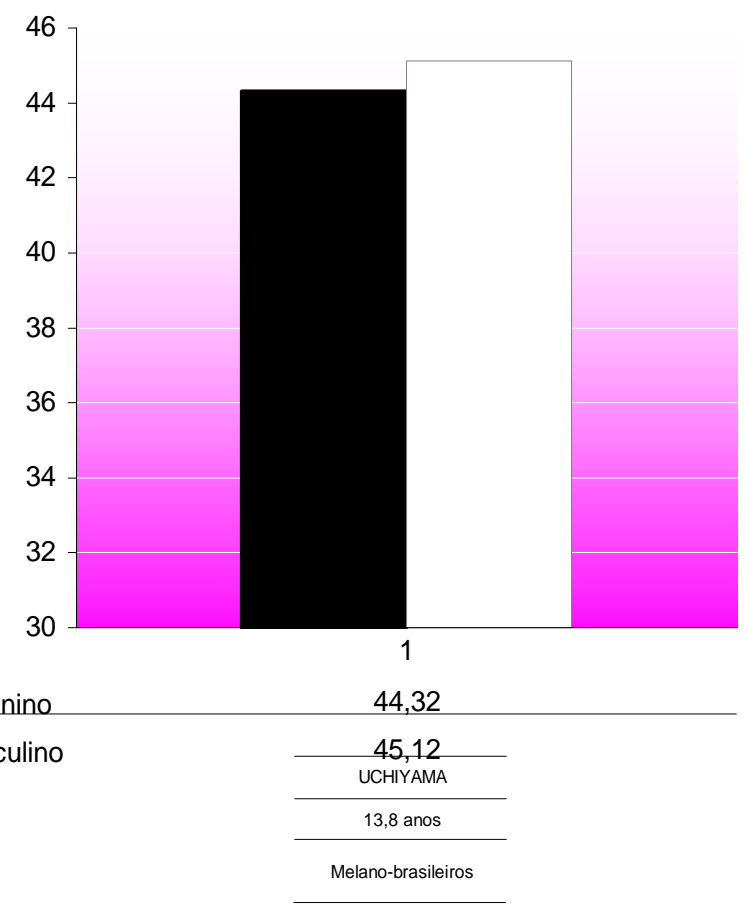


FI GURA 6.6C - Valores de IAF da amostra de melanodermas brasileiros $X$ melanodermas de distintas áreas geográficas

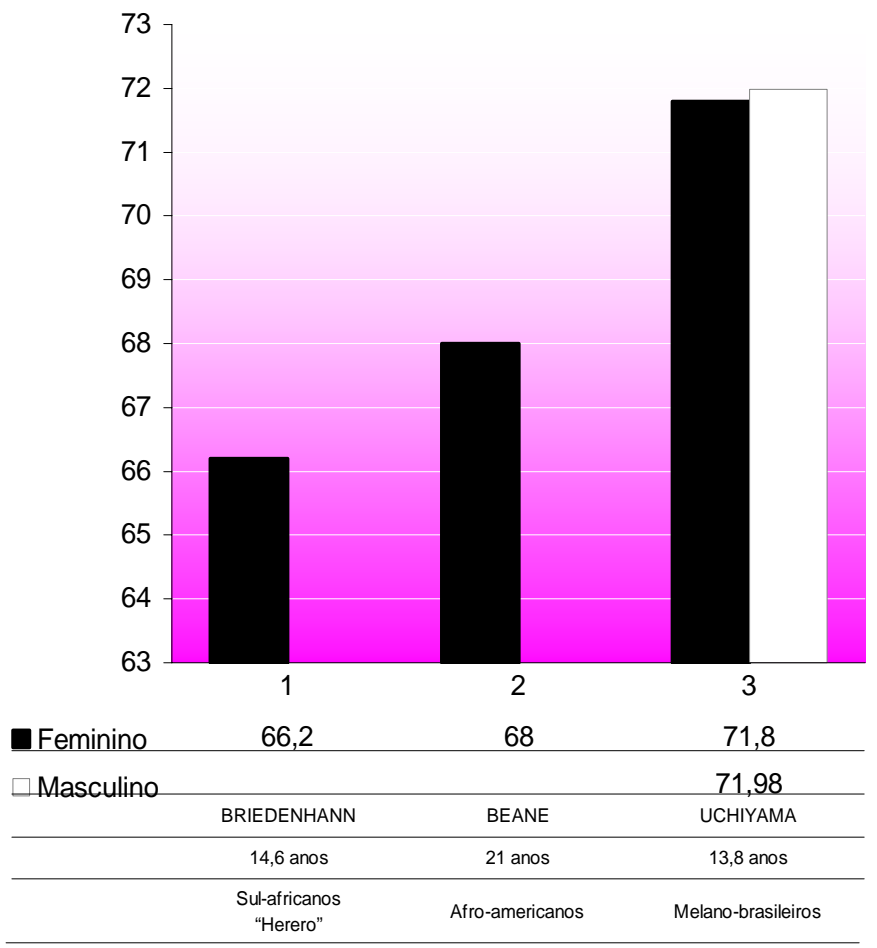

\subsubsection{Comparação das dimensões verticais entre indivíduos melanodermas e leucodermas brasileiros (Tabelas $6.1 ; 6.2 ; 6.3, p .74 / 75)$}

\subsubsection{AFAT; AFAS; AFAl (Tabelas 6.1;6.2;6.3, p.74/ 75)}

Divergindo dos resultados encontrados para os indivíduos melanodermas brasileiros, os valores de AFAT para o grupo leucoderma com idade média de 13,5 anos, estudado por TAKAHASHI ${ }^{103}$, em 2002, não apresentaram dimorfismo entre os gêneros. Comparando-se as médias das medidas para o gênero masculino entre indivíduos melanodermas e leucodermas brasileiros verificou-se uma proximidade dos valores. No gênero 
feminino, houve diferença dos valores da altura facial anterior total entre os grupos melanoderma e leucoderma.

A altura facial anterior superior apresentou diferença nos dois gêneros para ambos os grupos, sendo maior no grupo leucoderma para ambos os gêneros, da amostra de TAKAHASHI ${ }^{103}$, 2002. Um aumento da altura facial anterior superior para indivíduos leucodermas em relação aos melanodermas foi descrita na literatura por NAIDOO; MILES ${ }^{82}$, 1997, BRIEDENHANN; ROOS ${ }^{22}, 1988$, BACON et al. ${ }^{9}$, 1983, e LINDER-ARONSON; WOODSIDE ${ }^{69}$, 2000. Já FLYNN ${ }^{44}, 1989$, observou uma maior AFAS em melanodermas e ÁGUILA; ÁGUILA², 1993, relatou valores idênticos para AFAS em ambos, melanodermas e leucodermas.

Assim como o grupo leucoderma da amostra de TAKAHASHI ${ }^{103}$, em 2002, o grupo melanoderma da presente pesquisa não apresentou dimorfismo para os valores da AFAl. Essa grandeza expressou valores bastante aproximados com os da presente pesquisa para ambos os gêneros indicando ausência de diferença na altura facial ântero-inferior.

TABELA 6.1 - Valores das médias dos melanodermas brasileiros desta pesquisa $X$ leucodermas brasileiros da amostra de TAKAHASHI ${ }^{103}$

\begin{tabular}{|c|r|r|r|r|}
\hline & $\mathbf{X}$ & $\mathbf{X}$ & $\mathbf{N}$ & $\mathbf{N}$ \\
\hline AFAT(N-Me) & 110,15 & 112,45 & 56 & 78 \\
\hline AFAS(N-ENA') & 46,97 & 50,18 & 56 & 78 \\
\hline AFAI(ENA'-Me) & 63,18 & 62,26 & 56 & 78 \\
\hline AFAS/AFAT & 42,66 & 44,67 & 56 & 78 \\
\hline AFAl/AFAT & 57,33 & 55,32 & 56 & 78 \\
\hline AFPT(S-Go) & 70,10 & 71,09 & 56 & 78 \\
\hline AFPS(S-Ar') & 29,53 & 29,81 & 56 & 78 \\
\hline AFPI(Ar'-Go) & 40,57 & 41,27 & 56 & 78 \\
\hline AFPS/AFPT & 42,15 & 41,93 & 56 & 78 \\
\hline AFPI/AFPT & 57,84 & 58,06 & 56 & 78 \\
\hline AFA(Me-PP) & 62,32 & 62,13 & 56 & 78 \\
\hline AFP(Ar-PM) & 44,72 & 44,19 & 56 & 78 \\
\hline IAF(AFP/AFA) & 71,89 & 71,26 & 56 & 78 \\
\hline
\end{tabular}


TABELA 6.2 - Valores das médias dos melanodermas brasileiros do gênero feminino desta pesquisa $X$ leucodermas brasileiros da amostra de TAKAHASHI ${ }^{103}$

\begin{tabular}{|c|r|r|r|r|}
\hline & $\mathbf{X}$ & $\mathbf{X}$ & $\mathbf{N}$ & $\mathbf{N}$ \\
\hline AFAT(N-Me) & 108,73 & 111,58 & 28 & 39 \\
\hline AFAS(N-ENA') & 46,10 & 49,92 & 28 & 39 \\
\hline AFAI(ENA'-Me) & 62,63 & 61,66 & 28 & 39 \\
\hline AFAS/AFAT & 42,41 & 44,78 & 28 & 39 \\
\hline AFAI/AFAT & 57,58 & 55,21 & 28 & 39 \\
\hline AFPT(S-Go) & 68,55 & 70,28 & 28 & 39 \\
\hline AFPS(S-Ar') & 28,16 & 28,82 & 28 & 39 \\
\hline AFPI(Ar'-Go) & 40,39 & 41,45 & 28 & 39 \\
\hline AFPS/AFPT & 41,13 & 40,98 & 28 & 39 \\
\hline AFPI/AFPT & 58,86 & 59,01 & 28 & 39 \\
\hline AFA(Me-PP) & 61,84 & 61,42 & 28 & 39 \\
\hline AFP(Ar-PM) & 44,32 & 44,54 & 28 & 39 \\
\hline IAF(AFP/AFA) & 71,80 & 72,72 & 28 & 39 \\
\hline
\end{tabular}

TABELA 6.3 - Valores das médias dos melanodermas brasileiros do gênero masculino desta pesquisa $\mathrm{X}$ leucodermas brasileiros da amostra de TAKAHASHI ${ }^{103}$

\begin{tabular}{|c|c|c|c|c|}
\hline & \multicolumn{1}{|c}{$\mathbf{X}$} & \multicolumn{1}{c}{$\mathbf{X}$} & $\mathbf{N}$ & $\mathbf{N}$ \\
\hline AFAT(N-Me) & 111,57 & 113,32 & 28 & 39 \\
\hline AFAS(N-ENA') & 47,84 & 50,45 & 28 & 39 \\
\hline AFAI(ENA'-Me) & 63,73 & 62,87 & 28 & 39 \\
\hline AFAS/AFAT & 42,92 & 44,55 & 28 & 39 \\
\hline AFAI/AFAT & 57,07 & 55,44 & 28 & 39 \\
\hline AFPT(S-Go) & 71,66 & 71,90 & 28 & 39 \\
\hline AFPS(S-Ar') & 30,90 & 30,80 & 28 & 39 \\
\hline AFPI(Ar'-Go) & 40,75 & 41,08 & 28 & 39 \\
\hline AFPS/AFPT & 43,17 & 42,88 & 28 & 39 \\
\hline AFPI/AFPT & 56,82 & 57,11 & 28 & 39 \\
\hline AFA(Me-PP) & 62,81 & 62,84 & 28 & 39 \\
\hline AFP(Ar-PM) & 45,12 & 43,84 & 28 & 39 \\
\hline IAF(AFP/AFA) & 71,98 & 69,81 & 28 & 39 \\
\hline
\end{tabular}




\subsubsection{AFPT; AFPS; AFPI (Tabelas 6.1;6.2;6.3, p.74/ 75)}

A AFPT da presente amostra apresentou dimorfismo entre os gêneros, ao contrário dos resultados para os leucodermas brasileiros ${ }^{103}$. Seus valores, entretanto, para os dois grupos em ambos os gêneros foram bastante semelhantes e não apresentaram diferença. Da mesma forma se comportaram a AFPS e AFPI dos indivíduos melanodermas e leucodermas ${ }^{103}$ brasileiros para os gêneros feminino e masculino.

\subsubsection{Proporções entre as alturas faciais (AFAS/ AFAT; AFAI/ AFAT; AFPS/ AFPT; AFPI/ AFPT) (Tabelas 6.1;6.2;6.3, p.74/ 75)}

A proporção entre a AFAS e a AFAT no gênero masculino apresentou diferença entre os grupos leucoderma e melanoderma brasileiros, assim como para o gênero feminino, sendo que as maiores proporções foram encontradas para o grupo leucoderma ${ }^{103}$, cujos valores da altura facial anterior superior foram maiores que os valores da presente amostra.

Os valores da proporção AFAl/AFAT também foram bem próximos entre os grupos brasileiros para ambos os gêneros, apesar de apresentarem diferença entre as duas amostras entre gêneros

A relação AFPS/AFPT foi praticamente semelhante para os grupos, sem diferença.

A proporção AFPI/AFPT para indivíduos melanodermas e leucodermas brasileiros do gênero masculino expressou valores muito próximos, assim como para o gênero feminino em ambos os grupos. 


\subsubsection{IAF (AFP/ AFA) (Tabelas 6.1;6.2;6.3, p.74/ 75)}

Tanto quanto a maioria das medidas já citadas, os valores do IAF foram similares para indivíduos melanodermas e leucodermas brasileiros, sem diferença entre os dois grupos nas comparações para os gêneros masculino e feminino.

\subsection{CONSI DeRAções Clínicas}

É incontestável a dificuldade em se descrever as displasias esqueléticas verticais mediante somente à classificação ântero-posterior convencional (Classe I, II, III). O conhecimento das diferenças cefalométricas tem como conseqüência um melhor entendimento da patogenia, diagnóstico e tratamento das discrepâncias faciais verticais ${ }^{94}$.

A importância do controle da mecânica estabelecida no tratamento ortodôntico nos sentidos ântero-posterior e vertical, definem o sucesso do tratamento ${ }^{73}$. 0 desenvolvimento e 0 crescimento facial são de interesse do clínico, visto que a quantidade e direção do crescimento irão alterar de forma significativa a necessidade da terapia ortodôntica e a mecânica que será aplicada ${ }^{99}$. As controvérsias em diversos estudos apresentam que os efeitos da ação terapêutica do tratamento ortodôntico atuam principalmente nos componentes dentoalveolares, seguido dos componentes do complexo facial e influenciando o crescimento, seja em quantidade ou direção ${ }^{29}$. Com base nesta afirmativa, a literatura abordou inúmeros estudos que correlacionaram o aumento da dimensão vertical, associado aos diversos componentes, atuando de forma individual ou em comum, com o crescimento craniofacial.

A literatura é unânime em ressaltar uma maior contribuição da AFAl em relação a AFAS na altura facial total de indivíduos negros de diferentes regiões geográficas ${ }^{2,9,11,13,44,69}$. O aumento da AFAl em indivíduos melanodermas é descrito na literatura ${ }^{11}$ como um mecanismo compensatório 
que reduz a possibilidade da ocorrência de uma relação de má oclusão de Classe III que seria ocasionado pelo aumento do tamanho do corpo da mandíbula presente nestes indivíduos.

A relação entre a rotação dos maxilares e as alterações nas proporções faciais foram investigadas por vários autores. Estes autores sugeriram que deve existir harmonia na quantidade, direção de crescimento e grau de rotação entre a maxila e a mandíbula, se as proporções faciais constantes forem mantidas. O crescimento vertical extremo ou a rotação horária da maxila necessita de uma quantidade compensatória de rotação mandibular para manter a relação vertical e ântero-posterior. Isto pode ser conseguido somente com uma adequada quantidade de crescimento vertical do côndilo ${ }^{18,113}$.

Além disso, BEANE et al. ${ }^{13}$, em 2003, associaram a mordida aberta com o aumento da AFAl nos melanodermas. Esses dados devem ser considerados clinicamente no tratamento destes indivíduos. Resumidamente, os autores concluíram que: os indivíduos melanodermas com mordida aberta se diferem daqueles que não apresentam, na extensão do padrão de desenvolvimento vertical na região anterior da face e rotação mandibular e que uma inclinação dentoalveolar protrusiva seria um componente significativo desta má oclusão.

A correlação entre as alturas faciais ântero-inferior e superior, com a posição vertical dentoalveolar destaca-se como um fator relevante no planejamento ortodôntico ${ }^{64}$. Um exemplo seria a aplicação de mecânica com forças extrusivas dentoalveolares para melhorar e interferir no componente vertical, em indivíduos com a altura facial ântero-inferior diminuída ${ }^{64}$. Os dentes superiores apresentariam uma alta correlação com as alturas faciais, tanto superior como inferior ${ }^{64}$.

A modificação da posição dentária afetará a postura labial devido à íntima relação que os lábios mantém com a posição das estruturas alveolares e dentárias ${ }^{101}$. Desta forma, $\operatorname{CARTER}^{30}, 1988$ indicou as extrações dentárias apenas para a dissolução de apinhamento, pois considera 0 
prognóstico duvidoso no caso das extrações que objetivam puramente de retroposição dos lábios, prevendo a possibilidade de abertura dos espaços das extrações comprometendo a estabilidade pós-tratamento.

Dentre os resultados descritos pela literatura pertinente, há que se destacar as peculiaridades dos resultados encontrados para as alturas faciais do grupo de jovens brasileiros melanodermas, cujos valores diminuídos resultam em faces braquifaciais, expostas através da análise morfológica das radiografias em norma lateral da face. Uma vez definida a morfologia facial, permite-se o diagnóstico do indivíduo para o seu padrão de crescimento, permitindo a compreensão da má oclusão e as possibilidades de tratamento, ou seja, seu prognóstico.

As possibilidades de tratamento para os pacientes verticalmente equilibrados são mais numerosas, incluindo inclusive abordagens ortopédicas, as quais, se combinadas ao tratamento ortodôntico sem extrações pode resultar em características oclusais e estéticas satisfatórias. Neste aspecto, é de fundamental importância que se discuta e leve em consideração os interesses do paciente quanto ao resultado estético final esperado, já que as características faciais são influenciadas pelo tratamento ortodôntico.

YEHEZKEL ${ }^{115}$, em 2004, relatou uma preferência por um perfil mais retilíneo dos indivíduos do gênero feminino afro-americanos do século XX. Entretanto é importante ressaltar que o conceito de estética é extremamente subjetivo e está condicionado às influências sócio-culturais.

Um diferencial positivo para a presente amostra é a questão funcional, evidenciada pela presença de selamento labial passivo e conseqüente rotina fisiológica, o que torna as circunstâncias mais favoráveis. Porém, cabe ao ortodontista ao se deparar com este tipo de paciente na clínica avaliar a oclusão, de maneira estática e dinâmica, a face, a telerradiografia, investigar as expectativas do paciente e seu conceito em relação à auto-imagem, preservando suas características raciais próprias. Definindo a melhor opção de tratamento a fim de favorecer o prognóstico sem perder de vista a incontestável variabilidade individual. 
Constata-se a necessidade de estudos das análises cefalométricas, que consideram os grupos de mestiços, pois para eles, quais os parâmetros que devem ser aplicados? 


\section{CONCLUSÕES}




\section{CONCLUSÕES}

Com base na metodologia e nos resultados apresentados torna-se lícito afirmar que para os melanodermas brasileiros:

- O presente trabalho quantificou valores médios paras as alturas e proporções faciais tanto anteriores como posteriores, para ambos os gêneros;

- Ocorreu a presença de dimorfismo entre os gêneros, nas seguintes medidas: AFAT; AFAS; AFPT; AFPS; AFPS/AFPT; AFPI/AFPT. 


\section{REFERENCIAS BIBLIOGRÁFICAS}




\section{REFERÊNCI AS BI BLI OGRÁFI CAS*}

1. Enciclopédia Deltalarousse, Editora Delta SA, 1965.

2. ÁGUIlA, F. J.; ÁGUIlA, G. Atlas de Cefalometria. São Paulo, Pancast, 1993.

3. AKI, T. et al. Assessment of symphysis morphology as a predictor of the direction of mandibular growth. Am J Orthod Dentofacial Orthop, v.106, n.1, p.60-9, July 1994.

4. ALCALDE, R. E. et al. Cephalometric norms in Japanese adults. J Oral Maxillofac Surg, v.56, p.129-34, 1998.

5. ALEXANDER, T. L.; HITCHCOCK, H. P. Cephalometric standards for American negro children. Am J Orthod, v.74, n.3, p.298-304, 1978.

6. ALtemuS, L. A. Cephalofacial relationships. Angle Orthod, v.38, n.3, p.175-84, July 1968.

7. ALtemUS, L. A. A comparison of cephalofacial relationships. Angle Orthod, v.30, p.223-40, 1960.

8. ARIZA DIAS, M. C.; PINZAN, A.; HENRIQUES, J. F. C. Avaliação comparativa do crescimento maxilomandibular em crianças leucodermas brasileiras, com oclusão normal, utilizando as medidas Co-A, Co-Gn, AFAl e Dif. Mand./Max. da análise proposta por MCNAMARA J R. Ortodontia, v.26, n.1, p.14-37, 1993.

9. BACON, W.; GIRARDIN, P.; TURLOT, J. C. A comparison of cephalometric norms for the African Bantu and a Caucasoid population. Eur J Orthod, v.5, p.233-40, 1983.

10. BAILEY, K. L.; TAYLOR, W. H. Mesh diagram cephalometric norms for Americans of African descendent. Am J Orthod Dentofacial Orthop, v.114, p.218-23, 1998.

11. BARTER, M. A. et al. Cephalometric analysis of a Sotho-Tswana group. J Dent Assoc S Afr, v.50, p.539-44, 1995.

Normas recomendadas para uso no âmbito da Universidade de São Paulo, com base no documento "Referências Bibliográficas: exemplos", emanados do Conselho Supervisor do Sistema Integrado de Bibliotecas da USP, em reunião de 20 de setembro de 1990. 
12. BAUMRIND, S.; FRANTZ, R. C. The reliability of head film measurements.2. Conventional angular and linear measures. Am J Orthod, v.60, p.505, 1971.

13. BEANE, R. A. et al. A cephalometric comparison of black open-bite subjects and black normals. Angle Orthod, v.73, n.3, p.294-300, 2003.

14. BERTOZ, F. A. Determinação da linha "i" em melanodermas brasileiros, masculinos de 12 a 17 anos, com oclusão normal. Bauru, 1981. 55p. Dissertação (Mestrado) - Faculdade de Odontologia de Bauru, Universidade de São Paulo.

15. BERTOZ, F. A.; MARTINS, D. R. Determinação da linha "i" em melanodermas brasileiros, masculinos de 12 a 17 anos, com oclusão normal. Ortodontia, v.14, n.3, p.186-98, set./dez. 1981.

16. BISHARA, S. E. et al. Changes in the dental arches and dentition between 25 and 45 years of age. Angle Orthod, v.66, n.6, p.41622, Aug. 1996.

17. BISHARA, S. E.; TREDER, J. E.; JAKOBSEN, J. R. Facial and dental changes in adulthood. Am J Orthod Dentofacial Orthop, v.106, p.175-86, Aug. 1994.

18. BJÖRK, A. Prediction of mandibular growth rotation. Am J Orthod, v.55, n.6, p.585-99, June 1969.

19. BJÖRK, A. Some biological aspects of prognathism and occlusion of the teeth. Acta Odont Scand, v.9, p.1-40, 1950.

20. BJÖRK, A. Variations in the growth pattern of the mandible, longitudinal radiographic study of the implant method. J Dent Res, v.42, n.1, p.400-11, 1963.

21. BJÖRK, A.; SKIELLER, V. Facial development and tooth eruption: an implant study at the age of puberty. Am J Orthod, v.62, n.4, p.339-83, Oct. 1972.

22. BRIEDENHANN, S. J.; ROOS, E. C. A cephalometric appraisal of the Herero-speaking negro male. J Dent Assoc S Afr, v.43, p.569-75, 1988.

23. BROADBENT, B. H. A new x-ray technique and its application to orthodontia. Angle Orthod, v.1, n.2, p.45-66, Apr. 1931.

24. BRODIE, A. G. Facial patterns. A theme on variation. Angle Orthod, v.16, n.3, p.75-87, July 1946. 
25. BRODIE, A. G. On the growth of the jaws and the eruption of the teeth. Angle Orthod, v.12, n.3, p.109-23, July 1942.

26. BRODIE, A. G. On the growth pattern of the human head from the third month of eight years. Am J Anat, v.68, p.209-62, 1941.

27. CANNON, J. Craniofacial height and depth increments in normal children. Angle Orthod, v.40, n.3, p.202-18, July 1970.

28. CAPELOZZA FILHO, L. Diagnóstico em Ortodontia. Maringá, Dental Press, 2004.

29. CAPELOZZA FILHO, L.; CAVASSAN, A. O.; OZAWA, T. O. Alterações Verticais em Casos de Classe II Divisão 1 Dentária com Exodontias dos Quatro Primeiros Pré-molares. Rev Dent Press Ortod Ortop Facial, v.5, n.5, p.12-19, set./out. 2000.

30. CARTER, N. E.; SLATTERY, D. A. Bimaxillary proclination in patients of Afro-Caribbean origin. Br J Orthod, v.15, p.175-84, 1988.

31. COBEN, S. E. The integration of facial skeletal variants. Am J Orthod, v.41, p.407-34, 1955.

32. CONNOR, A. M.; MOSHIRI, F. Orthognathic surgery norms for American black patients. Am J Orthod, v.87, n.2, p.119-34, Feb. 1985.

33. COOK, M. S.; WEI, S. H. I. A comparative study of southern Chinese and British Caucasian cephalometric standards. Angle Orthod, v.59, p.131-8, 1989.

34. COTTON, W. N.; TAKANO, W. S.; WONG, W. L. The Downs analysis applied to three other ethnic groups. Angle Orthod, v.21, p.21320, 1951.

35. DAHLBERG, G. Statistical methods for medical and biological students. New York, Interscience, 1940.

36. DANDAJENA, T. C.; NANDA, R. S. Bialveolar protrusion in a Zimbabwean sample. Am J Orthod Dentofacial Orthop, v.123, n.2, p.133-7, 2003.

37. DERMAUT, L. R.; O'REILLY, M. I. T. Changes in anterior facial height in girls during puberty. Angle Orthod, v.48, n.2, p.163-71, Apr. 1978.

38. DOWNS, W. B. Analysis of the dentofacial profile. Angle Orthod, v.26, n.4, p.191-212, Oct. 1956. 
39. DOWNS, W. B. Variations in facial relationship: their significance in treatment and prognosis. Am J Orthod, v.34, n.10, p.812-40, Oct. 1948.

40. DRUMMOND, R. A determination of cephalometric norms of the Negro race. Am J Orthod, v.54, p.670-82, 1968.

41. ENLOW, D. H.; HANS, M. G. Essentials of facial growth. Philadelphia, W.B. Saunders, 1996.

42. ENLOW, D. H. et al. An analysis of black and caucasian craniofacial patterns. Angle Orthod, v.52, p.279-87, 1982.

43. FIELDS, H. W. et al. Facial pattern differences in long-faced children and adults. Am J Orthod, v.85, n.3, p.217-23, Mar. 1984.

44. FLYNN, T. R.; AMBROGIO, R. I.; ZEICHNER, S. J. Cephalometric norms of orthognathic surgery in black American adults. J Oral Maxillofac Surg, v.47, n.1, p.30, J an. 1989.

45. FONSECA, R. J.; KLEIN, W. O. A cephalometric evaluation of American Negro women. Am J Orthod, v.73, p.152-60, 1978.

46. FREITAS, M. R. Estudo analítico e comparativo do perfil facial mole, em adolescentes brasileiros, leucodermas, apresentando "oclusão normal", com as diversas linhas estéticas preconizadas Bauru, 1978. 69p. Dissertação (Mestrado) - Faculdade de Odontologia de Bauru, Universidade de São Paulo.

47. GEBECK, T. R.; MERRIFIELD, L. L. Analysis - concepts and values. Part I. J Charles H Tweed I nt Found, v.17, p.19-48, Apr. 1989.

48. GRABER, T. M. Problems and limitations of cephalometric analysis in orthodontics. J Am Dent Assoc, v.53, n.4, p.442-54, Oct. 1956.

49. HARRIS, J. E. et al. Age and race as factors in craniofacial growth and development. J Dent Res, v.56, n.3, p.266-74, Mar. 1977.

50. HAYASAKI, S. M. Estudo cefalométrico das alterações das alturas faciais anterior e posterior em pacientes nipobrasileiros com más oclusões de Classe I e Classe II, 1a divisão de Angle tratados ortodonticamente Bauru, 2002. 196p. Dissertação (Mestrado) - Faculdade de Odontologia de Bauru - Universidade de São Paulo.

51. HORN, A. J. Facial height index. Am J Orthod Dentofacial Orthop, v.102, n.2, p.180-6, Aug. 1992. 
52. HOUSTON, W. J. B. The analysis of errors in orthodontic measurements. Am J Orthod, v.83, n.5, p.382-90, May 1983.

53. HWANG, H.; KIM, W.; MCNAMARA JR, J. A. Ethnic differences in the soft tissue profile of Korean and European-American adults with normal occlusions and Well-Balanced faces. Angle Orthod, v.72, n.1, p.72-80, 2002.

54. INTERLANDI, S. O cefalograma padrão do curso de pós-graduação de Ortodontia da Faculdade de Odontologia da USP. Rev Fac Odont Bauru, v.6, n.1, p.63-74, jan./mar. 1968.

55. ISAACSON, J. R. et al. Extreme variation in vertical facial growth and associated variation in skeletal and dental relations. Angle Orthod, v.41, p.219-29, 1971.

56. ISAACSON, R.; ERDMAN, A.; HULTGREN, B. Facial and dental effects of mandibular rotation. In: CARLSON D. S. Craniofacial biology.: Ann Arbor Center for Human Growth and Development. University of Michigan.; 1981. p. 235-69.

57. ISAACSON, R. et al. Some effects of mandibular growth on the dental occlusion and profile. Angle Orthod, v.47, p.97-106, 1977.

58. ISAACSON, R. et al. Effects of rotational jaw growth on the occlusion and profile. Am J Orthod, v.72, p.276-86, 1977.

59. ISHII, N.; DEGUCHI, T.; HUNT, N. P. Morphological differences in the craniofacial structure between Japanese and Caucasian girls with Class II division 1 malocclusions. Eur J Orthod, v.24, n.3, p.61-7, Sept. 2002.

60. JACOBSON, A. The craniofacial skeleton of the South African Negro. Am J Orthod, v.73, p.681-91, 1978.

61. JANSON, G. R. P. Estudo Iongitudinal e comparativo do crescimento facial - dos 13 aos 18 anos de idade em jovens brasileiros leucodermas, utilizando a análise cefalométrica de MCNAMARA JR. Bauru, 1992. 138p. Tese (Doutorado) Faculdade de Odontologia de Bauru, Universidade de São Paulo.

62. JANSON, G. R. P. et al. Dental maturation in subjects with extreme vertical facial types. Eur J Orthod, v.20, n.1, p.73-8, Feb. 1998.

63. JANSON, G. R. P.; MARTINS, D. R. Estudo longitudinal e comparativo do crescimento facial - dos 13 aos 18 anos de idade em jovens brasileiros leucodermas, utilizando a análise cefalométrica de MCNAMARA J R. Ortodontia, v.25, n.3, p.4-18, set./dez. 1992. 
64. JANSON, G. R. P.; METAXAS, A.; WOODSIDE, D. G. Variation in maxillary and mandibular molar and incisor vertical dimension in 12-year-old subjects with excess, normal, and short lower anterior face height. Am J Orthod Dentofacial Orthop, v.106, n.4, p.409-18, Oct. 1994.

65. JARABAK, J. R. Treatment of Class II, division 1 malocclusion with an upper edgewise appliance and a cervical elastic strap. Angle Orthod, v.23, n.2, p.78-102, Apr. 1953.

66. JONES, B. H.; MEREDITH, H. V. Vertical change in osseous and odontic portions of human face height between the ages of 5 and 15 years. Am J Orthod, v.52, n.12, p.902-21, Oct. 1966.

67. KOWALSKI, C. J.; NASJ LETI, C. E.; WALKER, G. F. Differential diagnosis of adult male black and white populations. Angle Orthod, v.44, n.4, p.346-50, 1974.

68. KROGMAN, W. M.; SASSOUNI, V. A syllabus in roentgenographic cephalometric. Philadelphia, College Offset, 1957.

69. LINDER-ARONSON, S.; WOODSIDE, D. G. Excess Face Height Malocclusion: etiology, diagnosis and treatment. Chicago, Quintessence Publishing Co., 2000.

70. LOCKS, A. Estudo cefalométrico das alturas faciais anterior e posterior, em crianças brasileiras, portadoras de máoclusão Classe I de Angle, na fase de dentadura mista Araraquara, 1996. 128p. Tese (Doutorado) - Faculdade de Odontologia de Araraquara, Universidade Estadual Paulista.

71. MARTINS, D. R. Estudo comparativo dos valores cefalométricos das análises de Downs, Tweed, Steiner e Alabama, com os adolescentes brasileiros, leucodermas, de origem mediterrânea. Bauru, 1979. 141p. Tese (Livre-Docência) Faculdade de Odontologia de Bauru, Universidade de São Paulo.

72. MARTINS, D. R. et al. Atlas de crescimento craniofacial. São Paulo, Ed. Santos, 1998.

73. MARUO, H. Tratamento de uma Classe II divisão 1 severa em paciente adulto: sucesso ou insucesso? Rev Dent Press Ortod Ortop Facial, v.6, n.3, p.65-72, maio/jun. 2001.

74. MCNAMARA JR, J. A. A method of cephalometric evaluation. Am J Orthod, v.86, n.6, p.449-69, Dec. 1984. 
75. MEREDITH, H. V.; KNOTT, V. B.; HIXON, E. H. Relation of nasal and subnasal components of facial height in childhood. Am J Orthod, v.44, p.285-94, 1958.

76. MERRIFIELD, L. L. Analysis - concepts and values. Part II. J Charles H Tweed I nt Found, v.17, p.49-64, Apr. 1989.

77. MIYAJIMA, K. et al. Craniofacial structure of Japanese and EuropeanAmerican adults with normal occlusions and well-balanced faces. Am J Orthod Dentofacial Orthop, v.110, p.431-8, 1996.

78. MIYASHITA, K. Contemporary cephalometric radiography. Tokyo, Quintessence, 1996.

79. MORAES, C. Determinação do padrão esquelético das adolescentes melanodermas brasileiras, com "oclusão normal". Bauru, 1986. 80p. Dissertação (Mestrado) - Faculdade de Odontologia de Bauru, Universidade de São Paulo.

80. MORAES, C.; FREITAS, M. R.; HENRIQUES, J. F. C. Cefalometria Determinação do padrão esquelético das adolescentes melanodermas brasileiras, com "oclusão normal". Ortodontia, v.22, n.4, p.4-14, 1988.

81. NAHOUM, H. I. Vertical proportions and the palatal plane in anterior open-bite. Am J Orthod, v.59, p.273-82, 1971.

82. NAIDOO, L. C. D.; MILES, L. P. An evaluation of the mean cephalometric values for orthognathic surgery for black South Africa adults. Part I: Hard tissue. J Dent Assoc S Afr, v.52, p.495-502, 1997.

83. NAIDOO, L. C. D.; MILES, L. P. An evaluation of the mean cephalometric values for orthognathic surgery for black South Africa adults. Part II: Soft tissue. J Dent Assoc S Afr, v.52, p.545-50, Sept. 1997.

84. NANDA, S. K. Patterns of vertical growth in the face. Am J Orthod Dentofacial Orthop, v.93, p.103-16, 1988.

85. OKUYAMA, C. C. Preferência do perfil tegumentar em jovens melanodermas, leucodermas e xantodermas de ambos os sexos, avaliados por ortodontistas, leigos e artistas plásticos. Bauru, 1995. 94p. Dissertação (Mestrado) - Faculdade de Odontologia de Bauru, Universidade de São Paulo.

86. OLIVEIRA, J. N. Estudo longitudinal e comparativo da variação do pogônio com os incisivos inferiores, em relação à linha 
NB, em adolescentes brasileiros, leucodermas, de 12 aos 18 anos de idade, com "oclusão normal". Bauru, 1977. 71p. Dissertação (Mestrado) - Faculdade de Odontologia de Bauru, Universidade de São Paulo.

87. ORTIAL, J. P. Vertical dimensional and therapeutic choices. Am J Orthod Dentofacial Orthop, v.108, n.4, p.432-41, Oct. 1995.

88. PINZAN, A. et al. Estudo do crescimento maxilomandibular em jovens leucodermas, oclusão normal (dos 5 aos 12 anos de idade), de ambos os sexos, utilizando as medidas Co-A, Co-Gn, Dif. Mand./Max. e AFAl. Ortodontia, v.26, n.2, p.75-80, maio/ago. 1993.

89. PINZAN, A.; HENRIQUES, J. F. C.; FREITAS, M. R. Estudo cefalométrico longitudinal das medidas SNA, Nperp-A, SNB, SND, Nperp-P e ANB, em jovens leucodermas brasileiros de ambos os sexos com oclusão normal dos 5 aos 11 anos. Ortodontia, v.30, n.2, p.52-69, maio/ago. 1997.

90. RICHARDSON, E. R. Racial differences in dimensional traits of the human face. Angle Orthod, v.50, n.4, p.301-9, Oct. 1980.

91. RICKETTS, R. M. Planning treatment on the basis of the facial pattern and na estimate of its growth. Angle Orthod, v.27, p.14-37, 1957.

92. ROSA, R. A.; ARVYSTAS, M. G. An epidemiologic survey of malocclusions among American Negroes and American Hispanics. Am J Orthod, v.73, n.3, p.258-73, 1978.

93. SASSOUNI, V.; NANDA, S. Analysis of dentofacial vertical proportions. Am J Orthod, v.50, n.11, p.801-23, Nov. 1964.

94. SCHENDEL, S. A. The long face syndrome: vertical maxillary excess. Am J Orthod, v.70, n.4, p.398-408, Oct. 1976.

95. SCHUDY, F. F. The cant off the occlusal plane and axial inclination of teeth. Angle Orthod, v.33, p.69-82, 1963.

96. SCHUDY, F. F. The control of vertical overbite in clinical orthodontics. Angle Orthod, v.38, n.1, p.19-39, Jan. 1968.

97. SCHUDY, F. F. The rotation of the mandible resulting from growth; its implications in orthodontic treatment. Angle Orthod, v.34, p.7593, 1964.

98. SCHUDY, F. F. Vertical versus anteroposterior growth as related to function and treatment. Angle Orthod, v.34, p.75-93, 1964. 
99. SINCLAIR, P. M.; LITTLE, R. M. Dentofacial maturation of untreated normals. Am J Orthod, v.88, n.2, p.146-56, Aug. 1985.

100. SIRIWAT, P. P.; JARABAK, J. R. Malocclusion and facial morphology: is there a relationship?- an epidemiologic study. Angle Orthod, v.55, n.2, p.127-38, Apr. 1985.

101. SUBTELNY, J. D.; SAKUDA, M. Open bite: diagnosis and treatment. Am J Orthod, v.50, p.337-58, 1964.

102. SUSHNER, N. L. A photographic study of the soft-tissue profile of the negro population. Am J Orthod, v.72, n.4, p.373-85, Oct. 1977.

103. TAKAHASHI, R. Determinação cefalométrica das alturas faciais anterior e posterior, em jovens brasileiros, descendentes de xantodermas e leucodermas, com oclusão normal. Bauru, 2002. 182p. Tese (Doutorado) - Faculdade de Odontologia de Bauru, Universidade de São Paulo.

104. TAKAHASHI, R. Padrão cefalométrico FOB-USP para jovens nipo-brasileiros com oclusão normal. Bauru, 1998. 130p. Dissertação (Mestrado) - Faculdade de Odontologia de Bauru, Universidade de São Paulo.

105. TAYLOR, W. H.; HITCHCOCK, H. B. The Alabama analysis. Am J Orthod, v.52, p.245-65, 1966.

106. THOMPSON, J. R.; BRODIE, A. G. Factors in the position of the mandible. Am J Orthod, v.29, p.925-41, 1942.

107. VAN DER BEEK, M. C. J.; HOEKSMA, J. B.; ANDERSEN, P. Vertical facial growth: a longitudinal study from 7 to 14 years of age. Eur J Orthod, v.13, n.3, p.202-8, May 1991.

108. VAN DER LINDEN, F. P. G. M. Crescimento e Ortopedia Facial. São Paulo, Quintessence, 1990.

109. VAN DER LINDEN, P. G. M. O desenvolvimento das faces longas e curtas e as limitações do tratamento. Rev Dent Press Ortod Ortop Facial, v.4, p.6-11, 1999.

110. VION, P. E. Anatomia cefalométrica. São Paulo, Ed. Santos, 1994.

111. WEINBERG, H.; KRONMAN, J. H. Orthodontic influence upon anterior facial height. Angle Orthod, v.36, p.80-8, 1966. 
112. WOODSIDE, D. G. The channelization of upper and lower anterior face heights compared to population standard in males between ages 6 to 20 years. Eur J Orthod, v.1, n.1, p.25-40, 1979.

113. WYLIE, W. L. The relationship between ramus height, dental height and overbite. Am J Orthod, v.32, p.57-67, 1947.

114. WYLIE, W. L.; JOHNSON, E. L. Rapid evaluation of facial dysplasia in the vertical plane. Angle Orthod, v.22, n.3, p.165-82, July 1952.

115. YEHEZKEL, S.; TURLEY, P. K. Changes in the African American female profile as depicted in fashion magazines during the 20th century. Am J Orthod Dentofacial Orthop, v.125, n.4, p.407-17, Apr. 2004. 
Abstract 


\section{ABSTRACT}

With the purpose to present a specific cephalometric pattern for Brazilian young black subjects, this study aimed to achieve the mean values of normality for some vertical skeletal cephalometric variables (anterior and posterior facial heights) and to observe the presence of dimorphism between genders. The sample comprised 56 lateral cephalograms, 28 of male subjects with a mean age of 13.93 years (range 12.08 to 15.75 years) and 28 of females, with a mean age of 13.79 years (range 12.58 to 15.67 years), obtained from Brazilian black subjects nontreated orthodontically that presented "normal occlusion", from the records of the Discipline of Orthodontics at Bauru Dental School - University of São Paulo. The cephalometric measurements used followed the analyses of WYLIE; J OHNSON ${ }^{114}$ (1952); SirIwat; J JRABaK ${ }^{100}$ (1985); GebeCK; MerRIFIELd ${ }^{47}$, Horn ${ }^{51}$ $(1989,1992)$. The comparison between genders was performed by the independent " $\mathrm{t}$ " test. The results showed the presence of dimorphism, with significant differences for the TAFH, UAFH, TPFH and UPFH measurements, besides the ratios UPFH/TPFH and LPFH/TPFH. 
Apêndice 
Apêndice 1 - Valores cefalométricos individuais de jovens melanodermas brasileiros do gênero feminino

\begin{tabular}{|c|c|c|c|c|c|c|c|c|}
\hline & Raça & Idade & Gênero & AFAT & AFAS & AFAl & AFASIAFAT & AFAl/AFAT \\
\hline A.I.P. & Melano & 14,08 & F & 104,3 & 46,2 & 58,1 & 44,2 & 55,8 \\
\hline M.S.P. & Melano & 12,58 & F & 109,6 & 44,6 & 65 & 40,7 & 59,3 \\
\hline M.I.P. & Melano & 13,67 & F & 108,7 & 46,6 & 62,1 & 42,8 & 57,2 \\
\hline M.C.S. & Melano & 15,08 & F & 110,2 & 46,1 & 64,1 & 41,8 & 58,2 \\
\hline N.A.G. & Melano & 14,33 & F & 109,7 & 46,3 & 63,4 & 42,2 & 57,8 \\
\hline S.R. & Melano & 12,92 & F & 107,1 & 44,7 & 62,4 & 41,7 & 58,3 \\
\hline S.R.A. & Melano & 15,08 & F & 109,3 & 49,1 & 60,2 & 44,9 & 55,1 \\
\hline S.E. & Melano & 13,67 & F & 103,1 & 45,6 & 57,5 & 44,2 & 55,8 \\
\hline S.J.R. & Melano & 14,25 & F & 105,2 & 44,5 & 60,7 & 42,3 & 57,7 \\
\hline A.C.P. & Melano & 12,92 & F & 105,1 & 46,6 & 58,5 & 44,3 & 55,7 \\
\hline V.M.B. & Melano & 15,25 & F & 105,9 & 45,3 & 60,6 & 42,8 & 57,2 \\
\hline D.C. & Melano & 13,67 & F & 114,6 & 51,1 & 63,5 & 44,6 & 55,4 \\
\hline E.B. & Melano & 13,75 & F & 107,8 & 46,4 & 61,4 & 43,1 & 56,9 \\
\hline J.O.F. & Melano & 13,5 & F & 116,1 & 47,3 & 68,8 & 40,8 & 59,2 \\
\hline R.C. & Melano & 14,33 & F & 110,7 & 42,9 & 67,8 & 38,7 & 61,3 \\
\hline R.S. & Melano & 14,08 & F & 107,7 & 44,5 & 63,2 & 41,3 & 58,7 \\
\hline S.R.H. & Melano & 12,92 & F & 107,6 & 46 & 61,6 & 42,7 & 57,3 \\
\hline A.M.L. & Melano & 15,67 & F & 119 & 49 & 70 & 41,2 & 58,8 \\
\hline S.A.M. & Melano & 14,33 & F & 106,4 & 46,1 & 60,3 & 43,4 & 56,6 \\
\hline A.A. & Melano & 13,5 & F & 106,6 & 44,8 & 61,8 & 42 & 58 \\
\hline C.C.P. & Melano & 13,42 & F & 106,8 & 44 & 62,8 & 41,2 & 58,8 \\
\hline M.O. & Melano & 13,33 & F & 106,8 & 45,4 & 61,4 & 42,5 & 57,5 \\
\hline R.A.B. & Melano & 12,92 & F & 112,8 & 45,7 & 67,1 & 40,5 & 59,5 \\
\hline R.S. & Melano & 13,5 & F & 108,3 & 45,3 & 63 & 41,9 & 58,1 \\
\hline C.A.S. & Melano & 13,42 & F & 107,6 & 46,5 & 61,1 & 43,3 & 56,7 \\
\hline E.L.S. & Melano & 13,5 & F & 107,3 & 48,8 & 58,5 & 45,5 & 54,5 \\
\hline G.O. & Melano & 12,83 & F & 106,3 & 43,9 & 62,4 & 41,3 & 58,7 \\
\hline J.C.S. & Melano & 13,67 & F & 114 & 47,5 & 66,5 & 41,7 & 58,3 \\
\hline
\end{tabular}


Apêndice 2 - Continuação dos valores cefalométricos individuais de jovens melanodermas brasileiros do gênero feminino

\begin{tabular}{|c|c|c|c|c|c|c|c|}
\hline AFPT & AFPS & AFPI & AFPSIAFPT & AFPI/AFPT & AFA & AFP & IAF(AFPIAFA) \\
\hline 65,7 & 29,3 & 36,4 & 44,6 & 55,4 & 59,2 & 39,3 & 66,39 \\
\hline 69,3 & 26,5 & 42,8 & 38,2 & 61,8 & 64,2 & 46,3 & 72,12 \\
\hline 66,8 & 26,5 & 40,3 & 39,7 & 60,3 & 60,6 & 44,3 & 73,10 \\
\hline 73,7 & 29,6 & 44,1 & 40,1 & 59,9 & 63,2 & 47,9 & 75,79 \\
\hline 67,3 & 28,1 & 39,2 & 41,8 & 58,2 & 62,9 & 42,7 & 67,89 \\
\hline 65,1 & 27,4 & 37,8 & 42 & 58 & 61,5 & 42,1 & 68,46 \\
\hline 65,7 & 27,1 & 38,7 & 41,2 & 58,8 & 60,3 & 44 & 72,97 \\
\hline 66,9 & 30,2 & 36,6 & 45,2 & 54,8 & 57,6 & 41,2 & 71,53 \\
\hline 63,9 & 23,6 & 40,3 & 36,9 & 63,1 & 59,5 & 42,5 & 71,43 \\
\hline 67,6 & 26,5 & 41,1 & 39,2 & 60,8 & 58 & 45,1 & 77,76 \\
\hline 72,5 & 26,4 & 46,1 & 36,5 & 63,5 & 60,7 & 50,2 & 82,70 \\
\hline 69,4 & 31 & 38,5 & 44,6 & 55,4 & 63,7 & 42,9 & 67,35 \\
\hline 67,2 & 29 & 38,2 & 43,2 & 56,8 & 60 & 42 & 70,00 \\
\hline 66,7 & 31,5 & 35,3 & 47,2 & 52,8 & 67,7 & 42,1 & 62,19 \\
\hline 67 & 26,8 & 40,1 & 40 & 60 & 66,5 & 43,3 & 65,11 \\
\hline 69,9 & 29,9 & 40 & 42,8 & 57,2 & 60,2 & 45 & 74,75 \\
\hline 71,8 & 25,9 & 45,9 & 36 & 64 & 61,4 & 48,9 & 79,64 \\
\hline 77,5 & 30,2 & 47,3 & 39 & 61 & 67,6 & 52,1 & 77,07 \\
\hline 65,6 & 28,2 & 37,4 & 43 & 57 & 59,8 & 41 & 68,56 \\
\hline 68,4 & 25,8 & 42,6 & 37,7 & 62,3 & 60,9 & 46,8 & 76,85 \\
\hline 65,1 & 30 & 35,2 & 46 & 54 & 61,7 & 36,8 & 59,64 \\
\hline 67,5 & 25,5 & 42,1 & 37,7 & 62,3 & 60,6 & 46 & 75,91 \\
\hline 70,5 & 31,9 & 38,6 & 45,3 & 54,7 & 65,8 & 44,9 & 68,24 \\
\hline 67,2 & 26 & 41,2 & 38,7 & 61,3 & 62,5 & 45,6 & 72,96 \\
\hline 68,2 & 26,1 & 42,1 & 38,3 & 61,7 & 61,2 & 45,9 & 75,00 \\
\hline 75,2 & 29,4 & 45,7 & 39,1 & 60,9 & 57,3 & 50,1 & 87,43 \\
\hline 73,6 & 31,4 & 42,1 & 42,7 & 57,3 & 61,7 & 44,3 & 71,80 \\
\hline 64,1 & 28,9 & 35,3 & 45 & 55 & 65,3 & 37,9 & 58,04 \\
\hline
\end{tabular}


Apêndice 3 - Valores cefalométricos individuais de jovens melanodermas brasileiros do gênero masculino

\begin{tabular}{|c|c|c|c|c|c|c|c|c|}
\hline & Raça & Idade & Gênero & AFAT(N-Me) & AFAS(N-ENA') & AFAI(ENA'-Me) & AFASIAFAT & AFAI/AFAT \\
\hline A.A.A. & Melano & 14,33 & M & 109,5 & 48,7 & 60,8 & 44,5 & 55,5 \\
\hline G.P.C. & Melano & 15,67 & M & 105,3 & 44,3 & 61 & 42,1 & 57,9 \\
\hline J.T. & Melano & 13,5 & M & 115,6 & 47,4 & 68,2 & 41 & 59 \\
\hline J.A.S. & Melano & 13,5 & M & 124,3 & 50,2 & 74,1 & 40,4 & 59,6 \\
\hline J.L.S. & Melano & 13,33 & M & 102,1 & 44,3 & 57,8 & 43,4 & 56,6 \\
\hline L.E.C. & Melano & 14,42 & M & 106,5 & 44,5 & 62 & 41,8 & 58,2 \\
\hline R.M.A. & Melano & 13,5 & M & 110,6 & 43,8 & 66,8 & 39,6 & 60,4 \\
\hline L.M. & Melano & 12,08 & M & 112,3 & 46,4 & 65,9 & 41,3 & 58,7 \\
\hline S.L.M. & Melano & 15,75 & M & 117,2 & 51,5 & 65,7 & 43,9 & 56,1 \\
\hline M.T.P. & Melano & 15,08 & M & 116,3 & 52,1 & 64,2 & 44,8 & 55,2 \\
\hline A.O. & Melano & 13,5 & M & 121,2 & 48,6 & 72,6 & 40,1 & 59,9 \\
\hline M.A.C. & Melano & 15,33 & M & 118 & 51,2 & 66,8 & 43,4 & 56,6 \\
\hline R.C.T. & Melano & 13,5 & M & 112,6 & 48,6 & 64 & 43,1 & 56,9 \\
\hline S. & Melano & 13,33 & M & 116,3 & 50,8 & 65,5 & 43,7 & 56,3 \\
\hline J.C.S. & Melano & 13,83 & M & 103,8 & 45,8 & 58 & 44,1 & 55,9 \\
\hline S.L.P. & Melano & 12,5 & M & 101,2 & 45,6 & 55,6 & 45 & 55 \\
\hline M.P. & Melano & 15,08 & M & 109,3 & 45,9 & 63,4 & 42 & 58 \\
\hline M.G.S. & Melano & 14,5 & M & 111,3 & 47,7 & 63,6 & 42,9 & 57,1 \\
\hline C.A. & Melano & 14,42 & M & 103,6 & 46,9 & 56,7 & 45,3 & 54,7 \\
\hline G.I. & Melano & 13,75 & M & 113,1 & 47,9 & 65,2 & 42,3 & 57,7 \\
\hline H.L.O. & Melano & 12,67 & M & 114,2 & 48,6 & 65,6 & 42,5 & 57,5 \\
\hline J. & Melano & 13,33 & M & 115,4 & 48 & 67,4 & 41,6 & 58,4 \\
\hline A.C.B. & Melano & 13,33 & M & 113,3 & 51,4 & 61,9 & 45,4 & 54,6 \\
\hline A.C.O. & Melano & 12,58 & M & 105,8 & 44,1 & 61,7 & 41,7 & 58,3 \\
\hline A.M. & Melano & 13,25 & M & 106,6 & 47,8 & 58,8 & 44,8 & 55,2 \\
\hline B.D.S. & Melano & 15,75 & M & 115,8 & 51,2 & 64,6 & 44,2 & 55,8 \\
\hline E.R. & Melano & 13,08 & M & 121,5 & 48,9 & 72,6 & 40,3 & 59,7 \\
\hline R.C.T. & Melano & 15,33 & M & 101,5 & 47,5 & 54 & 46,7 & 53,3 \\
\hline
\end{tabular}


Apêndice 4 - Continuação dos valores cefalométricos individuais de jovens melanodermas brasileiros do gênero masculino

\begin{tabular}{|c|c|c|c|c|c|c|c|}
\hline AFPT(S-Go) & AFPS(S-Ar') & AFPI(Ar'-Go) & AFPSIAFPT & AFPI/AFPT & AFA(Me-PP) & AFP(Ar-PM) & IAF(AFPIAFA) \\
\hline 77,3 & 31,8 & 45,4 & 41,2 & 58,8 & 60,3 & 50,7 & 84,08 \\
\hline 68,1 & 27,7 & 40,4 & 40,7 & 59,3 & 60,2 & 45,1 & 74,92 \\
\hline 73,3 & 30 & 43,3 & 40,9 & 59,1 & 67,3 & 48,2 & 71,62 \\
\hline 72,9 & 32,7 & 40,2 & 44,8 & 55,2 & 73,5 & 46 & 62,59 \\
\hline 68,9 & 33,6 & 35,3 & 48,8 & 51,2 & 56,6 & 40,6 & 71,73 \\
\hline 62 & 24,5 & 37,5 & 39,5 & 60,5 & 60,8 & 41,7 & 68,59 \\
\hline 72,8 & 32,8 & 40 & 45 & 55 & 64,3 & 43,6 & 67,81 \\
\hline 72,1 & 35,3 & 36,8 & 49 & 51 & 65,1 & 40,4 & 62,06 \\
\hline 62,6 & 27,6 & 35 & 44,1 & 55,9 & 65,4 & 39,3 & 60,09 \\
\hline 71,4 & 29,5 & 41,9 & 41,3 & 58,7 & 63,2 & 46 & 72,78 \\
\hline 85,9 & 33,8 & 52,1 & 39,3 & 60,7 & 70,3 & 55,2 & 78,52 \\
\hline 77,6 & 30,7 & 46,9 & 39,5 & 60,5 & 66,9 & 52,6 & 78,62 \\
\hline 76,3 & 32,6 & 43,7 & 42,7 & 57,3 & 63 & 47,9 & 76,03 \\
\hline 76,5 & 36 & 40,4 & 47,1 & 52,9 & 63,8 & 43,7 & 68,50 \\
\hline 65,7 & 30,9 & 34,8 & 47 & 53 & 58,4 & 38 & 65,07 \\
\hline 70,2 & 30,7 & 39,5 & 43,8 & 56,2 & 55,8 & 44,2 & 79,21 \\
\hline 66,1 & 28,1 & 38 & 42,5 & 57,5 & 62,4 & 41,3 & 66,19 \\
\hline 78,6 & 32,6 & 46 & 41,5 & 58,5 & 63,9 & 55 & 86,07 \\
\hline 67,7 & 30,7 & 37 & 45,4 & 54,6 & 55,3 & 40,6 & 73,42 \\
\hline 62,3 & 27,2 & 35,1 & 43,7 & 56,3 & 64,8 & 37,5 & 57,87 \\
\hline 77,6 & 35,5 & 42 & 45,8 & 54,2 & 63,3 & 46,5 & 73,46 \\
\hline 72,7 & 28,8 & 43,9 & 39,6 & 60,4 & 66,8 & 47,7 & 71,41 \\
\hline 69,7 & 30,3 & 39,4 & 43,5 & 56,5 & 60,1 & 43,4 & 72,21 \\
\hline 64,8 & 32,2 & 32,7 & 49,6 & 50,4 & 59,5 & 38,6 & 64,87 \\
\hline 70,1 & 25,4 & 44,7 & 36,3 & 63,7 & 58,6 & 47,7 & 81,40 \\
\hline 77,5 & 34,4 & 43,1 & 44,4 & 55,6 & 64,3 & 47,6 & 74,03 \\
\hline 76,6 & 31,1 & 45,5 & 40,6 & 59,4 & 71 & 50,2 & 70,70 \\
\hline 69,3 & 28,7 & 40,6 & 41,4 & 58,6 & 53,9 & 44,1 & 81,82 \\
\hline
\end{tabular}


Apêndice 5 - Valores cefalométricos individuais de jovens melanodermas brasileiros do gênero feminino

\begin{tabular}{|c|c|c|c|c|c|}
\hline & Raça & Idade & Gênero & SN.GoGn \\
\hline A.I.P. & Melano & 14,08 & $\mathrm{~F}$ & $33^{\circ}$ \\
\hline M.S.P. & Melano & 12,58 & $\mathrm{~F}$ & $30^{\circ}$ \\
\hline M.I.P. & Melano & 13,67 & $\mathrm{~F}$ & $30^{\circ}$ \\
\hline M.C.S. & Melano & 15,08 & $\mathrm{~F}$ & $28^{\circ}$ \\
\hline N.A.G. & Melano & 14,33 & $\mathrm{~F}$ & $31,5^{\circ}$ \\
\hline S.R. & Melano & 12,92 & $\mathrm{~F}$ & $27^{\circ}$ \\
\hline S.R.A. & Melano & 15,08 & $\mathrm{~F}$ & $26^{\circ}$ \\
\hline S.E. & Melano & 13,67 & $\mathrm{~F}$ & $26^{\circ}$ \\
\hline S.J.R. & Melano & 14,25 & $\mathrm{~F}$ & $32^{\circ}$ \\
\hline A.C.P. & Melano & 12,92 & $\mathrm{~F}$ & $31^{\circ}$ \\
\hline V.M.B. & Melano & 15,25 & $\mathrm{~F}$ & $32^{\circ}$ \\
\hline D.C. & Melano & 13,67 & $\mathrm{~F}$ & $32^{\circ}$ \\
\hline E.B. & Melano & 13,75 & $\mathrm{~F}$ & $29^{\circ}$ \\
\hline J.O.F. & Melano & 13,5 & $\mathrm{~F}$ & $29^{\circ}$ \\
\hline R.C. & Melano & 14,33 & $\mathrm{~F}$ & $31^{\circ}$ \\
\hline R.S. & Melano & 14,08 & $\mathrm{~F}$ & $30^{\circ}$ \\
\hline S.R.H. & Melano & 12,92 & $\mathrm{~F}$ & $25^{\circ}$ \\
\hline A.M.L. & Melano & 15,67 & $\mathrm{~F}$ & $27^{\circ}$ \\
\hline S.A.M. & Melano & 14,33 & $\mathrm{~F}$ & $29^{\circ}$ \\
\hline A.A. & Melano & 13,5 & $\mathrm{~F}$ & $30^{\circ}$ \\
\hline C.C.P. & Melano & 13,42 & $\mathrm{~F}$ & $22^{\circ}$ \\
\hline M.O. & Melano & 13,33 & $\mathrm{~F}$ & $24^{\circ}$ \\
\hline R.A.B. & Melano & 12,92 & $\mathrm{~F}$ & $30^{\circ}$ \\
\hline R.S. & Melano & 13,5 & $\mathrm{~F}$ & $32^{\circ}$ \\
\hline C.A.S. & Melano & 13,42 & $\mathrm{~F}$ & $27^{\circ}$ \\
\hline E.L.S. & Melano & 13,5 & $\mathrm{~F}$ & $30^{\circ}$ \\
\hline G.O. & Melano & 12,83 & $\mathrm{~F}$ & $31^{\circ}$ \\
\hline J.S. & Melano & 13,67 & $\mathrm{~F}$ & $31^{\circ}$ \\
\hline & & $\mathrm{X}$ & $28,44^{\circ}$ \\
\hline
\end{tabular}


Apêndice 6 - Valores cefalométricos individuais de jovens melanodermas brasileiros do gênero masculino

\begin{tabular}{|c|c|c|c|c|}
\hline & Raça & Idade & Gênero & SN.GoGn \\
\hline A.A.A. & Melano & 14,33 & $M$ & $23^{\circ}$ \\
\hline G.P.C. & Melano & 15,67 & M & $24^{\circ}$ \\
\hline J.T. & Melano & 13,5 & M & $27^{\circ}$ \\
\hline J.A.S. & Melano & 13,5 & M & $32^{\circ}$ \\
\hline J.L.S. & Melano & 13,33 & M & $31^{\circ}$ \\
\hline L.E.C. & Melano & 14,42 & M & $30^{\circ}$ \\
\hline R.M.A. & Melano & 13,5 & M & $31^{\circ}$ \\
\hline L.M. & Melano & 12,08 & M & $31^{\circ}$ \\
\hline S.L.M. & Melano & 15,75 & M & $31^{\circ}$ \\
\hline M.T.P. & Melano & 15,08 & M & $29^{\circ}$ \\
\hline A.O. & Melano & 13,5 & $M$ & $27^{\circ}$ \\
\hline M.A.C. & Melano & 15,33 & M & $30^{\circ}$ \\
\hline R.C.T. & Melano & 13,5 & M & $25^{\circ}$ \\
\hline S. & Melano & 13,33 & M & $25^{\circ}$ \\
\hline J.C.S. & Melano & 13,83 & M & $31^{\circ}$ \\
\hline S.L.P. & Melano & 12,5 & M & $31^{\circ}$ \\
\hline M.P. & Melano & 15,08 & M & $29^{\circ}$ \\
\hline M.G.S. & Melano & 14,5 & M & $30^{\circ}$ \\
\hline C.A. & Melano & 14,42 & M & $27^{\circ}$ \\
\hline G.I. & Melano & 13,75 & M & $30^{\circ}$ \\
\hline H.L.O. & Melano & 12,67 & M & $24^{\circ}$ \\
\hline J. & Melano & 13,33 & M & $27^{\circ}$ \\
\hline A.C.B. & Melano & 13,33 & M & $32,5^{\circ}$ \\
\hline A.C.O. & Melano & 12,58 & M & $33^{\circ}$ \\
\hline A.M. & Melano & 13,25 & M & $25^{\circ}$ \\
\hline B.D.S. & Melano & 15,75 & M & $26^{\circ}$ \\
\hline E.R. & Melano & 13,08 & M & $25^{\circ}$ \\
\hline \multirow[t]{3}{*}{ R.C.T. } & Melano & 15,33 & M & $30^{\circ}$ \\
\hline & & & $x$ & $29,12^{0}$ \\
\hline & & & D.P & $2,72^{\circ}$ \\
\hline
\end{tabular}

